\title{
Guidelines for the diagnosis and management of syncope (version 2009)
}

\section{The Task Force for the Diagnosis and Management of Syncope of the European Society of Cardiology (ESC)}

\author{
Developed in collaboration with, European Heart Rhythm Association (EHRA) ${ }^{\mathbf{1}}$, \\ Heart Failure Association (HFA) ${ }^{2}$, and Heart Rhythm Society (HRS) ${ }^{3}$
}

Endorsed by the following societies, European Society of Emergency Medicine (EuSEM) ${ }^{4}$, European Federation of Internal Medicine (EFIM) ${ }^{5}$, European Union Geriatric Medicine Society (EUGMS) ${ }^{6}$, American Geriatrics Society (AGS), European Neurological Society (ENS) ${ }^{7}$, European Federation of Autonomic Societies (EFAS) ${ }^{8}$, American Autonomic Society (AAS) ${ }^{9}$

Authors/Task Force Members, Angel Moya (Chairperson) (Spain)*, Richard Sutton (Co-Chairperson) (UK)*, Fabrizio Ammirati (Italy), Jean-Jacques Blanc (France), Michele Brignole ${ }^{1}$ (Italy), Johannes B. Dahm (Germany), Jean-Claude Deharo (France), Jacek Gajek (Poland), Knut Gjesdal ${ }^{2}$ (Norway), Andrew Krahn ${ }^{3}$ (Canada), Martial Massin (Belgium), Mauro Pepi (Italy), Thomas Pezawas (Austria), Ricardo Ruiz Granell (Spain), Francois Sarasin ${ }^{4}$ (Switzerland), Andrea Ungar ${ }^{6}$ (Italy), J. Gert van Dijk ${ }^{7}$ (The Netherlands), Edmond P. Walma (The Netherlands), Wouter Wieling (The Netherlands)

External Contributors, Haruhiko Abe (Japan), David G. Benditt (USA), Wyatt W. Decker (USA), Blair P. Grubb (USA), Horacio Kaufmann (USA), Carlos Morillo (Canada), Brian Olshansky (USA), Steve W. Parry (UK), Robert Sheldon (Canada), Win K. Shen (USA)

ESC Committee for Practice Guidelines (CPG), Alec Vahanian (Chairperson) (France), Angelo Auricchio (Switzerland), Jeroen Bax (The Netherlands), Claudio Ceconi (Italy), Veronica Dean (France), Gerasimos Filippatos (Greece), Christian Funck-Brentano (France), Richard Hobbs (UK), Peter Kearney (Ireland), Theresa McDonagh (UK), Keith McGregor (France), Bogdan A. Popescu (Romania), Zeljko Reiner (Croatia), Udo Sechtem (Germany), Per Anton Sirnes (Norway), Michal Tendera (Poland), Panos Vardas (Greece), Petr Widimsky (Czech Republic)

Document Reviewers, Angelo Auricchio (CPG Review Coordinator) (Switzerland), Esmeray Acarturk (Turkey), Felicita Andreotti (Italy), Riccardo Asteggiano (Italy), Urs Bauersfeld (Switzerland), Abdelouahab Bellou 4 (France), Athanase Benetos ${ }^{6}$ (France), Johan Brandt (Sweden), Mina K. Chung ${ }^{3}$ (USA), Pietro Cortelli ${ }^{8}$ (Italy), Antoine Da Costa (France), Fabrice Extramiana (France), José Ferro ${ }^{7}$ (Portugal), Bulent Gorenek (Turkey), Antti Hedman (Finland), Rafael Hirsch (Israel), Gabriela Kaliska (Slovak Republic), Rose Anne Kenny ${ }^{6}$ (Ireland), Keld Per Kjeldsen (Denmark), Rachel Lampert ${ }^{3}$ (USA), Henning Mølgard (Denmark), Rain Paju (Estonia), Aras Puodziukynas (Lithuania), Antonio Raviele (Italy), Pilar Roman ${ }^{5}$ (Spain), Martin Scherer (Germany), Ronald Schondorf ${ }^{9}$ (Canada), Rosa Sicari (Italy), Peter Vanbrabant ${ }^{4}$ (Belgium), Christian Wolpert ${ }^{1}$ (Germany), Jose Luis Zamorano (Spain)

The disclosure forms of the authors and reviewers are available on the ESC website www.escardio.org/guidelines

\footnotetext{
* Corresponding authors: Angel Moya (Chairperson), Hospital Vall d'Hebron, P. Vall d'Hebron 119-129, 08035 Barcelona, Spain. Tel: +34 93 2746166, Fax: +34 93 2746002, Email: amoya@comb.cat

Richard Sutton (UK) (Co-Chairperson), Imperial College, St Mary's Hospital, Praed Street, London W2 1NY, UK. Tel: +44 20 79351011, Fax: +44 20 79356718, Email: r.sutton@ imperial.ac.uk

The content of these European Society of Cardiology (ESC) Guidelines has been published for personal and educational use only. No commercial use is authorized. No part of the ESC Guidelines may be translated or reproduced in any form without written permission from the ESC. Permission can be obtained upon submission of a written request to Oxford University Press, the publisher of the European Heart Journal and the party authorized to handle such permissions on behalf of the ESC.

Disclaimer. The ESC Guidelines represent the views of the ESC and were arrived at after careful consideration of the available evidence at the time they were written. Health professionals are encouraged to take them fully into account when exercising their clinical judgement. The guidelines do not, however, override the individual responsibility of health professionals to make appropriate decisions in the circumstances of the individual patients, in consultation with that patient, and where appropriate and necessary the patient's guardian or carer. It is also the health professional's responsibility to verify the rules and regulations applicable to drugs and devices at the time of prescription.

(C) The European Society of Cardiology 2009. All rights reserved. For permissions please email: journals.permissions@oxfordjournals.org.
} 


\section{Table of Contents}

Abbreviations and acronyms ... . . . . . . . . . . 2632

Preamble ... . . . . . . . . . . . . . . . . . . . 2633

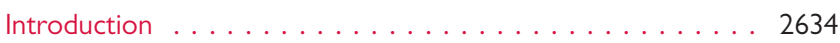

Part 1. Definitions, classification and pathophysiology, epidemiology, prognosis, impact on quality of life, and economic issues . . . . . . . . . . . . . . . . . . . 2635

1.1 Definitions . . . . . . . . . . . . . . . 2635

1.2 Classification and pathophysiology . . . . . . . . 2635

1.2.1 Placing syncope in the larger framework of transient loss of consciousness (real or apparent) . . . . . . 2635

1.2.2 Classification and pathophysiology of syncope . . . 2636

1.2.2.1 Reflex syncope (neurally mediated syncope) . . . 2637

1.2.2.2 Orthostatic hypotension and orthostatic intolerance syndromes . . . . . . . . . . . . . 2637

1.2.2.3 Cardiac syncope (cardiovascular) . . . . . . . 2639

1.3 Epidemiology . . . . . . . . . . . . . . . . . . . . . 2640

1.3.1 Prevalence of syncope in the general population. . 2640

1.3.2 Referral from the general population to medical settings . . . . . . . . . . . . . . . . 2640

1.3.3 Prevalence of the causes of syncope . . . . . . . 2641

1.4 Prognosis . . . . . . . . . . . . . . . . . . . . . . . 2641

1.4.1 Risk of death and life-threatening events . . . . . . 2641

1.4.2 Recurrence of syncope and risk of physical injury . 2641

1.5 Impact on quality of life . . . . . . . . . . . . . . 2641

1.6 Economic issues . . . . . . . . . . . . . . . . . . . 2643

Part 2. Initial evaluation, diagnosis, and risk stratification. . . . 2644

2.1 Initial evaluation . . . . . . . . . . . . . . . . . . . 2644

2.1.1 Diagnosis of syncope . . . . . . . . . . . . . . . 2644

2.1.2 Aetiological diagnosis . . . . . . . . . . . . . . . . . 2644

2.1 .3 Risk stratification . . . . . . . . . . . . . . . . . . 2645

2.2 Diagnostic tests . . . . . . . . . . . . . . . 2645

2.2.1 Carotid sinus massage . . . . . . . . . . . . 2645

2.2.2 Orthostatic challenge . . . . . . . . . . . . . . . 2647

2.2.2.1 Active standing . . . . . . . . . . . . . . . 2647

2.2.2.2 Tilt testing . . . . . . . . . . . . . . . . 2647

2.2.3 Electrocardiographic monitoring (non-invasive and invasive) . . . . . . . . . . . . . . . . . . . . 2649

2.2.3.1 In-hospital monitoring . . . . . . . . . . . . . 2649

2.2.3.2 Holter monitoring . . . . . . . . . . . . . . . . 2649

2.2.3.3 Prospective external event recorders . . . . . . 2649

2.2.3.4 External loop recorders . . . . . . . . . . . . . 2649

2.2.3.5 Implantable loop recorders . . . . . . . . . . . 2649

2.2.3.6 Remote (at home) telemetry . . . . . . . . . . 2650

2.2.3.7 Classification of electrocardiographic recordings 2650

2.2.3.8 Electrocardiographic monitoring in syncope-

where in the work-up? . . . . . . . . . . . . 2650

2.2.4 Electrophysiological study . . . . . . . . . . . . 2651

2.2.4.1 Suspected intermittent bradycardia . . . . . . . 2651

2.2.4.2 Syncope in patients with bundle branch block (impending high degree atrioventricular block) . 2652

2.2.4.3 Suspected tachycardia . . . . . . . . . . . . . 2652

2.2.5 Adenosine triphosphate test . . . . . . . . . . 2652

2.2.6 Echocardiography and other imaging techniques .. 2653

2.2 .7 Exercise stress testing . . . . . . . . . . . . . . . 2653

2.2.8 Cardiac catheterization . . . . . . . . . . . . . . . 2653
2.2.9 Psychiatric evaluation . . . . . . . . . . . . . . 2653

2.2 .10 Neurological evaluation. . . . . . . . . . . . . . . 2654

2.2.10.1 Clinical conditions . . . . . . . . . . . . . . . 2654

2.2.10.2 Neurological tests . . . . . . . . . . . . . . . . 2655

Part 3. Treatment . . . . . . . . . . . . . . . . . . . 2656

3.1 Treatment of reflex syncope and orthostatic

intolerance . . . . . . . . . . . . . . . . 2656

3.1.1 Reflex syncope . . . . . . . . . . . . . . . . . . . 2657

3.1.1.1 Therapeutic options . . . . . . . . . . . . . 2657

3.1.1.2 Individual conditions. . . . . . . . . . . . . . 2658

3.1.2 Orthostatic hypotension and orthostatic intolerance syndromes . . . . . . . . . . . . . . 2658

3.2 Cardiac arrhythmias as primary cause . . . . . . . . 2659

3.2.1 Sinus node dysfunction . . . . . . . . . . . . . . 2659

3.2.2 Atrioventricular conduction system disease... . . 2659

3.2.3 Paroxysmal supraventricular and ventricular tachycardias . . . . . . . . . . . . . . . . 2659

3.2.4 Implanted device malfunction . . . . . . . . . . . 2660

3.3 Syncope secondary to structural cardiac or cardiovascular disease . . . . . . . . . . . . 2660

3.4 Unexplained syncope in patients with high risk of sudden cardiac death . . . . . . . . . . . . . . . . . 2661

3.4.1 Ischaemic and non-ischaemic cardiomyopathies . . . 2661

3.4.2 Hypertrophic cardiomyopathy . . . . . . . . . . . 2661

3.4.3 Arrhythmogenic right ventricular cardiomyopathy/ dysplasia. . . . . . . . . . . . . . . 2661

3.4.4 Patients with primary electrical diseases . . . . . . 2661

Part 4. Special issues . . . . . . . . . . . . . . . . . . . . . . . 2662

4.1 Syncope in the elderly . . . . . . . . . . . . . . . . 2662

4.2 Syncope in paediatric patients . . . . . . . . . . . . 2663

4.3 Driving and syncope . . . . . . . . . . . . . . . . 2663

Part 5. Organizational aspects . . . . . . . . . . . . . . . . . 2664

5.1 Management of syncope in general practice . . . . . . . 2664

5.2 Management of syncope in the Emergency Department 2664

5.3 Syncope (T-LOC) Management Unit . . . . . . . . . . 2664

5.3.1 Existing models of Syncope (T-LOC) Management Units . . . . . . . . . . . . . . . . . 2665

5.3 .2 Proposed model . . . . . . . . . . . . . . . . 2665

References ........................ 2666

\section{Abbreviations and acronyms}

$\begin{array}{ll}\text { ANF } & \text { autonomic failure } \\ \text { ANS } & \text { autonomic nervous system } \\ \text { ARVC } & \text { arrhythmogenic right ventricular cardiomyopathy } \\ \text { ATP } & \text { adenosine triphosphate } \\ \text { AV } & \text { atrioventricular } \\ \text { AVID } & \text { Antiarrhythmics vs. Implantable Defibrillators } \\ \text { BBB } & \text { bundle branch block } \\ \text { BP } & \text { blood pressure } \\ \text { b.p.m. } & \text { beats per minute } \\ \text { CAD } & \text { coronary artery disease } \\ \text { CO } & \text { cardiac output } \\ \text { CPG } & \text { Committee for Practice Guidelines } \\ \text { CSH } & \text { carotid sinus hypersensitivity } \\ \text { CSM } & \text { carotid sinus massage }\end{array}$




$\begin{array}{ll}\text { CSS } & \text { carotid sinus syndrome } \\ \text { CSNRT } & \text { corrected sinus node recovery time } \\ \text { CT } & \text { computed tomography } \\ \text { DCM } & \text { dilated cardiomyopathy } \\ \text { ECG } & \text { electrocardiogram/electrocardiographic } \\ \text { ED } & \text { Emergency Department } \\ \text { EEG } & \text { electroencephalogram } \\ \text { EGSYS } & \text { Evaluation of Guidelines in Syncope Study } \\ \text { EPS } & \text { electrophysiological study } \\ \text { ESC } & \text { European Society of Cardiology } \\ \text { FASS } & \text { Falls and Syncope Service } \\ \text { FDA } & \text { Food and Drug Administration } \\ \text { HF } & \text { heart failure } \\ \text { HOCM } & \text { hypertrophic obstructive cardiomyopathy } \\ \text { HR } & \text { heart rate } \\ \text { HV } & \text { His-ventricle } \\ \text { ICD } & \text { implantable cardioverter defibrillator } \\ \text { ILR } & \text { implantable loop recorder } \\ \text { ISSUE } & \text { International Study on Syncope of Unknown Etiology } \\ \text { LBBB } & \text { left bundle branch block } \\ \text { LOC } & \text { loss of consciousness } \\ \text { LVEF } & \text { left ventricular ejection fraction } \\ \text { MRI } & \text { magnetic resonance imaging } \\ \text { OH } & \text { orthostatic hypotension } \\ \text { PCM } & \text { physical counterpressure manoeuvre } \\ \text { PDA } & \text { personal digital assistant } \\ \text { POTS } & \text { postural orthostatic tachycardia syndrome } \\ \text { RBBB } & \text { right bundle branch block } \\ \text { SCD } & \text { sudden cardiac death } \\ \text { SCD-HeFT } & \text { Sudden Cardiac Death in Heart Failure Trial } \\ \text { SNRT } & \text { sinus node recovery time } \\ \text { SVR } & \text { systemic vascular resistance } \\ \text { SVT } & \text { supraventricular tachycardia } \\ \text { TIA } & \text { transient ischaemic attack } \\ \text { TF } & \text { Task Force } \\ \text { T-LOC } & \text { transient loss of consciousness } \\ \text { VTS } & \text { ventricular tachycardia } \\ \text { vasovagal syncope }\end{array}$

\section{Preamble}

Guidelines and Expert Consensus Documents summarize and evaluate all currently available evidence on a particular issue with the aim of assisting physicians in selecting the best management strategies for a typical patient, suffering from a given condition, taking into account the impact on outcome, as well as the risk/ benefit ratio of particular diagnostic or therapeutic means. Guidelines are no substitutes for textbooks. The legal implications of medical guidelines have been previously discussed.

A great number of Guidelines and Expert Consensus Documents have been issued in recent years by the European Society of Cardiology (ESC) as well as by other societies and organizations. Because of the impact on clinical practice, quality criteria for the development of guidelines have been established in order to make all decisions transparent to the user. The recommendations for formulating and issuing ESC Guidelines and Expert Consensus
Documents can be found on the ESC Web Site (http://www .escardio.org/guidelines).

In brief, experts in the field are selected and undertake a comprehensive review of the published evidence for management and/ or prevention of a given condition. A critical evaluation of diagnostic and therapeutic procedures is performed, including assessment of the risk/benefit ratio. Estimates of expected health outcomes for larger societies are included, where data exist. The level of evidence and the strength of recommendation of particular treatment options are weighed and graded according to predefined scales, as outlined in Tables 1 and 2 .

The experts of the writing panels have provided disclosure statements of all relationships they may have which might be perceived as real or potential sources of conflicts of interest. These disclosure forms are kept on file at the European Heart House Headquarters of the ESC. Any changes in conflict of interest that arise during the writing period must be notified to the ESC. The Task Force (TF) report was entirely supported financially by the ESC and was developed without any involvement of industry.

The ESC Committee for Practice Guidelines (CPG) supervises and coordinates the preparation of new Guidelines and Expert Consensus Documents produced by TF expert groups or consensus panels. The Committee is also responsible for the endorsement process of these Guidelines and Expert Consensus Documents or statements. Once the document has been finalized and approved by all the experts involved in the TF, it is submitted to outside specialists for review. The document is revised, finally approved by the CPG,and subsequently published.

After publication, dissemination of the message is of paramount importance. Pocket-sized versions and personal digital assistant (PDA)-downloadable versions are useful at the point of care. Some surveys have shown that the intended end-users are sometimes not aware of the existence of the guidelines, or simply do not translate them into practice; this is why implementation programmes for new guidelines form an important component of the dissemination of knowledge. Meetings are organized by the ESC and are directed towards its member national societies and key opinion leaders in Europe. Implementation meetings can also be undertaken at national levels, once the guidelines have been endorsed by ESC member societies and translated into the national language. Implementation programmes are needed because it has been shown that the outcome of disease may be favourably influenced by thorough application of clinical recommendations.

Thus, the task of writing Guidelines or Expert Consensus Documents covers not only the integration of the most recent research, but also the creation of educational tools and implementation programmes for the recommendations. The loop between clinical research, the writing of guidelines, and implementing them into clinical practice can then only be completed if surveys and registries are performed to verify that real-life daily practice is in keeping with what is recommended in the guidelines. Such surveys and registries also make it possible to evaluate the impact of implementation of the guidelines on patient outcomes. Guidelines and recommendations should help physicians to make decisions in their clinical practice; however, the ultimate judgement regarding the care of an individual patient must be made by the physician in charge of that patient. 
Table I Classes of recommendations

\begin{tabular}{|c|l|}
\hline \multicolumn{1}{|c|}{$\begin{array}{c}\text { Classes of } \\
\text { Recommendations }\end{array}$} & \multicolumn{1}{c|}{ Definition } \\
\hline Class I & $\begin{array}{l}\text { Evidence and/or general agreement that a } \\
\text { given treatment or procedure is beneficial, } \\
\text { useful, effective. }\end{array}$ \\
\hline Class II & $\begin{array}{l}\text { Conflicting evidence and/or a divergence of } \\
\text { opinion about the usefulness/efficacy of the } \\
\text { given treatment or procedure. }\end{array}$ \\
\hline Class Ila & $\begin{array}{l}\text { Weight of evidence/opinion is in favour of } \\
\text { usefulness/efficacy. }\end{array}$ \\
\hline Class IIb & $\begin{array}{l}\text { Usefulness/efficacy is less well established by } \\
\text { evidence/opinion. }\end{array}$ \\
\hline Class III & $\begin{array}{l}\text { Evidence or general agreement that the given } \\
\text { treatment or procedure is not useful/effective, } \\
\text { and in some cases may be harmful. }\end{array}$ \\
\hline
\end{tabular}

Table 2 Levels of evidence

\begin{tabular}{|l|l|}
\hline Level of Evidence A & $\begin{array}{l}\text { Data derived from multiple randomized clinical trials or } \\
\text { meta-analyses. }\end{array}$ \\
\hline Level of Evidence B & $\begin{array}{l}\text { Data derived from a single randomized clinical trial or } \\
\text { large non-randomized studies. }\end{array}$ \\
\hline Level of Evidence C & $\begin{array}{l}\text { Consensus of opinion of the experts and/or small } \\
\text { studies, retrospective studies, registries. }\end{array}$ \\
\hline
\end{tabular}

\section{Introduction}

The first ESC Guidelines for the management of syncope, were published in 2001, and reviewed in 2004. ${ }^{1}$ In March 2008, the CPG considered that there were enough new data to justify production of new guidelines.

There are two main aspects of this document that differentiate it from its predecessors.

The first is to stress the concept that there are two distinct reasons for evaluating patients with syncope: one is to identify the precise cause in order to address an effective mechanismspecific treatment; the other is to identify the specific risk to the patient, which frequently depends on the underlying disease rather than on the mechanism of syncope itself. The background is provided for physicians to avoid confounding these two concepts.

The second aspect is to produce a comprehensive document which is addressed not only to cardiologists but to all physicians who are interested in the field. In order to achieve this aim a great number of other specialists were involved, as either full members, external contributors, or reviewers nominated by international societies of neurology, autonomic disease, internal medicine, emergency medicine, geriatrics, and general medicine. In total 76 specialists from different disciplines participated in this project.

The most relevant changes are listed here:

- An update of the classification of syncope in the larger framework of transient loss of consciousness (T-LOC).

- New data on epidemiology.

- A new diagnostic approach focusing on risk stratification of sudden cardiac death (SCD) and cardiovascular events after initial evaluation, including some recommendations for treatment in patients with unexplained syncope at high risk.

- Emphasis on the increasing role of a diagnostic strategy based on prolonged monitoring in contrast to the conventional strategy based on laboratory testing.

- An update of evidence-based therapy. 
The literature on syncope investigation and treatment is largely composed of case series, cohort studies, or retrospective analyses of already existing data. The impact of these approaches on guiding therapy and reducing syncope recurrences is difficult to discern without randomization and blinding. Because of these issues, the panel performed full reviews of the literature on diagnostic tests but did not use predefined criteria for selection of articles to be reviewed. This TF recognizes that for some of the recommendations related to diagnostic processes, controlled trials have never been performed. Consequently, some of these recommendations are based on brief observational studies, accepted clinical practice, expert consensus and sometimes common sense. In those cases, according to the current format of recommendations, a level of evidence $C$ is given.

\section{Part 1. Definitions, classification and pathophysiology, epidemiology, prognosis, impact on quality of life, and economic issues}

\subsection{Definitions}

Syncope is a T-LOC due to transient global cerebral hypoperfusion characterized by rapid onset, short duration, and spontaneous complete recovery.

This definition of syncope differs from others by including the cause of unconsciousness, i.e. transient global cerebral hypoperfusion. Without that addition, the definition of syncope becomes wide enough to include disorders such as epileptic seizures and concussion. In fact, the definition then becomes that of T-LOC, a term purposely meant to encompass all disorders characterized by self-limited loss of consciousness (LOC), irrespective of mechanism (Figure 1). By distinguishing both T-LOC and syncope, the present definition minimizes conceptual and diagnostic confusion. In the past, papers often did not define syncope, or did so in different ways. ${ }^{2}$ Syncope was sometimes used for T-LOC, thus including epileptic seizures and even stroke in 'syncope'. This source of confusion may still be found in the literature.

In some forms of syncope there may be a prodromal period in which various symptoms (e.g. lightheadedness, nausea, sweating, weakness, and visual disturbances) warn that syncope is imminent. Often, however, LOC occurs without warning. An accurate estimate of the duration of spontaneous episodes is rarely obtained. Typical syncope is brief. Complete LOC in reflex syncope lasts no longer than $20 \mathrm{~s}$ in duration. However, syncope may rarely be longer, even as much as several minutes. ${ }^{5}$ In such cases, the differential diagnosis between syncope and other causes of LOC can be difficult. Recovery from syncope is usually accompanied by almost immediate restoration of appropriate behaviour and orientation. Retrograde amnesia, although believed to be uncommon, may be more frequent than previously thought, particularly in older individuals. Sometimes the post-recovery period may be marked by fatigue. ${ }^{5}$

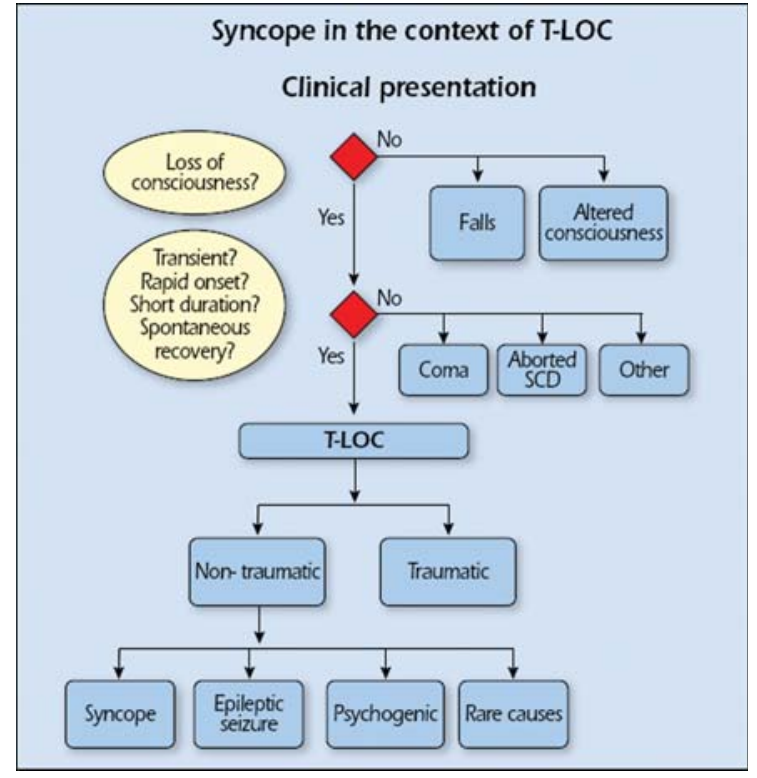

Figure I Context of transient loss of consciousness (T-LOC). $\mathrm{SCD}=$ sudden cardiac death

The adjective 'pre-syncopal' is used to indicate symptoms and signs that occur before unconsciousness in syncope, so its meaning is literal when used in this context and making it a synonym of 'warning' and 'prodromal'. The noun 'pre-syncope' or 'near-syncope' is used often to describe a state that resembles the prodrome of syncope but which is not followed by LOC; doubts remain as to whether the mechanisms involved are the same as in syncope.

\subsection{Classification and pathophysiology}

\subsubsection{Placing syncope in the larger framework of transient loss of consciousness (real or apparent)}

The context of T-LOC is shown in Figure 1. Two decision trees separating T-LOC from other conditions are whether consciousness appears lost or not, and whether the four features defining the presentation of T-LOC (transient, with rapid onset, short duration, and spontaneous recovery) are present.

T-LOC is divided into traumatic and non-traumatic forms. Concussion usually causes LOC; as the presence of a trauma is usually clear, the risk of diagnostic confusion is limited.

Non-traumatic T-LOC is divided into syncope, epileptic seizures, psychogenic pseudosyncope, and rare miscellaneous causes. Psychogenic pseudosyncope is discussed elsewhere in this document. Rare miscellaneous disorders include either those that are rare (e.g. cataplexy) or those whose presentation 


\section{Table 3 Conditions incorrectly diagnosed as syncope}

Disorders with partial or complete LOC but without global cerebral hypoperfusion

- Epilepsy

- Metabolic disorders including hypoglycaemia, hypoxia, hyperventilation with hypocapnia

- Intoxication

- Vertebrobasilar TIA

Disorders without impairment of consciousness

- Cataplexy

- Drop attacks

- Falls

- Functional (psychogenic pseudosyncope)

- TIA of carotid origin

$\mathrm{LOC}=$ loss of consciousness; $\mathrm{TIA}=$ transient ischaemic attack.

resembles other forms of T-LOC only in rare circumstances (e.g. excessive daytime sleepiness).

Several disorders may resemble syncope in two different ways (Table 3). In some, consciousness is truly lost, but the mechanism is something other than global cerebral hypoperfusion. Examples are epilepsy, several metabolic disorders (including hypoxia and hypoglycaemia), intoxication, and vertebrobasilar transient ischaemic attack (TIA). In other disorders, consciousness is only apparently lost; this is the case in cataplexy, drop attacks, falls, psychogenic pseudosyncope, and TIA of carotid origin. In these cases, the differential diagnosis from syncope is usually evident, but sometimes may be difficult because of lack of history, misleading features, or confusion over the definition of syncope. This differentiation is important for the clinician being confronted by patients with sudden LOC (real or apparent), which may be due to causes not associated with decreased global cerebral blood flow such as seizure and/or conversion reaction.

\subsubsection{Classification and pathophysiology of syncope}

Table 4 provides a pathophysiological classification of the principal causes of syncope, emphasizing large groups of disorders with a common presentation associated with different risk profiles. A distinction along pathophysiological lines centres on a fall in systemic blood pressure (BP) with a decrease in global cerebral blood flow as the basis for syncope. A sudden cessation of cerebral blood flow for as short as 6-8 $\mathrm{s}$ has been shown to be sufficient to cause complete LOC. Experience from tilt testing showed that a decrease in systolic BP to $60 \mathrm{mmHg}$ or lower is associated with syncope. $^{6}$ Systemic BP is determined by cardiac output (CO) and total peripheral vascular resistance, and a fall in either can cause syncope, but a combination of both mechanisms is often present, even if their relative contributions vary considerably. Figure 2 shows how pathophysiology underpins the classification, with low BP/global cerebral hypoperfusion at the centre, adjacent to low or inadequate peripheral resistance and low $\mathrm{CO}$.
Table 4 Classification of syncope

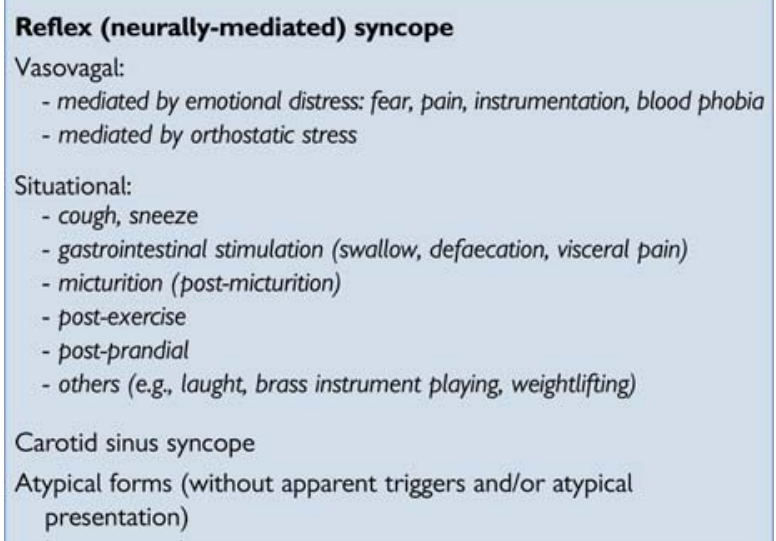

\section{Syncope due to orthostatic hypotension \\ Primary autonomic failure: \\ - pure autonomic failure, multiple system atrophy, Parkinson's disease with autonomic failure, Lewy body dementia}

Secondary autonomic failure:

- diabetes, amyloidosis, uraemia, spinal cord injuries

Drug-induced orthostatic hypotension:

- alcohol, vasodilators, diuretics, phenotiazines, antidepressants

Volume depletion:

- haemorrhage, diarrhoea, vomiting, etc

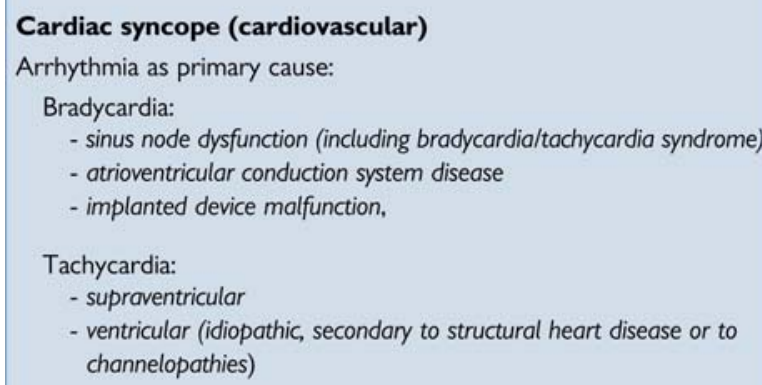

Drug induced bradycardia and tachyarrhythmias

Structural disease:

Cardiac: cardiac valvular disease, acute myocardial infarction/ischaemia, hypertrophic cardiomyopathy, cardiac masses (atrial myxoma, tumors, etc), pericardial disease/tamponade, congenital anomalies of coronary arteries, prosthetic valves dysfunction

Others: pulmonary embolus, acute aortic dissection, pulmonary hypertension

A low or inadequate peripheral resistance can be due to inappropriate reflex activity depicted in the next ring, causing vasodilatation and bradycardia manifesting as vasodepressor, mixed, or cardioinhibitory reflex syncope, seen in the outer ring. Other causes of a low or inadequate peripheral resistance are functional and structural impairments of the autonomic nervous system (ANS) with drug-induced, primary and secondary autonomic 


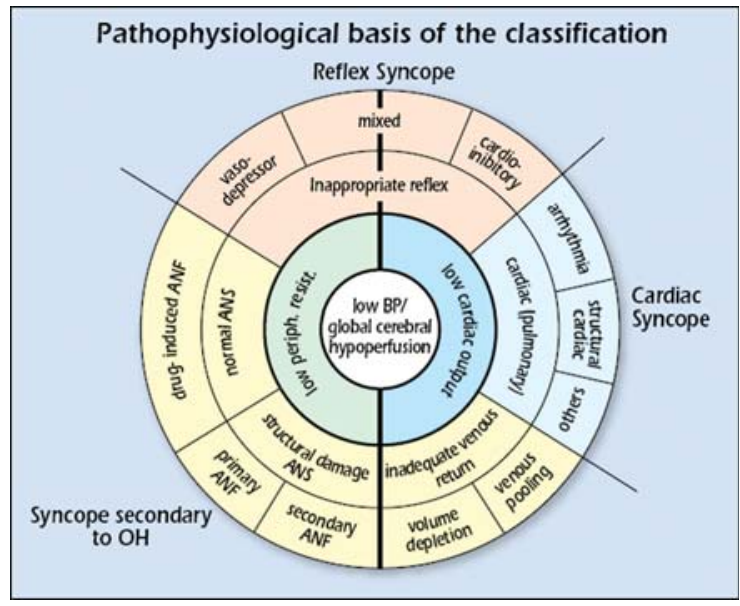

Figure 2 Pathophysiological basis of the classification (see text). ANF = autonomic nervous failure; ANS = autonomic nervous system; $\mathrm{BP}=$ blood pressure; low periph. resist. $=$ low peripheral resistance; $\mathrm{OH}=$ orthostatic hypotension.

failure (ANF) in the outer ring. In ANF, sympathetic vasomotor pathways are unable to increase total peripheral vascular resistance in response to the upright position. Gravitational stress, in combination with vasomotor failure, results in venous pooling of blood below the diaphragm, causing a decrease in venous return and consequently in $\mathrm{CO}$.

The causes of transient low $\mathrm{CO}$ are 3-fold. The first is a reflex causing bradycardia, known as cardioinhibitory type of reflex syncope. The second is cardiovascular causes, due to arrhythmia and structural disease including pulmonary embolism/hypertension. The third is inadequate venous return, due to volume depletion or venous pooling. The three final mechanisms, reflex, secondary to orthostatic hypotension $(\mathrm{OH})$, and cardiovascular, are shown outside the rings in Figure 2; reflex syncope and $\mathrm{OH}$ span the two main pathophysiological categories.

\subsubsection{Reflex syncope (neurally mediated syncope)}

Reflex syncope traditionally refers to a heterogeneous group of conditions in which cardiovascular reflexes that are normally useful in controlling the circulation become intermittently inappropriate, in response to a trigger, resulting in vasodilatation and/ or bradycardia and thereby in a fall in arterial BP and global cerebral perfusion. ${ }^{7}$

Reflex syncope is usually classified based on the efferent pathway most involved, i.e. sympathethic or parasympathetic. The term 'vasodepressor type' is commonly used if hypotension, due to a loss of upright vasoconstrictor tone, predominates. 'Cardioinhibitory' is used when bradycardia or asystole predominate, and 'mixed' is used if both mechanisms are present.

Reflex syncope may also be classified based on its trigger, i.e. the afferent pathway (Table 4). It must be recognized that this is a simplification, because many different mechanisms can be present in the context of a specific situation, such as micturition or defaecation syncope. The triggering situations vary considerably in and between individual patients. In most cases the efferent pathway does not depend strongly on the nature of the trigger [e.g. both micturition syncope and vasovagal syncope (VVS) may present as cardioinhibitory or vasodepressor syncope]. Knowing the various triggers is clinically important, as recognizing them may be instrumental in diagnosing syncope:

- 'Vasovagal' syncope (VVS), also known as the 'common faint', is mediated by emotion or by orthostatic stress. It is usually preceded by prodromal symptoms of autonomic activation (sweating, pallor, nausea).

- 'Situational' syncope traditionally refers to reflex syncope associated with some specific circumstances. Post-exercise syncope can occur in young athletes as a form of reflex syncope as well as in middle-aged and elderly subjects as an early manifestation of ANF before they experience typical $\mathrm{OH}$.

- 'Carotid sinus' syncope deserves special mention. In its rare spontaneous form it is triggered by mechanical manipulation of the carotid sinuses. In the more common form no mechanical trigger is found and it is diagnosed by carotid sinus massage (CSM). ${ }^{8}$

- The term 'atypical form' is used to describe those situations in which reflex syncope occurs with uncertain or even apparently absent triggers. The diagnosis then rests less on history taking alone, and more on the exclusion of other causes of syncope (absence of structural heart disease) and on reproducing similar symptoms with tilt testing. Such less clear presentations may overlap with clear-cut occurrences within patients.

The classical form of VVS usually starts in young subjects as an isolated episode and is distinct from other forms, frequently with an atypical presentation, starting in old age often associated with cardiovascular or neurological disorders possibly displaying orthostatic or post-prandial hypotension. In these latter forms, reflex syncope appears as an expression of a pathological process, mainly related to impairment of the ANS to activate compensatory reflexes, so there is an overlap with ANF.'

A comparison with other conditions causing syncope in the standing position is presented in Table 5.

\subsubsection{Orthostatic hypotension and orthostatic intolerance syndromes}

In contrast to reflex syncope, in ANF sympathetic efferent activity is chronically impaired so that vasoconstriction is deficient. Upon standing, BP falls and syncope or pre-syncope occurs. $\mathrm{OH}$ is defined as an abnormal decrease in systolic BP upon standing.

Strictly from a pathophysiological point of view there is no overlap between reflex syncope and ANF, but the clinical manifestations of the two conditions frequently overlap, sometimes making differential diagnosis difficult. 'Orthostatic intolerance' refers to symptoms and signs in the upright position due to a circulatory abnormality. Syncope is one symptom, and others are: (i) dizziness/ lightheadedness, pre-syncope; (ii) weakness, fatigue, lethargy; (iii) palpitations, sweating; (iv) visual disturbances (including blurring, enhanced brightness, tunnel vision); (v) hearing disturbances (including impaired hearing, crackles, and tinnitus); and (vi) pain in the neck (occipital/paracervical and shoulder region), low back pain, or precordial pain. ${ }^{10,11}$ 
Table 5 Syndromes of orthostatic intolerance which may cause syncope

\begin{tabular}{|c|c|c|c|c|c|}
\hline Classification & Test for diagnosis & $\begin{array}{l}\text { Time from } \\
\text { standing to } \\
\text { symptoms }\end{array}$ & Pathophysiology & Most frequent symptoms & $\begin{array}{l}\text { Most frequent associated } \\
\text { conditions }\end{array}$ \\
\hline Initial OH & $\begin{array}{l}\text { Beat-to-beat SBP on } \\
\text { lying-to-standing test } \\
\text { (active standing) }\end{array}$ & $0-30 \mathrm{~s}$ & Mismatch between CO and SVR & $\begin{array}{l}\text { Lightheadedness/dizziness, visual disturbances a } \\
\text { few seconds after standing up, (syncope rare) }\end{array}$ & $\begin{array}{l}\text { Young, asthenic subjects, old } \\
\text { age, drug induced } \\
\text { ( } \alpha \text {-blockers), CSS }\end{array}$ \\
\hline $\begin{array}{l}\text { Classical } \mathrm{OH} \text { (classical } \\
\text { autonomic failure) }\end{array}$ & $\begin{array}{l}\text { Lying-to-standing test } \\
\text { (active standing) or tilt } \\
\text { table }\end{array}$ & $30 s-3 \mathrm{~min}$ & $\begin{array}{l}\text { Impaired increase in SVR in autonomic failure } \\
\text { resulting in pooling of blood/or severe } \\
\text { volume depletion over-riding reflex } \\
\text { adjustments }\end{array}$ & $\begin{array}{l}\text { Dizziness, pre-syncope, fatigue, weakness, } \\
\text { palpitations, visual and hearing disturbances } \\
\text { (syncope rare) }\end{array}$ & $\begin{array}{l}\text { Old age, drug induced (any } \\
\text { vasoactive drugs and } \\
\text { diuretics) }\end{array}$ \\
\hline $\begin{array}{l}\text { Delayed (progressive) } \\
\text { OH }\end{array}$ & $\begin{array}{l}\text { Lying-to-standing test } \\
\text { (active standing) or tilt } \\
\text { table }\end{array}$ & $3-30 \mathrm{~min}$ & $\begin{array}{l}\text { Progressive fall in venous return: low } \mathrm{CO} \text {, } \\
\text { diminished vasoconstriction capacity } \\
\text { (failing adaptation reflex),no reflex } \\
\text { bradycardia }\end{array}$ & $\begin{array}{l}\text { Prolonged prodrome (dizziness, fatigue, } \\
\text { weakness, palpitations, visual and hearing } \\
\text { disturbances, hyperhydrosis, low back pain, neck } \\
\text { or precordial pain) frequently followed by rapid } \\
\text { syncope }\end{array}$ & $\begin{array}{l}\text { Old age, autonomic failure, } \\
\text { drug induced (any } \\
\text { vasoactive drugs and } \\
\text { diuretics), co-morbidities }\end{array}$ \\
\hline $\begin{array}{l}\text { Delayed (progressive) } \\
\text { OH + reflex } \\
\text { syncope }\end{array}$ & Tilt table & $3-45 \mathrm{~min}$ & $\begin{array}{l}\text { Progressive fall in venous return (as above) } \\
\text { followed by vasovagal reaction (active } \\
\text { reflex including reflex bradycardia and } \\
\text { vasodilation) }\end{array}$ & $\begin{array}{l}\text { Prolonged prodrome (dizziness, fatigue, } \\
\text { weakness, palpitations, visual and hearing } \\
\text { disturbances, hyperhydrosis, low back pain, neck } \\
\text { or precordial pain) always followed by rapid } \\
\text { syncope }\end{array}$ & $\begin{array}{l}\text { Old age, autonomic failure, } \\
\text { drug-induced (any } \\
\text { vasoactive drugs and } \\
\text { diuretics), comorbidities }\end{array}$ \\
\hline $\begin{array}{l}\text { Reflex syncope (VV) } \\
\text { triggered by } \\
\text { standing }\end{array}$ & Tilt table & $3-45 \mathrm{~min}$ & $\begin{array}{l}\text { Initial normal adaptation reflex followed by } \\
\text { rapid fall in venous return and vasovagal } \\
\text { reaction (active reflex including reflex } \\
\text { bradycardia and vasodilation) }\end{array}$ & $\begin{array}{l}\text { Clear prodrome ('classic') and triggers alwayss } \\
\text { followed by syncope }\end{array}$ & $\begin{array}{l}\text { Young healthy, female } \\
\text { dominance }\end{array}$ \\
\hline POTS & Tilt table & Variable & $\begin{array}{l}\text { Uncertain: severe deconditioning, inadequate } \\
\text { venous return or excessive blood venous } \\
\text { pooling advocated }\end{array}$ & $\begin{array}{l}\text { Symptomatic marked heart rate increases and } \\
\text { instability of blood pressure. No syncope }\end{array}$ & Young female \\
\hline
\end{tabular}

$\mathrm{CO}=$ cardiac output; $\mathrm{CSS}=$ carotid sinus syndrome; $\mathrm{OH}=$ orthostatic hypotension; POTS= postural orthostatic tachycardia syndrome; $\mathrm{SBP}=$ systolic blood pressure; $\mathrm{SVR}=$ systemic vascular resistance; $\mathrm{VVS}=$ vasovagal syncope. 


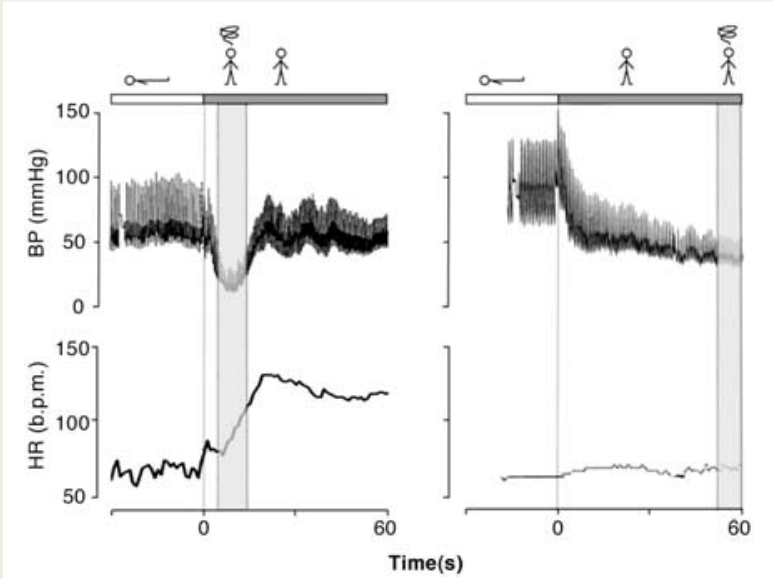

Figure 3 A case of 'initial orthostatic hypotension' (left panel) and of 'classical orthostatic hypotension' (right panel). In the left panel obtained in an otherwise healthy 17 -year-old teenager with complaints of severe transient lightheadedness upon active standing, a pronounced initial fall in BP is observed. The nadir is at $7-10 \mathrm{~s}$ and followed by recovery of BP. The tracing on the right is obtained in a 47-year-old male with pure ANF. BP starts to fall immediately after standing to very low levels after 1 min upright with little increase in HR despite the hypotension. $^{12,13} \mathrm{ANF}=$ autonomic failure; $\mathrm{BP}=$ blood pressure; $\mathrm{HR}=$ heart rate; b.p.m. $=$ beats per minute.

Various clinical syndromes of orthostatic intolerance are given in Table 5. Among these, the forms of reflex syncope in which orthostatic stress is the main trigger are also included.

- 'Classical $\mathrm{OH}^{\prime}$ is a physical sign defined as a decrease in systolic $\mathrm{BP} \geq 20 \mathrm{mmHg}$ and in diastolic BP $\geq 10 \mathrm{mmHg}$ within $3 \mathrm{~min}$ of standing $^{12}$ (Figure 3), described in patients with pure ANF, hypovolaemia, or other forms of ANF.

- "Initial $\mathrm{OH}^{13}$ is characterized by a BP decrease immediately on standing of $>40 \mathrm{mmHg}{ }^{13}$ BP then spontaneously and rapidly returns to normal, so the period of hypotension and symptoms is short (<30 s) (Figure 3).

- 'Delayed (progressive) $\mathrm{OH}^{14-16}$ is not uncommon in elderly persons. It is attributed to age-related impairment of compensatory reflexes and stiffer hearts in the elderly sensitive to a decrease in preload. ${ }^{16}$ Delayed $\mathrm{OH}$ is characterized by a slow progressive decrease in systolic BP on assuming erect posture. The absence of a bradycardiac reflex (vagal) differentiates delayed $\mathrm{OH}$ from reflex syncope. Delayed $\mathrm{OH}$ may, however, be followed by reflex bradycardia, where, in the elderly, the fall in BP is less steep than in the young (Figure 4).

- 'Postural orthostatic tachycardia syndrome' (POTS). Some patients, mostly young women, present with severe complaints of orthostatic intolerance, but not syncope, with very marked heart rate $(H R)$ increases $[>30$ beats per minute (b.p.m.) or to $>120$ b.p.m.] and instability of BP. ${ }^{17}$ POTS is frequently associated with chronic fatigue syndrome. The underlying pathophysiology remains to be determined.

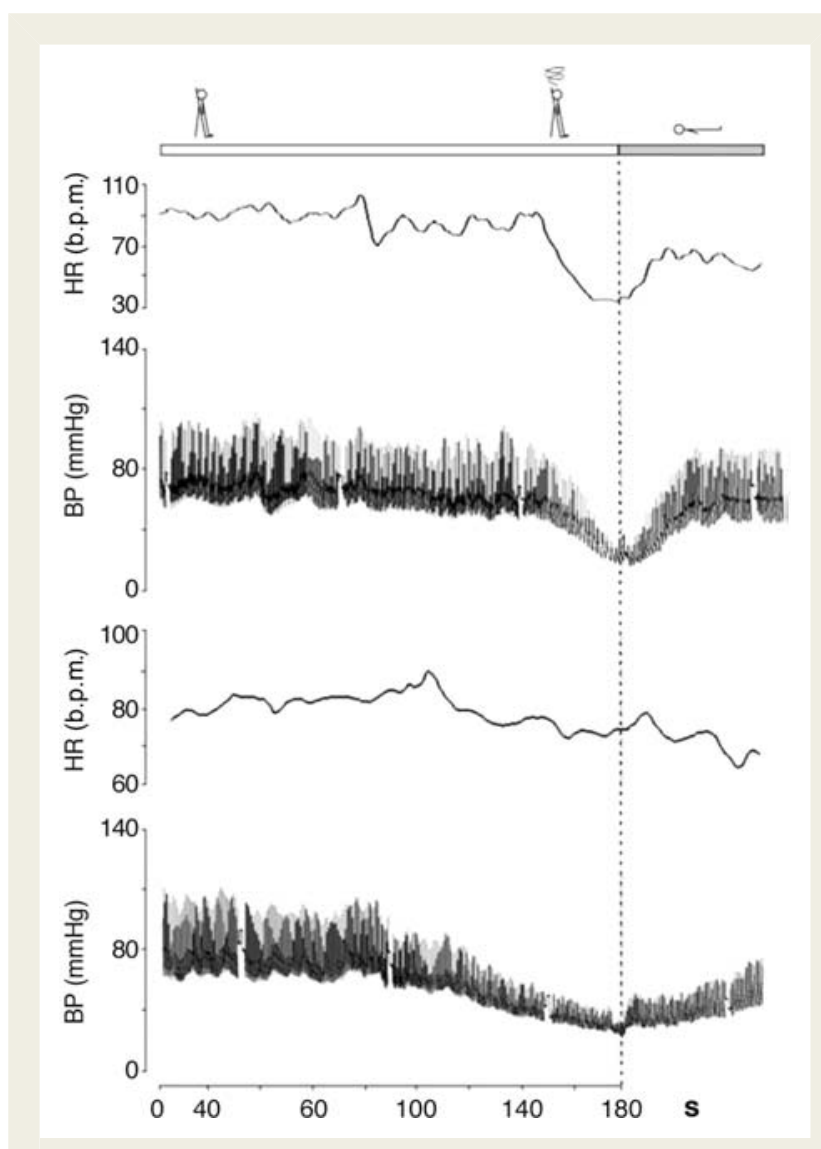

Figure 4 Reflex syncope (mixed form) induced by tilt testing in a 31-year-old (upper panel) and in a 69-year-old patient (lower panel). Note the typical age differences with a much steeper fall in BP in the younger subject compared with the older subject (revised after Verheyden et $a^{16}{ }^{16}$ ). $\mathrm{BP}=$ blood pressure; $\mathrm{HR}=$ heart rate; b.p.m. $=$ beats per minute.

\subsubsection{Cardiac syncope (cardiovascular)}

Arrhythmia

Arrhythmias are the most common cardiac causes of syncope. They induce haemodynamic impairment, which can cause a critical decrease in $\mathrm{CO}$ and cerebral blood flow. Nonetheless, syncope often has multiple contributory factors, including HR, type of arrhythmia (supraventricular or ventricular), left ventricular function, posture, and adequacy of vascular compensation. The latter include baroreceptor neural reflexes as well as responses to $\mathrm{OH}$ induced by the arrhythmia. ${ }^{18,19}$ Regardless of such contributing effects, when an arrhythmia is the primary cause of syncope, it should be specifically treated.

In intrinsic sick sinus syndrome, the sinoatrial node is damaged, because of either abnormal automaticity or sinoatrial conduction abnormalities. In this situation syncope is due to long pauses caused by sinus arrest or sinoatrial block and a failure of escape mechanism. These pauses are most frequently encountered when an atrial tachyarrhythmia suddenly stops (brady-tachy syndrome). ${ }^{19}$

As a rule, the more severe forms of acquired atrioventricular (AV) block (Mobitz II block, 'high grade', and complete AV block) are most closely related to syncope. In these cases, the 
cardiac rhythm may become dependent on subsidiary or escape (often unreliable) pacemaker sites. Syncope occurs because the delay before these pacemakers begin to 'fire' is long. In addition these subsidiary pacemaker sites typically have relatively slow rates (25-40 b.p.m.). Bradycardia also prolongs repolarization and predisposes to polymorphic ventricular tachycardia (VT), especially of the torsade de pointes type.

Syncope or near-syncope occurs at the onset of paroxysmal tachycardia, before vascular compensation develops. ${ }^{18,19}$ Consciousness is, in general, restored before tachycardia terminates. If haemodynamics remain inadequate due to tachycardia, unconsciousness is maintained. Recovery is then not spontaneous, no longer classified as syncope, and constitutes cardiac arrest.

Several drugs can cause brady- and tachyarrhythmias. Many antiarrhythmic drugs can cause bradycardia as a consequence of their specific effect on sinus node function or $\mathrm{AV}$ conduction. Syncope due to torsade de pointes is not uncommon, especially in women, and is caused by drugs prolonging the QT interval. It is particulary frequent in patients affected by the long QT syndrome. QT-prolonging drugs belong to different categories, i.e. antiarrhythmics, vasodilators, psychotropics, antimicrobials, non-sedating antihistamines, etc. Much has been learned about the inherited long QT syndrome through the collection of data in an international registry. Far less is known about the drug-induced syndrome because of the absence of a comprehensive database. Only $1 \%$ of serious adverse reactions to drugs are ever reported to the Food and Drug Administration (FDA). ${ }^{20,21}$ Owing to the wide variety of these drugs and the need for continuous updating, this TF recommends accessing a dedicated website (www.qtdrugs.org).

\section{Structural disease}

Structural cardiovascular diseases can cause syncope when circulatory demands outweigh the impaired ability of the heart to increase its output. Table 4 lists the most frequent cardiovascular diseases that can cause syncope. Syncope is of great concern when it is associated with conditions in which there is fixed or dynamic obstruction to left ventricular outflow. The basis for the faint is inadequate blood flow due to mechanical obstruction. Nonetheless, in several cases, syncope is not solely the result of restricted $\mathrm{CO}$, but may be in part due to an inappropriate reflex or $\mathrm{OH}$. For instance, in the setting of valvular aortic stenosis, syncope is not solely the result of restricted $\mathrm{CO}$, but may be in part due to inappropriate reflex vasodilation and/or primary cardiac arrhythmia. Furthermore, arrhythmias, particularly atrial fibrillation, are frequently important causes of faint. Thus, the mechanism of syncope may be multifactorial. To recognize the heart as the cause of the problem is justified by the need to correct the underlying structural disease, when possible.

\subsection{Epidemiology}

\subsubsection{Prevalence of syncope in the general population}

Syncope is common in the general population and the first episode presents at characteristic ages (Figure 5). About 1\% of toddlers may

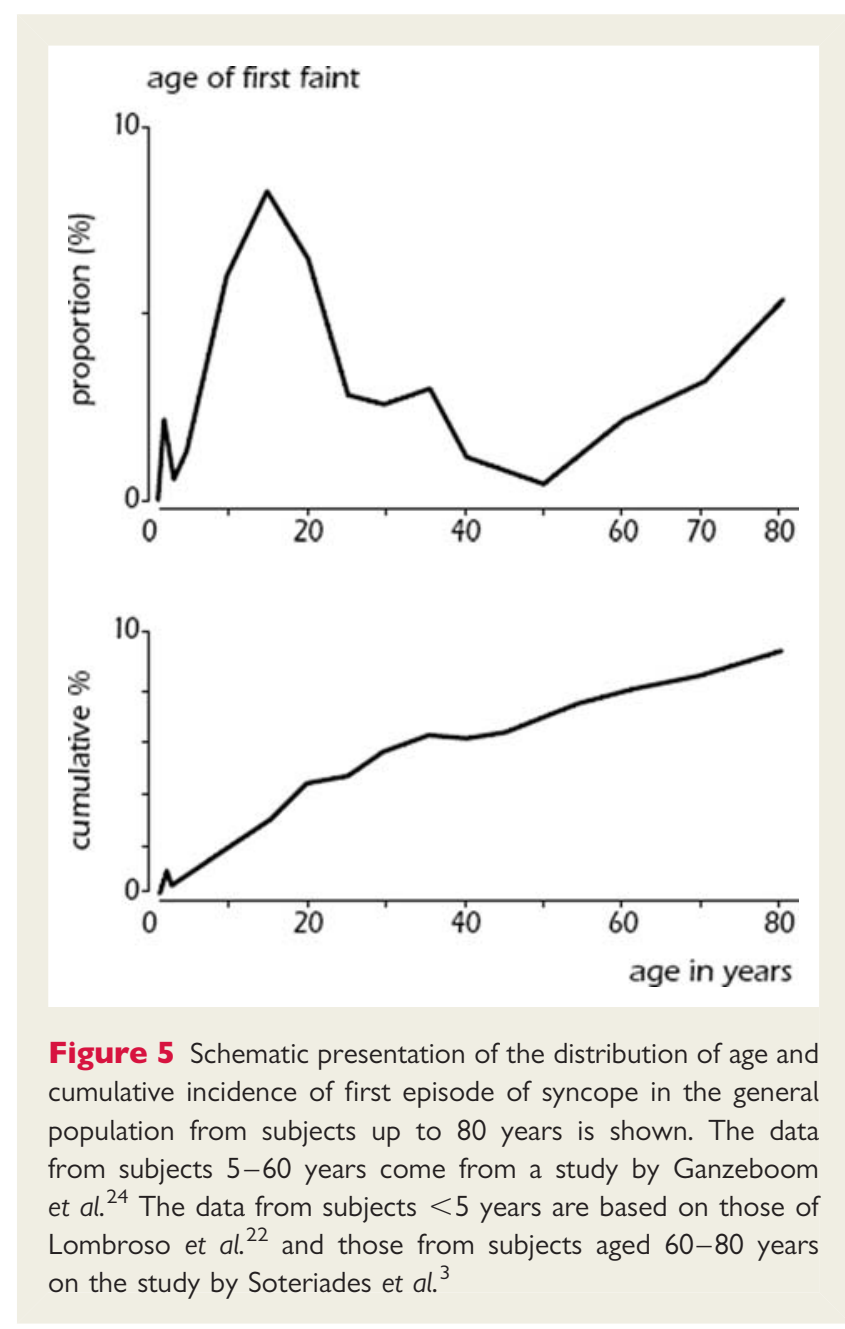

have a form of $\mathrm{VVS}{ }^{22,23}$ There is a very high prevalence of first faints in patients between 10 and 30 years, with a peak of $\sim 47 \%$ in females and $31 \%$ in males around the age of $15 .^{24,25}$ Reflex syncope is by far the most common cause. In contrast, the frequency of epileptic seizures in a similar young age group is much lower $(<1 \%)$ and syncope from cardiac arrhythmia is even less common. ${ }^{26}$ In a cohort study, only $5 \%$ of adults in the community have a first syncope over the age of 40 years. The majority have experienced reflex-mediated episodes as teenagers and adolescents. ${ }^{26}$ Finally, there appears to be a peak above the age of 65 years in both males and females. In the Framingham study the incidence of syncope shows a sharp rise after the age of 70 years, from 5.7 events per 1000 person-years in men aged 60-69, to 11.1 in men aged 70-79. ${ }^{3,26}$ However, in older adults and elderly subjects (>60 years) the lifetime cumulative incidence of syncope becomes increasingly difficult to obtain due to recollection bias of fainting episodes decades ago. ${ }^{26,27}$

\subsubsection{Referral from the general population to medical settings}

A very small fraction of patients with syncope in the general population, present in any clinical setting (Figure 6). In the Framingham offspring study, $44 \%$ of the participants (mean age 51 years, 
range 20-96 years) with an episode of LOC reported that they did not seek medical advice. ${ }^{3}$ The proportion of patients not seeking medical evaluation in the younger population is much higher. ${ }^{25,26}$

In The Netherlands the prevalence of the complaint of fainting in general practice is estimated at 9.3 per 1000 encounter-years. ${ }^{26,28}$ Recent studies report a remarkably constant frequency of syncope in community-based Emergency Departments (EDs) in Europe, with an incidence of $\sim 1 \%$ of all attendances (range $0.9-$ $1.7 \%){ }^{29-35}$

\subsubsection{Prevalence of the causes of syncope}

The prevalence of the causes of syncope is different depending on the clinical settings in which the patient is evaluated (Table 6) and the age of the patients (Table 7). Furthermore, other differences depend on diagnostic definitions, geographical factors, and local care pathways, making a comparison between different studies difficult.

Some general comments are however possible:

- Reflex syncope is the most frequent cause of syncope in any setting.

- Syncope secondary to cardiovascular disease is the second most common cause. The number of patients with a cardiovascular cause varies widely between studies; higher frequencies are observed in emergency settings mainly in older subjects, and in settings oriented toward cardiology.

- In patients $<40$ years $\mathrm{OH}$ is a rare cause of syncope; $\mathrm{OH}$ is frequent in very old patients.

- Non-syncopal conditions, misdiagnosed as syncope at initial evaluation, are more frequent in emergency referrals and reflect the multifactorial complexity of these patients.

- The high unexplained syncope rate in all settings justifies new strategies for evaluation and diagnosis.

While in the young reflex syncope is by far the most frequent cause of T-LOC, in the elderly multiple causes are often present and the medical history may be less reliable than in the young. ${ }^{36-39}$

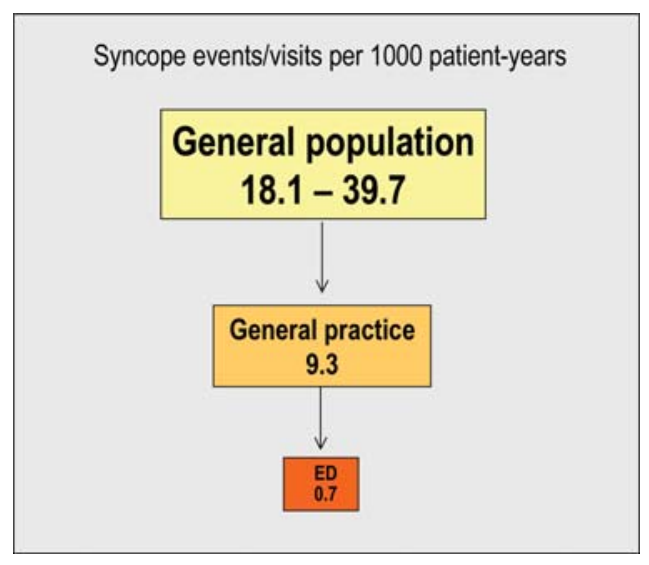

Figure 6 Syncope events/visits per 1000 patient-years in The Netherlands (from Ganzeboom et al. ${ }^{27}$ with permission). ED $=$ Emergency Department.

\subsection{Prognosis}

With regard to the prognosis (i.e. risk stratification) associated with syncope, two important elements should be considered: (i) risk of death and life-threatening events; and (ii) risk of recurrence of syncope and physical injury.

\subsubsection{Risk of death and life-threatening events}

Structural heart disease $e^{40-49}$ and primary electrical disease $e^{50-52}$ are major risk factors for SCD and overall mortality in patients with syncope. $\mathrm{OH}$ is associated with a 2-fold higher risk of death owing to the severity of co-morbidities compared with the general population. ${ }^{11}$ Conversely, young patients in whom structural or electrical heart disease have been excluded and are affected by reflex syncope have an excellent prognosis. ${ }^{3}$ Most of the deaths and many poor outcomes seem to be related to the severity of the underlying disease rather than to syncope per se. Several clinical factors able to predict outcome have been identified in some prospective population studies involving a validation cohort (Table 8).

\subsubsection{Recurrence of syncope and risk of physical injury}

In population studies, approximately one-third of patients have recurrence of syncope in 3 years follow-up. The number of episodes of syncope during life is the strongest predictor of recurrence. For example, in patients with uncertain diagnosis, low risk and age $>40$ years, a history of one or two episodes of syncope during life predicted a recurrence of 15 and $20 \%$ after 1 and 2 years, respectively, whereas a history of three episodes of syncope during life predicted a recurrence of 36 and $42 \%$ after 1 and 2 years, respectively. ${ }^{53}$

A psychiatric disease and age $<45$ years are also associated with higher rates of pseudosyncope. Conversely, gender, tilt test response, severity of presentation, and presence or absence of structural heart disease have minimal or absent predictive value. ${ }^{1,53}$

Major morbidity, such as fractures and motor vehicle accidents, were reported in $6 \%$ of patients, and minor injury, such as laceration and bruises, in $29 \%$. Recurrent syncope is associated with fractures and soft tissue injury in $12 \%$ of patients. ${ }^{1}$ In patients presenting to an ED, minor trauma were reported in $29.1 \%$ and major trauma in $4.7 \%$ of cases; the highest prevalence (43\%) was observed in older patients with carotid sinus syndrome (CSS). ${ }^{54}$

Morbidity is particulary high in the elderly and ranges from loss of confidence, depressive illness, and fear of falling, to fractures and subsequent institutionalization. ${ }^{55,56}$

\subsection{Impact on quality of life}

Recurrent syncope has serious effects on quality of life. The physical impairment due to syncope is comparable with chronic illnesses such as chronic arthritis, recurrent moderate depressive disorders, and end-stage renal disease. ${ }^{57-59}$ In 
Table 6 Frequency of the causes of syncope in general population, Emergency Department and specialized clinical settings from some recent studies

\begin{tabular}{|c|c|c|c|c|c|c|c|}
\hline Setting & Source & Reflex, \% & OH, \% & Cardiac, \% & $\begin{array}{l}\text { Non-syncopal } \\
\text { T-LOCs, \% }\end{array}$ & Unexplained, \% & Notes \\
\hline General population & Framingham studies ${ }^{3}$ & 21 & 9.4 & 9.5 & 9 & 37 & $\begin{array}{l}\text { Mean age at entry of } 51 \pm 14 \text { years, adolescents } \\
\text { excluded. Other causes of syncope (medication, } \\
\text { etc.) were found in } 14.3 \% \text { of the population. } \\
\text { Furthermore, } 44 \% \text { of population did not seek a } \\
\text { medical visit }\end{array}$ \\
\hline \multirow[t]{4}{*}{ ED } & Ammirati $^{29}$ & 35 & 6 & 21 & 20 & 17 & \multirow{4}{*}{ *Some differences in diagnostic definitions } \\
\hline & Sarasin $^{35}$ & $38^{*}$ & $24 *$ & 11 & 8 & 19 & \\
\hline & Olde Nordkamp ${ }^{28}$ & 39 & 5 & 5 & 17 & 33 & \\
\hline & Range & $35-48$ & $4-24$ & $5-21$ & $8-20$ & $17-33$ & \\
\hline \multirow[t]{4}{*}{ Syncope Unit (dedicated facility) } & Alboni $^{68}$ & 56 & 2 & 23 & 1 & 18 & In the Cardiology Department. \\
\hline & $\mathrm{Chen}^{36}$ & 56 & 6 & 37 & 3 & 20 & $\begin{array}{l}\text { In the Cardiology Department. Total percentage is } \\
>100 \% \text { because } 18.4 \% \text { of the patients had multiple } \\
\text { diagnoses }\end{array}$ \\
\hline & Shen ${ }^{213}$ & 65 & 10 & 6 & 2 & 18 & In the ED \\
\hline & Range & $56-73$ & $1-10$ & 6-37 & $1-6$ & $5-20$ & \\
\hline
\end{tabular}

$\mathrm{ED}=$ Emergency Department; $\mathrm{OH}=$ orthostatic hypotension; $\mathrm{T}-\mathrm{LOC}=$ transient loss of consciousness. 


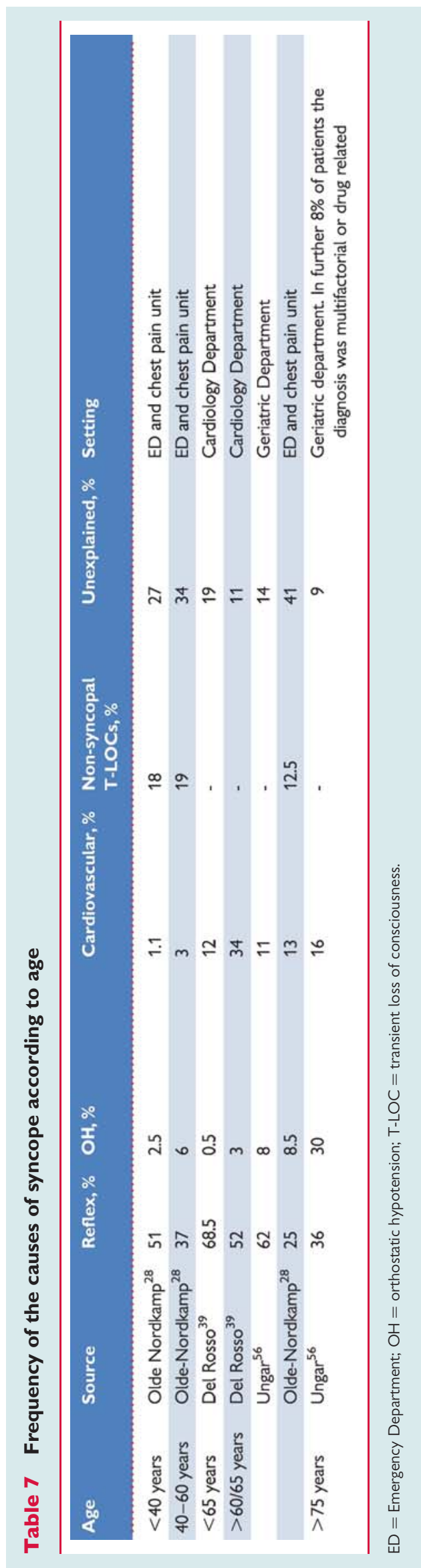

patients with frequent recurrent syncope, psychosocial impairment had an estimated average adverse impact on $33 \%$ of the assessed aspects of daily life. Syncope reduces mobility, usual abilities, and self-caring, and increases depression, pain, and discomfort. Female gender, high level of co-morbidity, number of episodes of syncope, and presence of pre-syncope seemed to be associated with poorer quality of life. Finally, it should be stressed that, while syncope occurs intermittently, its threat of recurrence continuously impairs quality of life. Although quality of life usually improves over time, it remains poor, especially in older age due to recurrences and higher level of co-morbidity. ${ }^{60}$

\subsection{Economic issues}

The management of syncope is expensive for a number of reasons:

(1) As syncope is very frequent in the general population, it inevitably results in high direct clinical and indirect social costs. Approximately $1 \%$ of referrals to the ED are for syncope; of these, $\sim 40 \%$ are hospitalized. ${ }^{30,31,33,61}$ In a large study ${ }^{32}$ the median in-hospital stay was 5.5 days (interquartile range $3-9)$. Hospitalization costs account for $>75 \%$ of the total costs. $^{62-64}$

(2) A wide range of conditions may cause syncope. Consequently, without strict adherence to published management guidelines the evaluation of syncope patients has proved to be inefficient. The absence of a gold standard clinical test able to provide a certain, easy, and cheap diagnosis, and the widespread inappropriate use of multiple but inefficiently directed diagnostic tests ('shotgun approach') results in overuse of medical resources and increased costs. By following a well defined standardized care pathway a considerable improvement in diagnostic yield and cost-effectiveness (i.e. cost per reliable diagnosis) can be achieved ${ }^{64}$ (see section 5.3).

Although a comparison of costs between different studies is difficult, owing to differences in methods of calculation and between healthcare systems in different countries, it is generally believed that costs associated with syncope management are high. In the USA, estimated total annual costs for syncope-related admissions, derived from the Medicare database, were US\$2.4 billion, with a mean cost of US\$5400 per hospitalization. ${ }^{65}$ In the UK, ${ }^{63}$ the overall cost per patient was $£ 611$, with $74 \%$ attributed to the costs of hospital stay. Cost per diagnosis of patients admitted to hospital was $\notin 1080$. In a multicentre study performed in Italy. ${ }^{64}$ 929 patients evaluated according to usual practice were compared with 725 patients evaluated using a standardized guideline-based approach. In the usual practice group, the cost per diagnosis was $€ 1753 \pm 2326$ per patient; it increased to $€ 3506 \pm 2729$ for hospitalized patients. When compared with the usual-care group, the standardized-care group had a $17 \%$ lower hospitalization rate, $24 \%$ fewer tests performed, and $11 \%$ shorter in-hospital stay. As a consequence, the mean cost per diagnosis was $29 \%$ lower ( $€ 1240 \pm$ $521 P=0.0001)$. 
Table 8 Risk stratification at initial evaluation in prospective population studies including a validation cohort

\begin{tabular}{|c|c|c|c|c|}
\hline Study & Risk factors & Score & Endpoints & $\begin{array}{l}\text { Results (validation } \\
\text { cohort) }\end{array}$ \\
\hline $\begin{array}{l}\text { S. Francisco Syncope } \\
\text { Rule }^{44}\end{array}$ & $\begin{array}{l}\text {-Abnormal ECG } \\
\text {-Congestive heart failure } \\
\text {-Shortness of breath } \\
\text { - Haematocrit }<30 \% \\
\text {-Systolic blood pressure }<90 \mathrm{mmHg}\end{array}$ & $\begin{array}{l}\text { No risk }=0 \text { item } \\
\text { Risk }=\geq 1 \text { item }\end{array}$ & Serious events at 7 days & $\begin{array}{l}98 \% \text { sensitive and } 56 \% \\
\text { specific }\end{array}$ \\
\hline Martin et al. ${ }^{40}$ & $\begin{array}{l}\text {-Abnormal ECG } \\
\text {-History of ventricular arrhythmia } \\
\text { - History of congestive heart failure } \\
\text {-Age }>45 \text { years }\end{array}$ & $\begin{array}{l}0 \text { to } 4 \text { ( } 1 \text { point each } \\
\text { item) }\end{array}$ & $\begin{array}{l}\text { 1-year severe arrhythmias or } \\
\text { arrhythmic death }\end{array}$ & $\begin{array}{l}0 \% \text { score } 0 \\
5 \% \text { score } 1 \\
16 \% \text { score } 2 \\
27 \% \text { score } 3 \text { or } 4\end{array}$ \\
\hline OESIL score ${ }^{41}$ & $\begin{array}{l}\text {-Abnormal ECG } \\
\text {-History of cardiovascular disease } \\
\text {-Lack of prodrome } \\
\text {-Age }>65 \text { years }\end{array}$ & $\begin{array}{l}0 \text { to } 4 \text { ( } 1 \text { point each } \\
\text { item) }\end{array}$ & 1-year total mortality & $\begin{array}{l}0 \% \text { score } 0 \\
0.6 \% \text { score } 1 \\
14 \% \text { score } 2 \\
29 \% \text { score } 3 \\
53 \% \text { score } 4 \\
\end{array}$ \\
\hline \multirow[t]{4}{*}{ EGSYS score ${ }^{42}$} & $\begin{array}{l}\text {-Palpitations before syncope }(+4) \\
\text {-Abnormal ECG and/or heart } \\
\text { disease }(+3)\end{array}$ & Sum of + and - points & 2-year total mortality & $\begin{array}{l}2 \% \text { score }<3 \\
21 \% \text { score } \geq 3\end{array}$ \\
\hline & -Syncope during effort $(+3)$ & & . & $\ldots \ldots \ldots \ldots+\cdots \cdots$ \\
\hline & $\begin{array}{l}\text {-Syncope while supine }(+2) \\
- \text {-Autonomic prodrome }^{\mathrm{a}}(-1)\end{array}$ & & Cardiac syncope probability & $\begin{array}{l}2 \% \text { score }<3 \\
13 \% \text { score } 3\end{array}$ \\
\hline & -Predisposing and/or precipitating & & & $33 \%$ score 4 \\
\hline
\end{tabular}

This table shows several different studies that have analysed the impact of different clinical data on the follow-up of patients presenting with syncope. Overall, the presence of abnormal ECG, increased age, or data suggestive of heart disease imply a worse prognosis at 1-2 year follow-up

${ }^{a}$ Nausea/vomiting

bWarm-crowded place/ prolonged orthostasis/fear-pain-emotion.

$\mathrm{ECG}=$ electrocardiogram

\section{Part 2. Initial evaluation, diagnosis, and risk stratification}

\subsection{Initial evaluation}

The initial evaluation of a patient presenting with T-LOC consists of careful history, physical examination, including orthostatic BP measurements, and electrocardiogram (ECG). Based on these findings, additional examinations may be performed:

- CSM in patients $>40$ years.

- Echocardiogram when there is previous known heart disease or data suggestive of structural heart disease or syncope secondary to cardiovascular cause.

- Immediate ECG monitoring when there is a suspicion of arrhythmic syncope.

- Orthostatic challenge (lying-to-standing orthostatic test and/or head-up tilt testing) when syncope is related to the standing position or there is a suspicion of a reflex mechanism.

- Other less specific tests such as neurological evaluation or blood tests are only indicated when there is suspicion of nonsyncopal T-LOC.

The initial evaluation should answer three key questions:

(1) Is it a syncopal episode or not?

(2) Has the aetiological diagnosis been determined?
(3) Are there data suggestive of a high risk of cardiovascular events or death?

\subsubsection{Diagnosis of syncope}

The differentiation between syncope and non-syncopal conditions with real or apparent LOC can be achieved in most cases with a detailed clinical history, ${ }^{66-68}$ but sometimes can be extremely difficult.

The following questions should be answered:

- Was LOC complete?

- Was LOC transient with rapid onset and short duration?

- Did the patient recover spontaneously, completely and without sequelae?

- Did the patient lose postural tone?

If the answers to these questions are positive, the episode has a high likelihood of being syncope. If the answer to one or more of these questions is negative, exclude other forms of LOC before proceeding with syncope evaluation.

\subsubsection{Aetiological diagnosis}

Initial evaluation is able to define the cause of syncope in $23-50 \%$ of patients. ${ }^{33,69}$ Table 9 lists some of the most important questions that must be answered by the clinical history. There are some findings in the clinical history, physical examination, or ECG that can be 


\section{Table 9 Important historical features}

Questions about circumstances just prior to the attack

- Position (supine, sitting or standing)

- Activity (rest, change in posture, during or after exercise, during or immediately after urination, defaecation, cough, or swallowing)

- Predisposing factors (e.g. crowded or warm places, prolonged standing, post-prandial period) and of precipitating events (e.g. fear, intense pain, neck movements)

Questions about onset of the attack

- Nausea, vomiting, abdominal discomfort, feeling of cold, sweating, aura, pain in neck or shoulders, blurred vision, dizziness

- Palpitations

Questions about the attack (eyewitness)

- Way of falling (slumping or kneeling over), skin colour (pallor. cyanosis, flushing), duration of loss of consciousness, breathing pattern (snoring), movements (tonic, clonic, tonic-clonic, minimal myoclonus or automatism), duration of movements, onset of movement in relation to fall, tongue biting

Questions about the end of the attack

- Nausea, vomiting, sweating, feeling of cold, confusion, muscle aches, skin colour, injury, chest pain, palpitations, urinary or faecal incontinence

Questions about the background

- Family history of sudden death, congenital arrhythmogenic heart disease or fainting

- Previous cardiac disease

- Neurological history (Parkinsonism, epilepsy, narcolepsy)

- Metabolic disorders (diabetes, etc.)

- Medication (antihypertensive, antianginal, antidepressant agent, antiarrhythmic, diuretics, and QT-prolonging agents) or other drugs including alcohol

- In the case of recurrent syncope, information on recurrences such as the time from the first syncopal episode and on the number of spells

considered diagnostic of the cause of syncope, permiting no further evaluation and institution of treatment.

In many other situations, the findings of initial evaluation do not permit a definite diagnosis to be made, but suggest some causes (Table 10). In these cases, additional testing is usually needed.

\subsubsection{Risk stratification}

When the cause of syncope remains uncertain after initial evaluation the next step is to assess the risk of major cardiovascular events or SCD. Figure 7 shows the diagnostic flow chart to be followed in these patients.

The main high risk features, in accordance with recent guidelines on SCD and cardiac pacing, ${ }^{70-73}$ are listed in Table 11.

\subsection{Diagnostic tests}

\subsubsection{Carotid sinus massage}

It has long been observed that pressure at the site where the common carotid artery bifurcates produces a slowing in HR and fall in BP. In some individuals, this reflex initiated by CSM results in an abnormal response. A ventricular pause lasting $>3$ $s$ and/or a fall in systolic BP of $>50 \mathrm{mmHg}$ defines carotid sinus hypersensitivity $(\mathrm{CSH})$. When associated with spontaneous syncope, CSH defines CSS. Precise methodology and results of CSM are reported in the previous guidelines on syncope. ${ }^{1}$ Diagnosis of CSS requires the reproduction of spontaneous symptoms during $10 \mathrm{~s}$ sequential right and left CSM performed supine and erect, under continuous monitoring of $H R$ and periodic measurement of BP, permitting better evaluation of the vasodepressor component. ${ }^{74}$ In up to $30 \%$ of patients, an abnormal reflex is present only in the upright position. It should be stressed that $\mathrm{CSH}$ is a common finding in older male individuals, ${ }^{8}$ but patients with CSS are more unusual. ${ }^{75}$ CSS is exceptional in patients $<40$ years old. ${ }^{74}$

\section{Recommendations: diagnostic criteria with initial evaluation}

\begin{tabular}{|c|c|c|}
\hline Recommendations & Class $^{a}$ & Level $^{b}$ \\
\hline $\begin{array}{l}\text { WS is diagnosed if syncope is precipitated by } \\
\text { emotional distress or orthostatic stress and is } \\
\text { associated with typical prodrome }\end{array}$ & I & C \\
\hline $\begin{array}{l}\text { Situational syncope is diagnosed if syncope occurs } \\
\text { during or immediately after specific triggers listed in } \\
\text { Table } 4\end{array}$ & 1 & C \\
\hline $\begin{array}{l}\text { Orthostatic syncope is diagnosed when it occurs after } \\
\text { standing up and there is documentation of } \\
\mathrm{OH}\end{array}$ & I & C \\
\hline $\begin{array}{l}\text { Arrhythmia-related syncope is diagnosed by ECG } \\
\text { when there is: } \\
\text { - Persistent sinus bradycardia }<40 \mathrm{bpm} \text { in awake or } \\
\text { repetitive sinoatrial block or sinus pauses } \geq 3 \mathrm{~s} \\
\text { - Mobitz II second or third degree AV block } \\
\text { - Alternating left and right BBB } \\
\text { - VT or rapid paroxysmal SVT } \\
\text { - Non-sustained episodes of polymorphic VT and } \\
\text { long or short QT interval } \\
\text { - Pacemaker or ICD malfunction with cardiac pauses }\end{array}$ & I & C \\
\hline $\begin{array}{l}\text { Cardiac ischaemia-related syncope is diagnosed when } \\
\text { syncope presents with ECG evidence of acute } \\
\text { ischaemia with or without myocardial infarction }\end{array}$ & I & C \\
\hline $\begin{array}{l}\text { Cardiovascular syncope is diagnosed when syncope } \\
\text { presents in patients with prolapsing atrial myxoma, } \\
\text { severe aortic stenosis, pulmonary hypertension, } \\
\text { pulmonary embolus, or acute aortic dissection }\end{array}$ & I & C \\
\hline
\end{tabular}

${ }^{\mathrm{a} C l a s s}$ of recommendation.

bLevel of evidence.

$\mathrm{AV}=$ atrioventricular; $\mathrm{BBB}=$ bundle branch block; $\mathrm{ECG}=$ electrocardiogram; $\mathrm{ICD}=$ implantable cardioverter defibrillator; $\mathrm{OH}=$ orthostatic hypotension; $\mathrm{SVT}=$ supraventricular tachycardia; VVS = vasovagal syncope; VT = ventricular tachycardia.

The relationship between abnormal response to CSM and syncope is a crucial point that has been studied by two different methods. The first was a pre-post comparison of the recurrence rate of syncope after pacing. Nonrandomized studies demonstrated fewer recurrences at follow-up in patients implanted than in patients without 


\section{Table I 0 Clinical features that can suggest a diagnosis on initial evaluation}

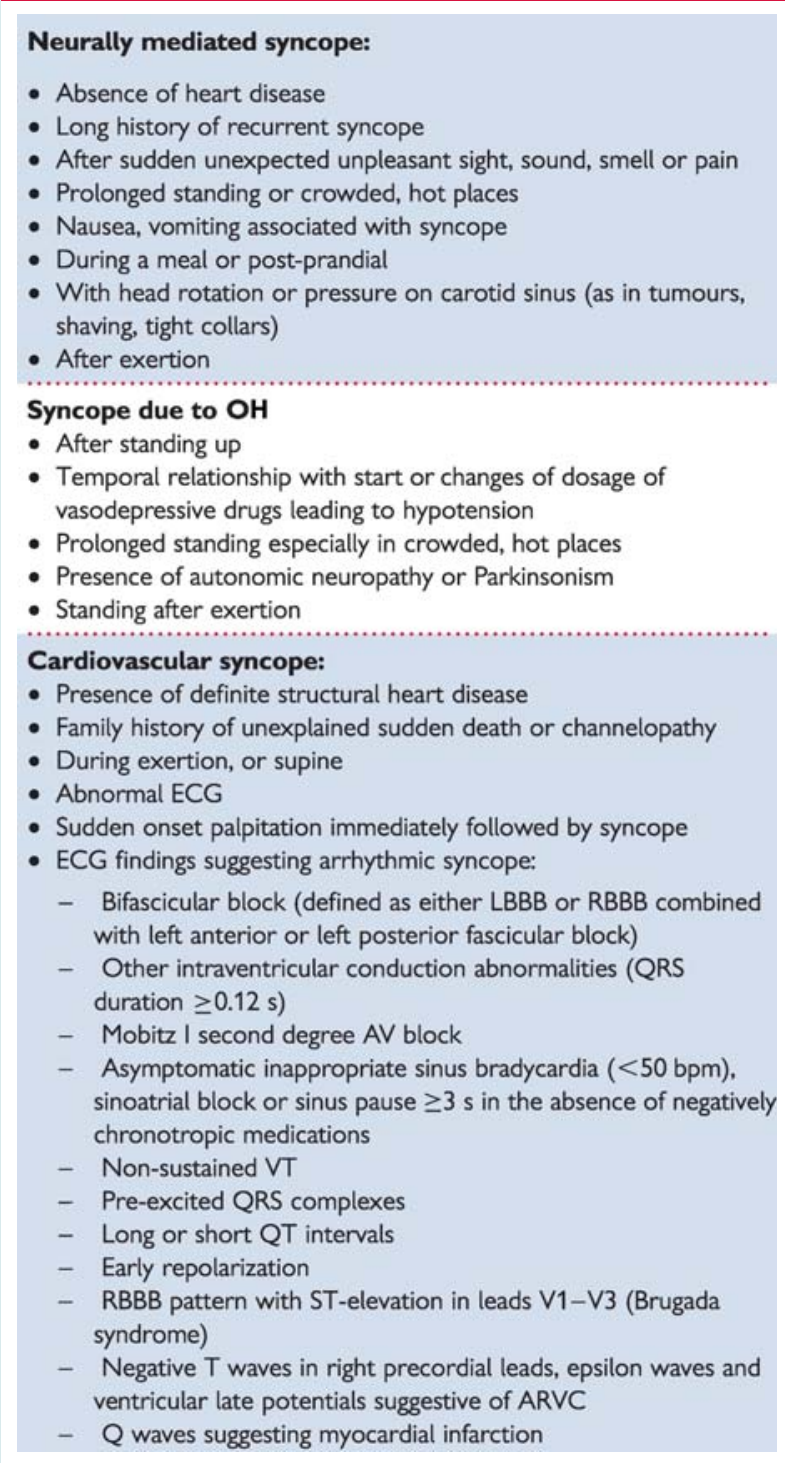

$\mathrm{ARVC}=$ arrhythmogenic right ventricular cardiomyopathy; $\mathrm{AV}=$ atrioventricular; $\mathrm{LBBB}=$ left bundle branch block; $\mathrm{OH}=$ orthostatic hypotension; $\mathrm{RBBB}=$ right bundle branch block; VT = ventricular tachycardia

pacing, and these results were confirmed by two randomized trials. $^{76,77}$ The second method was to analyse the occurrence of asystolic episodes registered in patients with cardioinhibitory response to CSM by an implanted device. In the two trials that employed this methodology, recordings of long pauses were very common. ${ }^{78,79}$ These results suggest that a positive response to CSM in patients with syncope is highly predictive of the occurrence of spontaneous asystolic episodes.

The main complications of CSM are neurological. Pooling the data of three studies ${ }^{74,80,81}$ in which 7319 patients were analysed, neurological complications were observed in 21 (0.29\%). CSM

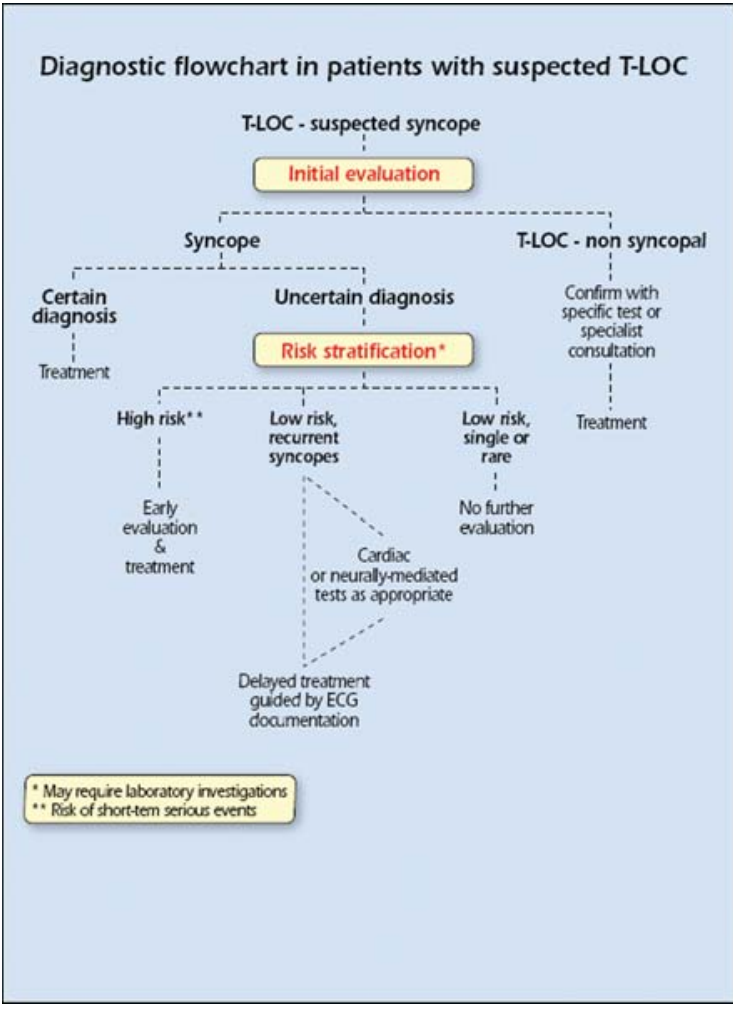

Figure 7 Diagnostic flowchart in patients with suspected T-LOC. $E C G=$ electrocardiographic; T-LOC $=$ transient loss of consciousness.

\section{Recommendations: carotid sinus massage}

Recommendations
- CSM is indicated in patients $>40$ years with
syncope of unknown aetiology after initial
evaluation
- CSM should be avoided in patients with previous
TIA or stroke within the past 3 months and in
patients with carotid bruits (except if carotid
Doppler studies excluded significant stenosis)
Diagnostic criteria
- CSM is diagnostic if syncope is reproduced in the ।
presence of asystole longer than 3 s and/or a fall in
systolic BP $>50$ mmHg

${ }^{\mathrm{a} C l a s s}$ of recommendation.

bLevel of evidence.

$\mathrm{BP}=$ blood pressure; $\mathrm{CSM}=$ carotid sinus massage; $\mathrm{TIA}=$ transient ischaemic attack.

should be avoided in patients with previous TIA, stroke within the past 3 months, or with carotid bruits, except if carotid Doppler studies excluded significant stenosis. ${ }^{80}$ 
Table I I Risk stratification

Short-term high risk criteria which require prompt
hospitalization or intensive evaluation
Severe structural or coronary artery disease (heart failure, low
LVEF, or previous myocardial infarction)
Clinical or ECG features suggesting arrhythmic syncope
- Syncope during exertion or supine
- Palpitations at the time of syncope
- Family history of SCD
- Non-sustained VT
- Bifascicular-block (LBBB or RBBB combined with left anterior or
left posterior fascicular block) or other intraventricular conduction
abnormalities with QRS duration $\geq 120$ ms
- Inadequate sinus bradycardia (<50 bpm) or sinoatrial block in
absence of negative chronotropic medications or physical training
- Pre-excited QRS complex
- Prolonged or short QT interval
- RBBB pattern with ST-elevation in leads V1-V3 (Brugada pattern)
- Negative T waves in right precordial leads, epsilon waves, and
ventricular late potentials suggestive of ARVC
Im...........................................................................
Important co-morbidities
- Severe anaemia

ARVC $=$ arrhythmogenic right ventricular cardiomyopathy; b.p.m. = beats per minute; $\mathrm{LBBB}=$ left bundle branch block; $\mathrm{LVEF}=$ left ventricular ejection fraction; $\mathrm{RBBB}=$ right bundle branch block; $\mathrm{SCD}=$ sudden cardiac death; $\mathrm{VT}=$ ventricular tachycardia.

\subsubsection{Orthostatic challenge}

Changing from supine to upright position produces a displacement of blood from the thorax to the lower limbs that leads to a decrease in venous return and $\mathrm{CO}$. In the absence of compensatory mechanisms, a fall in BP may lead to syncope. $^{82}$

Currently, there are two different methods for assessing the response to change in posture from supine to erect ${ }^{11}$ (Table 5).

One is 'active standing', in which patients arise actively from supine to erect, and the other is head up tilt at 60 or $70^{\circ}$.

\subsubsection{Active standing}

This test is used to diagnose different types of orthostatic intolerance; see section 1.2.2.2 and Table 5.

The sphygmomanometer is adequate for routine clinical testing because of its ubiquity and simplicity. Automatic arm-cuff devices, as they are programmed to repeat and confirm measurements when discrepant values are recorded, may be a disadvantage due to the rapidly falling BP during $\mathrm{OH}$. With a sphygmomanometer more than four measurements per minute cannot be obtained without venous obstruction in the arm. When more frequent values are required continuous beat-to-beat non-invasive BP measurement can be used.

\section{Recommendations: active standing}

Recommendations
Indications
- Manual intermittent determination with
sphygmomanometer of $\mathrm{BP}$ supine and
during active standing for 3 min is indicated
as initial evaluation when $\mathrm{OH}$ is suspected
Continuous beat-to-beat non-invasive pressure
measurement may be helpful in cases of doubt
Diagnostic criteria
The test is diagnostic when there is a symptomatic
fall in systolic $\mathrm{BP}$ from a baseline value
$\geq 20 \mathrm{mmHg}$ or diastolic $\mathrm{BP} \geq 10$ mmHg, or a
decrease in systolic $\mathrm{BP}$ to $<90$ mmHg
The test should be considered diagnostic when
there is an asymptomatic fall in systolic $\mathrm{BP}$ from
baseline value $\geq 20$ mmHg or diastolic $\mathrm{BP}$
$\geq 10 \mathrm{mmHg}$ or a decrease in systolic $\mathrm{BP}$ to
$<90 \mathrm{mmHg}$

\subsubsection{Tilt testing}

\section{Background}

Tilt testing enables the reproduction of a neurally mediated reflex in laboratory settings. Blood pooling and decrease in venous return due to orthostatic stress and immobilization trigger the reflex. The final effect, hypotension and usually concomitant HR slowing, is related to impaired vasoconstrictor capability followed by sympathetic withdrawal and vagal overactivity.

The clinical situation corresponding to tilt testing is reflex syncope triggered by prolonged standing. However, this test can also be positive in patients with other forms of reflex syncope ${ }^{83}$ and in patients with sick sinus syndrome. ${ }^{84}$

\section{Methodology}

Tilt testing was introduced into clinical evaluation of patients with syncope of unknown origin by Kenny et al. in $1986 .{ }^{85}$ Since then, many protocols have been reported with variations in the initial stabilization phase, duration, tilt angle, type of support, and different pharmacological provocation. The sensitivity and specificity of different protocols are described in detail in different reviews. ${ }^{1,86}$

The most commonly used protocols are the low-dose intravenous isoproterenol test, which uses incremental doses in order to increase average HR by $\sim 20-25 \%$ over baseline (usually $\leq 3 \mu \mathrm{g} / \mathrm{min})^{87}$ and the protocol using $300-400 \mu \mathrm{g}$ of sublingual nitroglycerine after a 20 min unmedicated phase. ${ }^{88}$ In older patients omission of the passive phase and commencing the test with nitroglycerine may be effective and improve compliance. ${ }^{89}$ Both protocols have a similar rate of positive responses (61$69 \%)$, with a high specificity (92-94\%). Patients should be fasted for $4 \mathrm{~h}$ prior to the test. Due to the need for venous cannulation 
in the isoproterenol protocol a pre-tilt phase of stabilization of $20 \mathrm{~min}$ is required, whereas with sublingual nitroglycerine the pre-tilt phase can be shortened to $5 \mathrm{~min}$.

Indications. In most studies the main indication for tilt testing has been to confirm a diagnosis of reflex syncope in patients in whom this diagnosis was suspected but not confirmed by initial evaluation. ${ }^{85-89}$

Tilt testing is not usually needed in patients whose reflex syncope is already diagnosed by clinical history and in patients with single or rare syncope unless special situations (e.g. injury, anxiety, occupational implications such as aircraft pilots, etc.). In patients with a high risk profile for cardiovascular events or with data suggestive of arrhythmic syncope, tilt testing has been reported to be useful when a cardiovascular cause has been reasonably excluded by a comprehensive evaluation. In patients with T-LOC associated with jerking movements tilt testing has been demonstrated to be helpful in discriminating syncope from epilepsy. ${ }^{90}$ Tilt testing has been used in patients with frequent episodes of T-LOC and suspicion of psychiatric problems, even with traumatic injury, to investigate the reflex nature of the syncope. ${ }^{91}$ Similarly, tilt testing has been used in the elderly in order to distinguish syncope from falls. ${ }^{92}$

The pattern of response to tilt testing has recently been used to discriminate pure reflex syncope from non-classical forms of delayed $\mathrm{OH}$ (see Table 5). ${ }^{14}$

Tilt testing has no value in assessing the treatment efficacy. ${ }^{93}$ However tilt table testing is widely accepted as a useful tool to demonstrate susceptibility of the patient to reflex syncope, and thereby to initiate treatment (e.g. physical manoeuvres, see Part 3). ${ }^{94-96}$

Responses to tilt testing. The endpoint of tilt testing is the induction of either reflex hypotension/bradycardia or delayed $\mathrm{OH}$ associated with syncope or pre-syncope. When a reflex is induced, according to the predominance of vasodepressor or cardioinhibitory components, the responses have been classified as cardioinhibitory, vasodepressor, or mixed. ${ }^{97}$ A negative tilt table response does not exclude the diagnosis of reflex syncope. The clinical significance of the type of response to tilt testing in predicting the behaviour of BP and HR during spontaneous syncope has recently been questioned. ${ }^{98,99}$ Some studies have compared the response to tilt testing with spontaneous syncope recorded by implantable loop recorder (ILR). While a positive cardioinhibitory response to tilt testing predicts with a high probability an asystolic spontaneous syncope, the presence of a positive vasodepressor or mixed response or even a negative response does not exclude the presence of asystole during spontaneous syncope. ${ }^{98,99}$

Complications and contraindications. Tilt testing is safe. There have been no reported deaths during the test. However, some rare life-threatening ventricular arrhythmias with isoproterenol in the presence of ischaemic heart disease ${ }^{100}$ or sick sinus syndrome ${ }^{101}$ have been reported. No complications have been published with the use of nitroglycerine. Minor side effects are common and include palpitations with isoproterenol and headache with nitroglycerine. Atrial fibrillation can be induced during or after a positive tilt test and is usually self-limited. ${ }^{102}$ Despite the low risk, it is recommended that resuscitation equipment should available.

Contraindications to the administration of isoproterenol include ischaemic heart disease, uncontrolled hypertension, left ventricular outflow tract obstruction, and significant aortic stenosis. Caution should be used in patients with known arrhythmias.

\section{Recommendations: tilt testing}

\section{Recommendations \\ Methodology}

Class $^{a}$ Level

- Supine pre-tilt phase of at least $5 \mathrm{~min}$, when no venous cannulation, and of at least $20 \mathrm{~min}$, when cannulation is undertaken, is recommended

- Tilt angle between 60 and $70^{\circ}$ is recommended

- Passive phase of a minimum of $20 \mathrm{~min}$ and a maximum of $45 \mathrm{~min}$ is recommended

- For nitroglycerine, a fixed dose of 300-400 $\mu \mathrm{g}$ sublingually administered in the upright position is recommended

- For isoproterenol, an incremental infusion rate from 1 up to $3 \mu \mathrm{g} / \mathrm{min}$ in order to increase average heart rate by $\sim 20-25 \%$ over baseline is recommended

\section{Indications}

- Tilt testing is indicated in the case of an unexplained single syncopal episode in high risk settings (e.g. occurrence of, or potential risk of physical injury or with occupational implications), or recurrent episodes in the absence of organic heart disease, or in the presence of organic heart disease, after cardiac causes of syncope have been excluded

- Tilt testing is indicated when it is of clinical value to demonstrate susceptibility to reflex syncope to the patient

- Tilt testing should be considered to discriminate between reflex and $\mathrm{OH}$ syncope

- Tilt testing may be considered for differentiating syncope with jerking movements from epilepsy

- Tilt testing may be indicated for evaluating patients with recurrent unexplained falls

- Tilt testing may be indicated for evaluating patients with frequent syncope and psychiatric disease

- Tilt testing is not recommended for assessment of treatment

- Isoproterenol tilt testing is contraindicated in patients with ischaemic heart disease

\section{Diagnostic criteria}

- In patients without structural heart disease the induction of reflex hypotension/bradycardia with reproduction of syncope or progressive $\mathrm{OH}$ (with or without symptoms) are diagnostic of reflex syncope and $\mathrm{OH}$, respectively

- In patients without structural heart disease the induction of reflex hypotension/bradycardia without reproduction of syncope may be diagnostic of reflex syncope

- In patients with structural heart disease, arrhythmia or other cardiovascular cause of syncope should be excluded prior to considering positive tilt test results as diagnostic

- Induction of LOC in absence of hypotension and/or bradycardia should be considered diagnostic of psychogenic pseudosyncope

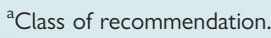

bLevel of evidence.

$\mathrm{BP}=$ blood pressure; $\mathrm{CSM}=$ carotid sinus massage; $\mathrm{HR}=$ heart rate; $\mathrm{LOC}=$ loss of consciousness; $\mathrm{OH}=$ orthostatic hypotension; $\mathrm{TIA}=$ transient ischaemic attack; $\mu \mathrm{g}=$ micrograms. 


\subsubsection{Electrocardiographic monitoring (non-invasive and invasive)}

ECG monitoring is a procedure for diagnosing intermittent bradyand tachyarrhythmias. Currently several systems of ECG ambulatory monitoring are available: conventional ambulatory Holter monitoring, in-hospital monitoring, event recorders, external or implantable loop recorders, and remote (at home) telemetry.

The gold standard for the diagnosis of syncope is when a correlation between the symptoms and a documented arrhythmia is recorded. ${ }^{103,104}$ The presence of some asymptomatic significant arrhythmias, defined by prolonged asystole ( $\geq 3 \mathrm{~s}$ ), rapid supraventricular tachycardias (SVTs) (i.e. $\geq 160$ b.p.m. for $>32$ beats), or VTs, has been considered by several authors as a diagnostic finding. ${ }^{105-107}$ On the other hand, although the absence of documentation of an arrhythmia during a syncopal episode cannot be considered a specific diagnosis, it allows exclusion of an arrhythmia as the mechanism of the syncope.

As a general rule, ECG monitoring is indicated only when there is a high pre-test probability of identifying an arrhythmia associated with syncope (see Table 11). However, it has been observed that in patients $>40$ years, with recurrent syncope, without significant structural heart disease, and a normal ECG, an arrhythmia, usually asystole, is present during syncope in up to $50 \% .^{108-111}$

\subsubsection{In-hospital monitoring}

In-hospital monitoring (in bed or telemetry) is warranted only when the patient is at high risk for a life-threatening arrhythmia. A few days of ECG monitoring may be of value in patients with clinical features or ECG abnormalities suggesting arrhythmic syncope such as those listed in Table 11, especially if the monitoring is applied immediately after syncope. Although in such circumstances the diagnostic yield of ECG monitoring may be only as high as $16 \%,{ }^{69}$ it is justified by the need to avoid immediate risk to the patient.

\subsubsection{Holter monitoring}

In current practice ECG monitoring is usually undertaken with conventional $24-48 \mathrm{~h}$, or even 7 day, Holter recorders. However, since in most of the patients symptoms do not recur during the monitoring period, the true yield of Holter in syncope may be as low as $1-2 \%$ in an unselected population. In $15 \%$ of patients, symptoms were not associated with arrhythmia. ${ }^{112}$ Thus, in these patients, a rhythm disturbance could potentially be excluded as a cause of syncope. Holter monitoring in syncope is inexpensive in terms of set-up costs, but expensive in terms of cost per diagnosis. Holter monitoring in syncope may be of more value if symptoms are very frequent. Daily single or multiple episodes of LOC might increase the potential for symptom-ECG correlation. Experience in patients with very frequent symptoms suggests that many have psychogenic pseudosyncope. Undoubtedly, in such patients, true negative findings of Holter monitoring may be useful in confirming the underlying cause.

\subsubsection{Prospective external event recorders}

Event recorders are external devices which are applied by the patient when symptoms occur. Whereas these types of recorders can be useful in the investigation of patients with palpitations, ${ }^{113}$ they have no role in the evaluation of syncope.

\subsubsection{External loop recorders}

These devices have a loop memory that continuously records and deletes ECG. When activated by the patient, typically after a symptom has occurred, 5-15 min of pre-activation ECG is stored and can be retrieved for analysis. They are connected to the patient through cutaneous patch electrodes. Previous studies gave conflicting results about the usefulness of external loop recorders: one study showed that external retrospective loop recorders allowed ECG documentation of syncope in up to $25 \%$ of enrolled patients ${ }^{114}$ monitored for 1 month, whereas in another ${ }^{115}$ external loop recorders were not useful. A recent study found that external loop recorders had an increased diagnostic yield, when compared with Holter monitoring. ${ }^{116}$ However, since patients usually do not comply for more than a few weeks, symptom-ECG correlation cannot be achieved when syncope recurrence is infrequent.

\subsubsection{Implantable loop recorders}

ILRs are implanted subcutaneously under local anaesthesia and have a battery life of up to 36 months. These devices have a solid-state loop memory that stores retrospective ECG recordings, when activated either by the patient or a bystander, usually after a syncopal episode, ${ }^{103,104}$ or automatically activated in the case of occurrence of predefined arrhythmias. ${ }^{105-107}$ Some of these devices have the capability of transmitting the signals transtelephonically. Advantages of ILRs include continuous loop high-fidelity ECG recording. Disadvantages include: the need for a minor surgical procedure, the fact that sometimes it can be difficult to differentiate between supraventricular or ventricular arrhythmias, the presence of under- or oversensing that may fill the memory, and the high cost of the implantable device. The ILR has a high initial cost. However, if symptom-ECG correlation can be achieved in a substantial number of patients during the active life of the device, then analysis of the cost per symptom-ECG yield has shown than the implanted device may be more cost-effective than a strategy using conventional investigation. ${ }^{117,118}$ In the initial experience, ILRs were used for diagnosis in patients with unexplained syncope at the end of complete negative work-up. In a small series of highly selected patients, symptom-ECG correlation was achieved in $88 \%$ of patients within a mean of 5 months of implantation. ${ }^{103}$ Pooled data from nine studies, ${ }^{103,104,108,119-124}$ including 506 patients with unexplained syncope at the end of a complete conventional investigation, show that a correlation between syncope and ECG was found in 176 patients (35\%); of these, $56 \%$ had asystole (or bradycardia in a few cases) at the time of the recorded event, $11 \%$ had tachycardia and $33 \%$ had no arrhythmia. In pooled data from seven studies $^{104,108,119-123}$ pre-syncope was much less likely to be associated with an arrhythmia than syncope. These data suggest that in the absence of a documented arrhythmia pre-syncope cannot be considered a surrogate for syncope; in contrast, the documentation of a significant arrhythmia at the time of pre-syncope can be considered a diagnostic finding. 


\section{Recommendations: electrocardiograhic monitoring}

\begin{tabular}{|c|c|c|c|c|}
\hline \multicolumn{3}{|c|}{ Recommendations } & Class $^{\mathrm{a}}$ & Level $^{b}$ \\
\hline \multicolumn{5}{|c|}{ Indications } \\
\hline \multicolumn{3}{|c|}{$\begin{array}{l}\text { ECG monitoring is indicated in patients who have } \\
\text { clinical or ECG features suggesting arrhythmic } \\
\text { syncope (listed in Table 10). The duration (and } \\
\text { technology) of monitoring should be selected } \\
\text { according the risk and the predicted recurrence } \\
\text { rate of syncope: }\end{array}$} & 1 & B \\
\hline o & & $\begin{array}{l}\text { nediate in-hospital monitoring (in bed } \\
\text { elemetric) is indicated in high risk } \\
\text { ents defined in Table } 11\end{array}$ & 1 & C \\
\hline 0 & & $\begin{array}{l}\text { ter monitoring is indicated in } \\
\text { ents who have very frequent } \\
\text { cope or pre-syncope ( } \geq 1 \text { per week) }\end{array}$ & 1 & B \\
\hline \multicolumn{5}{|c|}{ ILR is indicated in: } \\
\hline & & $\begin{array}{l}\text { An early phase of evaluation in patients } \\
\text { with recurrent syncope of uncertain } \\
\text { origin, absence of high risk criteria listed } \\
\text { in Table } 11 \text { and a high likelihood of } \\
\text { recurrence within battery longevity of } \\
\text { the device }\end{array}$ & 1 & B \\
\hline & $\square$ & $\begin{array}{l}\text { High risk patients in whom a } \\
\text { comprehensive evaluation did not } \\
\text { demonstrate a cause of syncope or lead } \\
\text { to a specific treatment }\end{array}$ & I & B \\
\hline O & $\begin{array}{l}\text { ILR } \\
\text { con } \\
\text { emb } \\
\text { with } \\
\text { pres } \\
\text { sync }\end{array}$ & $\begin{array}{l}\text { should be considered to assess the } \\
\text { tribution of bradycardia before } \\
\text { barking on cardiac pacing in patients } \\
\text { h suspected or certain reflex syncope } \\
\text { senting with frequent or traumatic } \\
\text { copal episodes }\end{array}$ & $\mathrm{lla}$ & B \\
\hline 0 & $\begin{array}{l}\text { Exte } \\
\text { con } \\
\text { inte }\end{array}$ & $\begin{array}{l}\text { ernal loop recorders should be } \\
\text { sidered in patients who have an } \\
r \text {-symptom interval } \leq 4 \text { weeks }\end{array}$ & $\mathrm{Ila}$ & B \\
\hline \multicolumn{5}{|c|}{ Diagnostic criteria } \\
\hline \multicolumn{3}{|c|}{$\begin{array}{l}\text { - ECG monitoring is diagnostic when a correlation } \\
\text { between syncope and an arrhythmia (brady- or } \\
\text { tachyarrhythmia) is detected }\end{array}$} & I & B \\
\hline \multicolumn{3}{|c|}{$\begin{array}{l}\text { - In the absence of such correlation, ECG } \\
\text { monitoring is diagnostic when periods of Mobitz II } \\
\text { or III degree AV block or a ventricular pause }>3 \mathrm{~s} \\
\text { (with the possible exception of young trained } \\
\text { persons, during sleep, medicated patients, or } \\
\text { rate-controlled atrial fibrillation), or rapid } \\
\text { prolonged paroxysmal SVT or VT are detected. } \\
\text { The absence of arrhythmia during syncope } \\
\text { excludes arrhythmic syncope }\end{array}$} & 1 & C \\
\hline \multicolumn{3}{|c|}{$\begin{array}{l}\text { - The ECG documentation of pre-syncope without } \\
\text { any relevant arrhythmia is not an accurate } \\
\text { surrogate for syncope }\end{array}$} & III & C \\
\hline \multicolumn{3}{|c|}{$\begin{array}{l}\text { Asymptomatic arrhythmias (other than those } \\
\text { listed above) are not an accurate surrogate for } \\
\text { syncope }\end{array}$} & III & C \\
\hline \multicolumn{3}{|c|}{$\begin{array}{l}\text { - Sinus bradycardia (in the absence of syncope) is } \\
\text { not an accurate surrogate for syncope }\end{array}$} & III & C \\
\hline
\end{tabular}

${ }^{\mathrm{a}}$ Class of recommendation.

bLevel of evidence.

$\mathrm{AV}=$ atrioventricular; $\mathrm{ECG}=$ electrocardiogram; ILR = implantable loopr recorder; SVT = supraventricular tachyradia; VT = ventricular tachycardia.

There are several areas of interest other than unexplained syncope in which ILRs have been investigated:
- Patients in whom epilepsy was suspected but the treatment has proven ineffective. $^{90}$

- Patients who have suspected recurrent neurally mediated syncope when the understanding of the mechanism of spontaneous syncope may alter the therapeutic approach. ${ }^{110}$

- Patients with bundle branch block (BBB) in whom paroxysmal AV block is likely despite negative complete electrophysiological evaluation. $^{120}$

- Patients with definite structural heart disease and/or nonsustained ventricular tachyarrhythmia in whom a ventricular tachyarrhythmia is likely despite a negative complete electrophysiological study (EPS). ${ }^{119}$

- Patients with unexplained falls. ${ }^{125}$

\subsubsection{Remote (at home) telemetry}

Most recently, external and implantable device systems that are able to provide continuous ECG recording or $24 \mathrm{~h}$ loop memory, with wireless transmission (real time) to a service centre, have been developed. Daily and warning reports for predefined events are sent from the centre to the physician. Initial data showed that a mobile cardiac outpatient telemetry system had a higher diagnostic yield than a patient-activated external looping event monitor in patients with syncope or pre-syncope. ${ }^{126}$ The potential role of these systems in the diagnostic work-up of patients with syncope needs to be further evaluated.

\subsubsection{Classification of electrocardiographic recordings}

Because of the heterogeneity of findings and the wide variety of rhythm disturbances recorded with an ILR at the time of syncope, the International Study on Syncope of Unknown Etiology (ISSUE) investigators have proposed a classification aimed to group the observations into homogeneous patterns in order to define an acceptable standard useful for future studies and clinical practice. ${ }^{127}$ This classification divided ECG recordings into four groups according to the main rhythm change and the suggested mechanism of syncope (Table 12).

\subsubsection{Electrocardiographic monitoring in syncope- where in the work-up?}

The role of ECG monitoring cannot be defined in isolation. Physicians will be guided by the results of initial evaluation. In some situations, where the clinical evidence strongly suggests a diagnosis of reflex syncope, and especially when syncope occurs occasionally, ECG monitoring may be deemed unnecessary. In those patients with frequent symptoms or in those in whom arrhythmic syncope is suspected, but who are not at high risk, an ILR can be useful. In the initial experience, ILRs were used as last resort in the evaluation of syncope after all investigations were negative. In one study, ${ }^{128} 60$ patients with unexplained syncope were randomized to "conventional' strategy consisting of an external loop recorder, tilt testing, and EPS or to prolonged monitoring with an ILR. The results were that a strategy of implantation of an ILR initially in the work-up was more likely to provide a diagnosis than the conventional strategy (52 vs. 20\%). However, patients at high risk of life-threatening arrhythmias, as well as those with a left ventricular ejection fraction (LVEF) $<35 \%$, were excluded. According to these data and due to the limited diagnostic value of tilt testing, ${ }^{98,99}$ adenosine triphosphate (ATP) test, ${ }^{99,129}$ EPS, ${ }^{119,120}$ and short-term ECG monitoring (Holter, 
Table 12 Classification of ECG recordings obtained with ILR, with their probable-related mechanism (adapted from ISSUE classification)

\begin{tabular}{|c|c|c|}
\hline & Classification & $\begin{array}{l}\text { Suggested } \\
\text { mechanism }\end{array}$ \\
\hline \multirow[t]{3}{*}{ Type 1, asystole: $R-R$ pause $\geq 3 \mathrm{~s}$} & $\begin{array}{l}\text { Type } 1 \mathrm{~A} \text {. Sinus arrest: progressive sinus bradycardia or initial sinus } \\
\text { tachycardia followed by progressive sinus bradycardia until sinus arrest. }\end{array}$ & Probably reflex \\
\hline & $\begin{array}{l}\text { Type } 1 \mathrm{~B}, \text { Sinus bradycardia plus AV block: } \\
\text {-progressive sinus bradycardia followed by AV block (and ventricular } \\
\text { pause/s) with concomitant decrease in sinus rate } \\
\text {-or sudden onset AV block (and ventricular pause/s) with concomitant } \\
\text { decrease in sinus rate }\end{array}$ & Probably reflex \\
\hline & $\begin{array}{l}\text { Type } 1 C \text {, AV block: sudden onset AV block (and ventricular pause/s) with } \\
\text { concomitant increase in sinus rate }\end{array}$ & Probably intrinsic \\
\hline $\begin{array}{l}\text { Type 2, bradycardia: decrease in HR }>30 \% \text { or } \\
<40 \mathrm{bpm} \text { for }>10 \mathrm{~s}\end{array}$ & & Probably reflex \\
\hline $\begin{array}{l}\text { Type 3, no or slight rhythm variations: variations } \\
\text { in } \mathrm{HR}<30 \% \text { and heart rate }>40 \text { b.p.m. }\end{array}$ & & Uncertain \\
\hline \multirow{4}{*}{$\begin{array}{l}\text { Type } 4 \text {, tachycardia: increase in heart rate }>30 \% \\
\text { of }>120 \text { b.p.m. }\end{array}$} & Type 4 A. Progressive sinus tachycardia & Uncertain \\
\hline & Type 4 B. Atrial fibrillation & $\begin{array}{l}\text { Cardiac } \\
\text { arrhythmia }\end{array}$ \\
\hline & Type 4 C. SVT (except sinus) & $\begin{array}{l}\text { Cardiac } \\
\text { arrhythmia }\end{array}$ \\
\hline & Type 4 D. VT & $\begin{array}{l}\text { Cardiac } \\
\text { arrhythmia }\end{array}$ \\
\hline
\end{tabular}

$\mathrm{AV}=$ atrioventricular; b.p.m. = beats per minute; ECG = electrocardiographic; $\mathrm{HR}=$ heart rate; ILR = implantable loop recorder; ISSUE = International Study on Syncope of Unknown Etiology; SVT = supraventricular tachycardia; VT = ventricular tachycardia.

external loop recorder), it appears that early use of an ILR in the diagnostic work-up might become the reference standard to be adopted when an arrhythmic cause of syncope is suspected but not sufficiently proven to allow treatment based on aetiology.

Future technology may allow recording of multiple signals in addition to the ECG and will place emphasis on the features occurring during spontaneous syncope, rather than provoked syncope. For this reason it is likely that implantable monitors will become increasingly emphasized in syncope and that their use will be anticipated in the diagnostic work-up instead or before many other conventional investigations. However, in patients with important structural heart disease that expose them to a high risk of lifethreatening arrhythmias, the implantation of an implantable cardioverter defibrillator (ICD) or an EPS preceding the use of ECG monitoring systems should be performed. Although the documentation of a bradyarrhythmia concurrent with syncope is considered diagnostic, further evaluation may sometimes be necessary in order to discriminate between an intrinsic cardiac abnormality and a reflex mechanism, the latter being the most frequent cause of paroxysmal bradyarrhythmia in patients without structural heart disease and normal ECG.

\subsubsection{Electrophysiological study}

The diagnostic efficacy of EPS to determine the cause of syncope is highly dependent on the degree of suspicion of the abnormality (pre-test probability), and also on the EPS protocol.
In an overview of eight studies including 625 patients with syncope undergoing EPS, ${ }^{130}$ it was shown that positive results occurred predominantly in patients with structural heart disease.

Sensitivity and specificity of EPS in general are not good. For a complete review of this topic please refer to previous guidelines. ${ }^{1}$ In addition, in recent years the development of powerful noninvasive methods, i.e. prolonged monitoring, showing a higher diagnostic value has decreased the importance of EPS as a diagnostic test. Moreover, EPS is no longer indicated in the setting of patients with severely depressed LVEF, because in these cases there is general consensus that ICD implantation should be performed regardless of mechanism of syncope, as discussed elsewhere in this document. In clinical practice, data from some registries show that nowadays $\sim 2 \%$ of patients with unexplained syncope evaluated by cardiologists undergo EPS and even fewer if they are evaluated by other specialists. ${ }^{27,31,36,40,56,131}$ Nevertheless, this test still remains useful for diagnosis in specific clinical situations listed below.

\subsubsection{Suspected intermittent bradycardia}

The pre-test probability of syncope-related bradycardia is relatively high when there is asymptomatic sinus bradycardia ( $<50$ b.p.m.) or sinoatrial block, usually documented by 12-lead ECG or ECG monitoring.

The prognostic value of a prolonged sinus node recovery time (SNRT) is not well defined. An abnormal response is defined as 
$\geq 1.6$ or 2 s for SNRT or $\geq 525$ ms for corrected sinus node recovery time (CSNRT). ${ }^{132,133}$ One observational study, however, showed a relationship between the presence of prolonged SNRT at EPS and the effect of pacing on symptoms. Another small prospective study showed that patients with a CSNRT $\geq 800 \mathrm{~ms}$ had an eight times higher risk of syncope than patients with a CSNRT below this value. ${ }^{134}$

\subsubsection{Syncope in patients with bundle branch block (impending high degree atrioventricular block)}

Patients with $\mathrm{BBB}$ are at higher risk of developing high degree AV block. Two factors were shown to increase the risk of AV block in BBB patients: a history of syncope and a prolonged His-ventricular $(\mathrm{HV})$ interval. The risk of developing AV block increased from $2 \%$ in patients without syncope to $17 \%$ in patients with syncope during 42 months follow-up. ${ }^{135}$ The progression rate to AV block at 4 years was 4, 12, and 24\%, respectively, for patients with an HV interval $<55 \mathrm{~ms}$ (normal), $\geq 70 \mathrm{~ms}$ and $\geq 100 \mathrm{~ms}^{136}$

The development of intra- or infra-His block on incremental atrial pacing is highly predictive of impending AV block, but has low sensitivity. The development of intra- or infra-His block with pharmacological challenge by class I antiarrhythmic drugs predicts the subsequent development of spontaneous AV block with higher sensitivity. The prognostic value of a pharmacologically prolonged $\mathrm{HV}$ interval to a value of $\geq 120 \mathrm{~ms}$ without induction of AV block is uncertain. On the other hand, about one-third of patients with negative EPS in whom an ILR was implanted developed intermittent or permanent AV block on follow-up. ${ }^{120}$ Thus EPS has a low sensitivity and specifity.

In pooled data from nine studies (1761 patients) the total mortality was $28 \%$ at 40 months; $32 \%$ of deaths were sudden. ${ }^{1}$ However, neither syncope nor prolonged HV interval were associated with a higher risk of death, and pacemaker therapy did not decrease this risk. ${ }^{135}$

In conclusion, prolonged HV interval or induction of AV block by pacing or by pharmacological stress identifies a group of patients at higher risk of developing AV block in follow-up, but the absence of abnormal findings does not exclude the development of $\mathrm{AV}$ block.

\subsubsection{Suspected tachycardia}

In patients with syncope preceded by sudden-onset brief palpitations suggesting SVT, an EPS may be indicated in order to assess the exact mechanism especially when a curative catheter ablation procedure can be performed.

In patients with previous myocardial infarction and preserved LVEF, induction of sustained monomorphic VT is strongly predictive of the cause of syncope, ${ }^{137}$ whereas the induction of ventricular fibrillation is considered a non-specific finding. ${ }^{138}$ The absence of induction of ventricular arrhythmias identifies a group of patients at lower risk of arrhythmic syncope. ${ }^{139}$

The role of EPS and the use of pharmacological challenge by class I antiarrhythmic drugs in patients with syncope and suspected Brugada syndrome is controversial. ${ }^{52}$ In a meta-analysis of worldwide published data, concerning 1036 patients, in 54\% of whom VT or ventricular fibrillation had been induced by premature ventricular stimulation, no difference in outcome was observed in 34 months follow-up. ${ }^{140}$

\section{Recommendations: electrophysiological study}

\begin{tabular}{|c|c|c|}
\hline Recommendations & Class $^{n}$ & Level $\mathrm{L}^{\mathrm{S}}$ \\
\hline \multicolumn{3}{|l|}{ Indications } \\
\hline $\begin{array}{l}\text { In patients with ischaemic heart disease EPS is indicated } \\
\text { when initial evaluation suggests an arrhythmic cause of } \\
\text { syncope (listed in Table 10) unless there is already an } \\
\text { established indication for ICD }\end{array}$ & 1 & B \\
\hline $\begin{array}{l}\text { In patients with BBB, EPS should be considered when } \\
\text { non-invasive tests have failed to make the diagnosis }\end{array}$ & Ila & B \\
\hline $\begin{array}{l}\text { In patients with syncope preceded by sudden and brief } \\
\text { palpitations, EPS may be performed when other non-invasive } \\
\text { tests have failed to make the diagnosis }\end{array}$ & llb & B \\
\hline $\begin{array}{l}\text { - In patients with Brugada syndrome, ARVC and hypertrophic } \\
\text { cardiomyopathy an EPS may be performed in selected cases }\end{array}$ & $\| \mathrm{lb}$ & C \\
\hline $\begin{array}{l}\text { In patients with high-risk occupations, in whom every effort } \\
\text { to exclude a cardiovascular cause of syncope is warranted, } \\
\text { an EPS may be performed in selected cases }\end{array}$ & llb & C \\
\hline $\begin{array}{l}\text { EPS is not recommended in patients with normal ECG, no } \\
\text { heart disease, and no palpitations }\end{array}$ & III & B \\
\hline \multicolumn{3}{|l|}{$\begin{array}{l}\text { Diagnostic criteria } \\
\text { - EPS is diagnostic, and no additional tests are required, in the } \\
\text { following cases: }\end{array}$} \\
\hline$\square$ Sinus bradycardia and prolonged CSNRT (>525 ms) & 1 & B \\
\hline $\begin{array}{l}\text { BBB and either a baseline HV interval of } \geq 100 \mathrm{~ms} \text {, or } \\
\text { second or third degree His - Purkinje block is demonstrated } \\
\text { during incremental atrial pacing, or with pharmacological } \\
\text { challenge }\end{array}$ & 1 & B \\
\hline $\begin{array}{l}\square \text { Induction of sustained monomorphic VT in patients with } \\
\text { previous myocardial infarction }\end{array}$ & 1 & B \\
\hline $\begin{array}{l}\square \text { Induction of rapid SVT which reproduces hypotensive or } \\
\text { spontaneous symptoms }\end{array}$ & 1 & B \\
\hline $\begin{array}{l}\text { - An HV interval between } 70 \text { and } 100 \mathrm{~ms} \text { should be } \\
\text { considered diagnostic }\end{array}$ & $\mathrm{lla}$ & B \\
\hline $\begin{array}{l}\text { The induction of polymorphic VT or ventricular fibrillation in } \\
\text { patients with Brugada syndrome, ARVC, and patients } \\
\text { resuscitated from cardiac arrest may be considered } \\
\text { diagnostic }\end{array}$ & llb & B \\
\hline $\begin{array}{l}\text { The induction of polymorphic VT or ventricular fibrillation in } \\
\text { patients with ischaemic cardiomyopathy or DCM cannot be } \\
\text { considered a diagnostic finding }\end{array}$ & III & B \\
\hline \multicolumn{3}{|c|}{$\begin{array}{l}\text { Class of recommendation. } \\
\text { Level of evidence. } \\
\text { ARVC = arrhythmogenic right ventricular cardiomyopathy; BBB = bundle branch } \\
\text { block; CSNRT = corrected sinus node recovery time; DCM = dilated } \\
\text { cardiomyopathy; EPS = electrophysiological study; ICD = implantable } \\
\text { cardioverter defibrillator; HV = His-ventricle; SVT = supraventricular } \\
\text { tachycardia; VT = ventricular tachycardia. }\end{array}$} \\
\hline
\end{tabular}

\subsubsection{Adenosine triphosphate test}

The test requires the rapid $(<2 \mathrm{~s})$ injection of a $20 \mathrm{mg}$ bolus of ATP (or adenosine) during ECG monitoring. The induction of AV block with ventricular asystole lasting $>6 \mathrm{~s}$, or the induction of AV block lasting $>10 \mathrm{~s}$, are considered abnormal. ATP testing produced an abnormal response in some patients with syncope of unknown origin (especially older women without structural heart disease), but not in controls, thus suggesting that paroxysmal AV block could be the cause of unexplained syncope. Nevertheless, recent studies showed no correlation between AV block induced by ATP and the ECG findings (documented by ILR) during spontaneous syncope. ${ }^{98,99}$ Thus, the low predictive value of the test does not support its use in selecting patients for cardiac pacing. The role of 
endogenous adenosine release in triggering some forms of syncope due to otherwise unexplained paroxysmal AV block (the so-called 'adenosine-sensitive syncope') remains under investigation.

\section{Recommendations: adenosine triphosphate test}

Recommendations
Indications
- Owing to lack of correlation with spontaneous
syncope, ATP test cannot be used as a diagnostic
test to select patients for cardiac pacing

${ }^{\mathrm{a}}$ Class of recommendation.

bLevel of evidence.

ATP $=$ adenosine triphosphate test.

\subsubsection{Echocardiography and other imaging techniques}

Echocardiography including evaluation of structural and functional haemodynamic data is a key technique to diagnose the presence of structural cardiac disease. Echocardiography plays an important role in risk stratification on the basis of LVEF. In the presence of structural heart disease, other tests to evaluate a cardiac cause of syncope should be performed. Echocardiography identifies the cause of syncope in very few patients when no more tests are needed (e.g. aortic stenosis, atrial myxoma, tamponade, etc.).

Transoesophageal echocardiography, computed tomography (CT), and magnetic resonance imaging (MRI) may be performed in selected cases (e.g. aortic dissection and haematoma, pulmonary embolism, cardiac masses, pericardial and myocardial diseases, congenital anomalies of coronary arteries).

\section{Recommendations: echocardiography

Recommendations:
Indications
- Echocardiography is indicated for diagnosis and ।
risk stratification in patients who are suspected of
having structural heart disease
Diagnostic criteria
- Echocardiography alone is diagnostic of the cause ।
of syncope in severe aortic stenosis, obstructive
cardiac tumours or thrombi, pericardial
tamponade, aortic dissection, and congenital
anomalies of coronary arteries.

${ }^{\mathrm{a} C}$ Class of recommendation.

bLevel of evidence.

\subsubsection{Exercise stress testing}

Exercise-induced syncope is infrequent. Exercise testing should be performed in patients who have experienced episodes of syncope during or shortly after exertion. Careful ECG and BP monitoring should be performed during both the test and the recovery phase as syncope can occur during or immediately after exercise.
These two situations should be considered separately. Indeed, syncope occurring during exercise may be due to cardiac causes (even if some case reports showed that it might be a manifestation of an exaggerated reflex vasodilatation), whereas syncope occurring after exercise is almost invariably due to a reflex mechanism. Tachycardia-related exercise-induced second and third degree AV block has been shown to be located distal to the AV node and predicts progression to permanent AV block. Resting ECG frequently shows intraventricular conduction abnormalities. ${ }^{141}$ There are no data supporting an indication for exercise testing in a general population with syncope.

\section{Recommendations: exercise testing}

Recommendations
Indications
- Exercise testing is indicated in patients who
experience syncope during or shortly after
exertion
Diagnostic criteria
- Exercise testing is diagnostic when syncope is
reproduced during or immediately after exercise
in the presence of ECG abnormalities or severe
hypotension
- Exercise testing is diagnostic if Mobitz II second । C
degree or third degree AV block develops during
exercise even without syncope

${ }^{a}$ Class of recommendation.

'Level of evidence.

$\mathrm{AV}=$ atrioventricular; $\mathrm{ECG}=$ electrocardiogram.

\subsubsection{Cardiac catheterization}

Cardiac catheterization techniques (e.g. coronary angiogram) should be carried out in suspected myocardial ischaemia or infarction and to rule out ischaemia-driven arrhythmias.

\subsubsection{Psychiatric evaluation}

Syncope and psychiatry interact in two ways. Various psychiatric drugs can contribute to syncope through $\mathrm{OH}$ and prolonged QT intervals. Disruption of a psychiatric drug regimen may have severe psychiatric consequences and should not be undertaken without relevant expertise.

The second interaction concerns 'functional' attacks. 'Functional' is used for conditions that resemble known somatic conditions without a somatic explanation being found, and with a presumed psychological mechanism. Two types of patients have to be included in the differential diagnosis of T-LOC. In both, patients are non-responsive and do not show normal motor control, implying that falls are common. In one type gross movements resemble epileptic seizures; these attacks have been described as 'pseudoepilepsy', 'non-epileptic seizures', 'psychogenic nonepileptic seizures', and 'non-epileptic attack disorder'. In the other type there are no gross movements, so the attacks resemble syncope or longer lasting LOC. These attacks have been described as 'psychogenic syncope', 'pseudosyncope', 'syncope of psychiatric origin', and 'medically unexplained syncope'. Note that the latter two 
terms are inconsistent with the definition of syncope because there is no cerebral hypoperfusion in functional T-LOC.

The basic difference between functional T-LOC and what it resembles is the absence of a somatic mechanism: in pseudoepilepsy there is no epileptiform brain activity, and in pseudosyncope BP and $H R$ are not low, and the electroencephalogram (EEG) does not show delta activity or flattening during the attack.

The frequency of such attacks is not known, as they vary with the setting. Functional T-LOC mimicking epilepsy occurs in 15$20 \%$ of cases in specialized epilepsy clinics and in up to $6 \%$ in syncope clinics. $^{142}$

\section{Diagnosis}

Pseudosyncope usually lasts longer than syncope: patients may lie on the floor for many minutes; $15 \mathrm{~min}$ is not exceptional. Other clues are a high frequency including numerous attacks in a day, and lack of a recognizable trigger. Injury does not exclude functional T-LOC: trauma occurred in $>50 \%$ in pseudoseizures. The eyes are usually open in epileptic seizures and syncope but are usually closed in functional T-LOC. Documenting attacks is very helpful; parameters to assess are posture and muscle tone (video recording or neurological investigation), BP, HR, and EEG. The latter is feasible as functional disorders are prone to suggestion, allowing a near certain diagnosis. ${ }^{142}$ During tilt testing, the combination of apparent unconsciousness with loss of motor control, normal BP, HR, and EEG rules out syncope and most forms of epilepsy.

Proving the nature of attacks is useful in confirming the diagnosis. Announcing a 'psychogenic' diagnosis to patients may be difficult, but, without it, referral may be impossible. A psychological explanation may imply to patients that they are personally responsible or that they fake attacks on purpose. Patients see their attacks as involuntary, as they probably are. Stressing that attacks are as involuntary as syncope or an epileptic seizure avoids stigmatization, avoids counterproductive clashes, and provides a therapeutic opening.

\section{Recommendations: psychiatric evaluation}

\begin{tabular}{l}
\hline Recommendations \\
Indications \\
- Psychiatric evaluation is indicated in patients in \\
whom T-LOC is suspected to be psychogenic \\
pseudosyncope \\
Tilt testing, preferably with concurrent EEG \\
recording and video monitoring, may be \\
considered for diagnosis of T-LOC mimicking \\
syncope ('pseudosyncope') or epilepsy.
\end{tabular}

${ }^{\mathrm{a}}$ Class of recommendation.

bLevel of evidence.

EEG $=$ electroencephalogram; T-LOC $=$ transient loss of consciousness.

\subsubsection{Neurological evaluation}

This section discusses neurological disorders causing syncope or resembling it, and neurological tests in syncope.

\subsubsection{Clinical conditions}

Autonomic failure

In ANF the ANS cannot cope with physiological demands, which is expressed as $\mathrm{OH}$. Post-exercise hypotension, a related condition, concerns hypotension directly following the cessation of physical exercise. There are three categories of ANF.

Primary ANF comprises degenerative neurological disease such as pure ANF, multiple system atrophy, Parkinson's disease, and Lewy body dementia. ${ }^{143}$

Secondary ANF involves autonomic damage by other diseases, such as diabetes mellitus, amyloidosis, and various polyneuropathies. ${ }^{143}$

Drug-induced $\mathrm{OH}$ is the most frequent cause of $\mathrm{OH}$; drugs commonly causing $\mathrm{OH}$ are antihypertensives, diuretics, tricyclic antidepressives, phenothiazines, and alcohol. While in primary and secondary ANF the dysfunction is due to structural damage to the ANS system (either central or peripheral), in drug-induced $\mathrm{OH}$ the failure is functional.

Neurological evaluation should be considered in primary ANF. Warning signs are early impotence and disturbed micturition, and later Parkinsonism and ataxia. Referral in secondary ANF and in drug-induced $\mathrm{OH}$ depends on which physician treats the underlying disease.

\section{Cerebrovascular disorders}

'Subclavian steal' refers to rerouting of blood flow to the arm through the vertebral artery due to stenosis or occlusion of the subclavian artery. TIA may occur when flow through the vertebral artery cannot supply both the arm and part of the brain, during forceful use of the arm. Steal most often affects the left side. When detected with ultrasound, 'steal' is asymptomatic in $64 \% .{ }^{144}$ A TIA is only likely to be due to steal when it is vertebrobasilar (see below) and associated with exercise of one arm. There are no reliable reports of isolated LOC without focal neurological symptoms and signs in subclavian steal.

TIA related to a carotid artery does not cause T-LOC. When almost all cerebral arteries are occluded, transient obstruction of the remaining vessel subtending a large portion of the brain may extremely rarely affect consciousness only in the standing position. Moreover, focal neurological signs are much more prevalent.

TIA of the vertebrobasilar system can cause LOC, but there are always focal signs, usually limb weakness, gait and limb ataxia, oculomotor palsies, and oropharyngeal dysfunction. For all practical purposes a TIA concerns a focal deficit without LOC, and syncope the opposite.

\section{Migraine}

Syncope occurs more often in patients with migraine, who have a higher lifetime prevalence of syncope and often frequent syncope. ${ }^{145}$ Syncopal and migraine attacks do not usually occur together in these patients.

\section{Epilepsy}

Epilepsy can cause T-LOC: patients are non-responsive, fall, and later have amnesia. This only occurs in tonic, clonic, tonic-clonic, and atonic generalized seizures. In absence epilepsy in children and partial complex epilepsy in adults consciousness is altered, not lost; these patients remain upright during attacks, in contrast to T-LOC. 
Complete flaccidity during unconsciousness argues against epilepsy. The only exception is 'atonic seizure', but it is rare, and occurs without a trigger in children with pre-existing neurological problems. Movements can be present in both epilepsy and syncope. In epilepsy movements last $\sim 1 \mathrm{~min}$ and, in syncope, seconds. The jerks in epilepsy are coarse, rhythmic, and usually synchronous, whereas those in syncope are usually asynchronous, small, and non-rhythmic. However, synchronous jerks may occur in syncope, ${ }^{146}$ and eyewitnesses may incorrectly report movements. ${ }^{147}$ In syncope movements only occur after the onset of unconsciousness and after the fall; this is not the case in epilepsy.

Syncope is usually triggered; epilepsy rarely is. The triggers in reflex epilepsy such as flashing lights differ from those in syncope. A typical aura consists of a rising sensation in the abdomen (epigastric aura) and/or an unusual unpleasant smell. A rising sensation may rarely occur in syncope. Sweating and pallor are uncommon in epilepsy. A tongue bite occurs much more often in epilepsy and is on the side of the tongue whereas it is the tip in syncope. 5,147 Urinary incontinence occurs in both. Patients may be confused post-ictally a long time in epilepsy, whereas in syncope clearheadedness is usually immediate (Table 13). Headache, muscle pain, and elevation of creatinine kinase and prolactin are more frequent after epilepsy.

\section{Other attacks}

Cataplexy concerns paresis or paralysis triggered by emotions, usually laughter. Patients are conscious, so there is no amnesia. Together with daytime sleepiness cataplexy ensures a diagnosis of narcolepsy.

Falls may be due to syncope; elderly subjects may not be aware of having lost consciousness. In some subjects disorders of posture, gait, and equilibrium may mimic falls in syncope.

The term 'drop attacks' is variably used for Menière's disease, atonic epileptic seizures, and unexplained falls. The clearest use of the term concerns middle-aged women (rarely men) who suddenly find themselves falling. ${ }^{148}$ They remember hitting the floor. Unexplained falls deserve medical attention. ${ }^{148}$

\subsubsection{Neurological tests}

Electroencephalography

Interictal EEGs are normal in syncope., ${ }^{5,149}$ An interictal normal EEG cannot rule out epilepsy, but must always be interpreted in a clinical context. When uncertain it is better to postpone the diagnosis of epilepsy than falsely diagnose it.

An EEG is not recommended when syncope is the most likely cause of T-LOC, but it is when epilepsy is the likely cause or when clinical data are equivocal. The EEG may be useful to establish psychogenic pseudosyncope, if recorded during a provoked attack.

Table I 3 The value of history for distinguishing seizure from syncope (adapted from Hoefnagels et al. ${ }^{5}$ )

\begin{tabular}{|c|c|c|}
\hline \multicolumn{3}{|c|}{ Clinical findings that suggest the diagnosis } \\
\hline & Seizure likely & Syncope likely \\
\hline \multirow[t]{2}{*}{ Symptoms before the event } & Aura (such as funny smell) & $\begin{array}{l}\text { Nausea, vomiting, abdominal discomfort, feeling of cold } \\
\text { sweating (neurally mediated) }\end{array}$ \\
\hline & & Lightheadedness, blurring of vision \\
\hline \multirow[t]{5}{*}{$\begin{array}{l}\text { Findings during loss of consciousness } \\
\text { (as observed by an eyewitness) }\end{array}$} & $\begin{array}{l}\text { Tonic-clonic movements are usually prolonged } \\
\text { and their onset coincides with loss of } \\
\text { consciousness }\end{array}$ & $\begin{array}{l}\text { Tonic-clonic movements are always of short duration } \\
(<15 \mathrm{~s}) \text { and they start after the loss of consciousness }\end{array}$ \\
\hline & Hemilateral clonic movement & \\
\hline & $\begin{array}{l}\text { Clear automatisms such as chewing or lip } \\
\text { smacking or frothing at the mouth (partial } \\
\text { seizure) }\end{array}$ & \\
\hline & Tongue biting & \\
\hline & Blue face & \\
\hline \multirow[t]{2}{*}{ Symptoms after the event } & Prolonged confusion & Usually of short duration \\
\hline & Aching muscles & Nausea, vomiting, pallor (neurally mediated) \\
\hline \multicolumn{3}{|c|}{ Other clinical findings of less value for suspecting seizure (low specificity) } \\
\hline \multicolumn{3}{|c|}{ Family history } \\
\hline \multicolumn{3}{|l|}{ Timing of the event (night) } \\
\hline \multicolumn{3}{|l|}{ 'Pins and needles' before the event } \\
\hline \multicolumn{3}{|l|}{ Incontinence after the event } \\
\hline \multicolumn{3}{|l|}{ Injury after the event } \\
\hline \multicolumn{3}{|l|}{ Headache after the event } \\
\hline \multicolumn{3}{|l|}{ Sleepy after the event } \\
\hline Nausea and abdominal discomfort & & \\
\hline
\end{tabular}


Computed tomography and magnetic resonance imaging

No studies evaluated the use of brain imaging for syncope. CT or $\mathrm{MRI}$ in uncomplicated syncope should be avoided. Imaging may be needed based on a neurological evaluation.

\section{Neurovascular studies}

No studies suggest that carotid Doppler ultrasonography is valuable in patients with typical syncope

Recommendations: neurological evaluation
Recommendations
Indications
- Neurological evaluation is indicated in patients in ।
whom T-LOC is suspected to be epilepsy
- Neurological evaluation is indicated when
syncope is due to ANF in order to evaluate the
underlying disease
EEG, ultrasound of neck arteries, and computed
tomography or magnetic resonance imaging of the
brain are not indicated, unless a non-syncopal
cause of T-LOC is suspected

${ }^{\mathrm{a}}$ Class of recommendation.

bLevel of evidence.

$\mathrm{ANF}=$ autonomic failure; $\mathrm{EEG}=$ electroencephalography; $\mathrm{TIA}=$ transient ischaemic attack; T-LOC $=$ transient loss of consciousness.

\section{Part 3. Treatment}

\section{General principles of treatment of syncope}

The principal goals of treatment for patients with syncope are to prolong survival, limit physical injuries, and prevent recurrences.

The importance and priority of these different goals are dependent on the cause of syncope. For example, in patients with VT causing syncope, the mortality risk is clearly predominant, while in patients with reflex syncope it is the prevention of recurrences and/or limitation of injuries.

Knowledge of the cause of syncope has a key role in selection of treatment. Once the cause has been ascertained, the second goal is to assess the mechanism leading to syncope. For example, the mechanism is obvious in the case of AV block in the context of intraventricular conduction defects, but it could be more complex in the context of reflex syncope: is it cardioinhibitory, vasodepressor, or a mixed response?

Investigations of the cause and mechanism of syncope are generally performed at the same time and could lead to different treatments (or absence of treatment). For example, syncope during the acute phase of an inferior myocardial infarction is generally of reflex origin, and consequent severe bradycardia, hypotension, or both are just a part of the infarction and have to be treated as a complication of the infarct. On the other hand, recurrent reflex syncope due to severe bradycardia, hypotension, or both in the absence of an acute disease has to be treated for what it is. Finally, the optimal treatment of syncope must be directed to the responsible cause of the global cerebral hypoperfusion. However, to the extent that these causes are

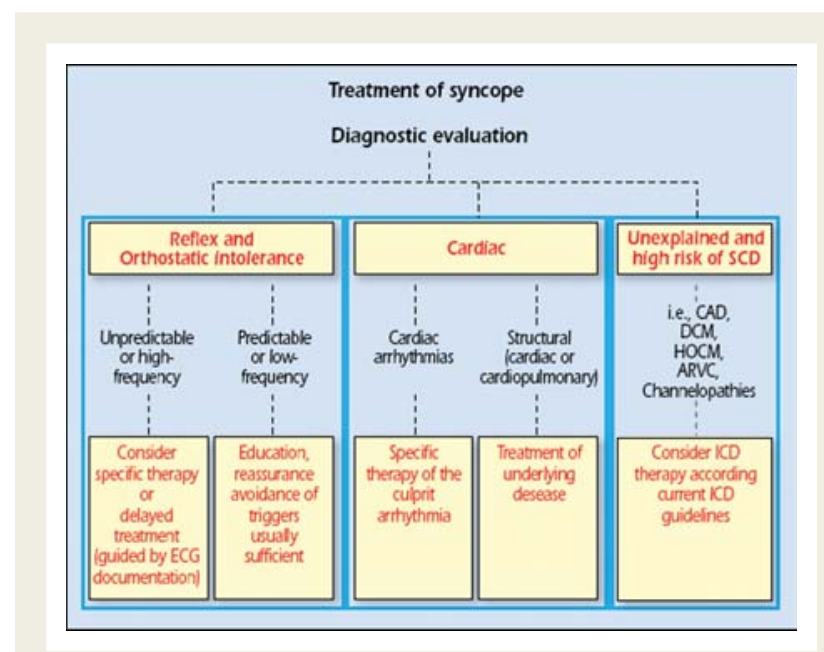

Figure 8 Treatment of syncope. ARVC = arrythmogenic right ventricular cardiomyopathy; $\mathrm{CAD}=$ coronary artery disease; DCM = dilated cardiomyopathy; $E C G=$ electrocardiographic; HOCM = hypertrophic obstructive cardiomyopathy; ICD = implantable cardioverter defibrillator; SCD = sudden cardiac death.

either unknown or not responsive to present therapy (e.g. there is no specific treatment for degenerative AV block) treatment is directed to the mechanisms leading to global cerebral hypoperfusion (pacing in the above-mentioned example). The general framework of treatment is based on risk stratification and the identification of specific mechanisms when possible, as summarized in Figure 8.

\subsection{Treatment of reflex syncope and orthostatic intolerance}

\section{Introduction}

This section deals with measures and interventions for prevention of reflex syncope (vasovagal, situational, CSS) and syncope secondary to ANF with $\mathrm{OH}$. Although there are many physiological mechanisms that lead to syncope, the strategies for prevention of syncope apply to the entire range of causes. The goal of therapy is primarily prevention of recurrence and associated injuries, and improvement in quality of life, but not to prolong survival.

\section{Lifestyle measures}

Since the 2004 guidelines, the greatest advances in treatment lie in the field of lifestyle measures, stemming from basic physiological knowledge and controlled trials.

The cornerstone of the non-pharmacological management of patients with reflex syncope is education and reassurance regarding the benign nature of the condition. In general, initial treatment comprises education regarding awareness and possible avoidance of triggers (e.g. hot crowded environments, volume depletion), early recognition of prodromal symptoms, and performing manoeuvres to abort the episode [e.g. supine posture, physical counterpressure manoeuvres (PCMs)]. If possible, triggers should be addressed directly, such as cough suppression in cough 
syncope. Careful avoidance of agents that lower BP (including $\alpha$-blockers, diuretics, and alcohol) is important.

Additional treatment may be necessary in unpredictable and frequent syncope. In particular when:

- very frequent syncope alters quality of life

- recurrent syncope without, or with very short prodrome exposes patients to risk of trauma

- syncope occurs during high risk activity (e.g. driving, machine operation, flying, competitive athletics, etc.).

\subsubsection{Reflex syncope}

\subsubsection{Therapeutic options}

\section{Physical counterpressure manoeuvres}

Non-pharmacological 'physical' treatments are emerging as a new front-line treatment of reflex syncope. Two clinical trials ${ }^{94,95}$ have shown that isometric PCMs of the legs (leg crossing), or of the arms (hand grip and arm tensing), are able to induce a significant BP increase during the phase of impending reflex syncope that allows the patient to avoid or delay losing consciousness in most cases. The results have been confirmed in a multicentre prospective trial $^{96}$ which assessed the effectiveness of PCMs in daily life in 223 patients, aged $38 \pm 15$ years, with recurrent reflex syncope and recognizable prodromal symptoms: 117 patients were randomized to standardized conventional therapy alone and 106 patients received conventional therapy plus training in PCMs. The median yearly syncope burden during follow-up was significantly lower in the group trained in PCMs than in the control group $(P<0.004)$; overall $51 \%$ of the patients with conventional treatment and $32 \%$ of the patients trained in PCMs experienced recurrence of syncope $(P<0.005)$. Actuarial recurrence-free survival was better in the treatment group (log-rank $P<0.018)$, resulting in a relative risk reduction of $39 \%$ ( $95 \%$ confidence interval, $11-53 \%)$. No adverse events were reported.

\section{Tilt training}

In highly motivated young patients with recurrent vasovagal symptoms triggered by orthostatic stress, the prescription of progressively prolonged periods of enforced upright posture (so-called 'tilt training') may reduce syncope recurrence. ${ }^{150,151}$ However, this treatment is hampered by the low compliance of patients in continuing the training programme for a long period, and four randomized controlled trials failed to confirm short-term effectiveness of tilt training in reducing the positive response rate of tilt testing. ${ }^{152-155}$

\section{Pharmacological therapy}

Many drugs have been tested in the treatment of reflex syncope, for the most part with disappointing results. The list includes $\beta$-blockers, disopyramide, scopolamine, theophylline, ephedrine, etilefrine, midodrine, clonidine, and serotonin reuptake inhibitors. While results have been satisfactory in uncontrolled trials or shortterm controlled trials, several long-term placebo-controlled prospective trials have been unable to show a benefit of the active drug over placebo, with some exceptions.

Since failure to achieve proper vasoconstriction of the peripheral vessels is common in reflex syncope, $\alpha$-agonist vasoconstrictors (etilefrine and midodrine) have been used. Two double-blind acute tilt studies have showed apparent contrasting effects. Moya et al. ${ }^{93}$ administered etilefrine for 1 week, then repeated the test and found no difference between active and placebo treatment. In contrast, Kaufman et al. ${ }^{156}$ administered a single dose of midodrine just $1 \mathrm{~h}$ before tilt testing, and found a significant reduction in syncope during tilt with active treatment. Etilefrine was studied in a randomized placebo-controlled double-blind clinical trial. ${ }^{157}$ During follow-up, patients treated with etilefrine $25 \mathrm{mg}$ twice daily or placebo showed no difference in frequency or time to recurrent syncope. Thus, the evidence fails to support use of etilefrine. Midodrine was studied in three small, open label, randomized trials in patients affected by very frequent 'hypotensive' symptoms (>1 syncope/month). ${ }^{158-160}$ Even if defined as 'neurally mediated', there is overlap in clinical features of patients in these studies with other forms of orthostatic intolerance, rendering the results difficult to interpret. Positive results were obtained in one small, randomized trial of paediatric patients. ${ }^{161}$ The major limitation of midodrine is frequent dosing, limiting long-term compliance. Caution in its use in older males is necessary because of adverse effects on urinary outflow. Overall, these data suggest that chronic pharmacological treatment with $\alpha$-agonists alone may be of little use in reflex syncope, and long-term treatment cannot be advised for occasional symptoms. Even if not proven, a selfadministered single dose, for example one dose $1 \mathrm{~h}$ before prolonged standing or performing an activity that usually triggers syncope (the so-called 'pill in the pocket' strategy), may be useful in selected patients in addition to lifestyle measures and PCMs. It must be advised, however, that currently, midrodine is not available in all countries in Europe.

Fludrocortisone has been shown to be ineffective in a small, randomized double-blind trial in children. ${ }^{162}$ Fludrocortisone has been widely used in adults with reflex syncope, but there is no trial evidence to support this.

$\beta$-Blockers have been presumed to lessen the degree of ventricular mechanoreceptor activation owing to their negative inotropic effect in reflex syncope. This theory has not been supported by the outcome of clinical trials. A rationale for use of $\beta$-blockers in other forms of neurally mediated syncope is lacking. They may enhance bradycardia in CSS. $\beta$-Blockers have failed to be effective in five of six long-term follow-up studies. ${ }^{163-167}$

Paroxetine was shown to be effective in one placebo-controlled trial, which included highly symptomatic patients from one institution. ${ }^{168}$ This has not been confirmed by other studies. Paroxetine may reduce anxiety, which precipitates events. Paroxetine is a psychotropic drug requiring caution in use in patients without severe psychiatric disease.

\section{Cardiac pacing}

Pacing for reflex syncope has been the subject of five major multicentre, randomized controlled trials, which gave contrasting results. ${ }^{169-173}$ In all the patients the pre-implant selection was based on tilt testing response. Adding together the results of the five trials, 318 patients were evaluated; syncope recurred in $21 \%$ of the paced patients and in $44 \%$ of unpaced patients ( $P$ $<0.001)$. A recent meta-analysis of all studies suggested a nonsignificant $17 \%$ reduction in syncope from the double-blinded studies, and an $84 \%$ reduction in the studies where the control group did not receive a pacemaker. ${ }^{174}$ The suboptimal results 
are not surprising if we consider that pacing may affect the cardioinhibitory component of the vasovagal reflex, but will have no effect on the vasodepressor component, which is often dominant.

Two non-randomized trials evaluated the efficacy of pacing by selecting patients with documented asystole during spontaneous syncope by ILR. In the study of Sud et al., ${ }^{175}$ after the insertion of a cardiac pacemaker, syncope burden decreased from 2.7 per year to 0.45 per year $(P=0.02)$. The ISSUE 2 study ${ }^{110}$ hypothesized that spontaneous asystole and not tilt test results should form the basis for patient selection for pacemaker therapy. This study followed 392 patients with presumed reflex syncope with an ILR. Of the 102 patients with a symptomrhythm correlation, 53 underwent loop recorder-guided therapy, predominantly pacing for asystole. These patients experienced a striking reduction in recurrence of syncope compared with non-loop recorder-guided therapy $(10 \%$ vs. $41 \%, P=$ 0.002). It must be stressed that ISSUE 2 was not a randomized trial. It merely provides the basis for such a trial, now ongoing, ISSUE 3.

In conclusion, pacing plays a small role in therapy for reflex syncope, unless severe spontaneous bradycardia is detected during prolonged monitoring.

\subsubsection{Individual conditions}

Vasovagal syncope

Management of this condition has been covered above.

A few points require emphasis. Tilt table testing can be employed to teach the patient to recognize early prodromal symptoms. All patients should be taught PCMs, which now form the cornerstone of therapy together with education and reassurance. In patients that continue to faint despite adequate lifestyle measures and PCMs, tilt training may be considered, particularly in the younger, very symptomatic, well-motivated patients, despite lack of proven efficacy, because it can act by reassuring the patient without side effects.

\section{Situational syncope}

Treatment strategies are similar to VVS and have been covered. Treatment of most forms of situational syncope relies heavily on avoiding or ameliorating the triggering event. Avoidance of the trigger may be difficult, but the response may be attenuated by maintenance of central volume, protected posture, and slower changes in posture.

\section{Carotid sinus syndrome}

Cardiac pacing appears to be beneficial in CSS, ${ }^{75-77,176}$ and, although only two relatively small, randomized controlled trials have been undertaken, pacing is acknowledged to be the treatment of choice when bradycardia has been documented. ${ }^{76,77}$ Singlechamber atrial pacing is not appropriate for CSS, and dual-chamber pacing is generally preferred over single-chamber ventricular pacing. ${ }^{78,177}$ There are as yet no randomized studies examining treatment of dominant vasodepressor CSS, which also pertains for other vasodepressor conditions.

\section{Recommendations: treatment of reflex syncope}

\begin{tabular}{|c|c|c|}
\hline Recommendations & Class $^{\mathrm{a}}$ & Level ${ }^{\mathrm{B}}$ \\
\hline $\begin{array}{l}\text { Explanation of the diagnosis, provision of } \\
\text { reassurance, and explanation of risk of recurrence } \\
\text { are indicated in all patients }\end{array}$ & 1 & C \\
\hline $\begin{array}{l}\text { Isometric PCMs are indicated in patients with } \\
\text { prodrome }\end{array}$ & 1 & B \\
\hline $\begin{array}{l}\text { - Cardiac pacing should be considered in patients } \\
\text { with dominant cardioinhibitory CSS }\end{array}$ & Ila & B \\
\hline $\begin{array}{l}\text { - Cardiac pacing should be considered in patients } \\
\text { with frequent recurrent reflex syncope, age }>40 \\
\text { years, and documented spontaneous } \\
\text { cardioinhibitory response during monitoring }\end{array}$ & Ila & B \\
\hline $\begin{array}{l}\text { - Midodrine may be indicated in patients with WV } \\
\text { refractory to lifestyle measures }\end{array}$ & llb & B \\
\hline $\begin{array}{l}\text { Tilt training may be useful for education of } \\
\text { patients but long-term benefit depends on } \\
\text { compliance }\end{array}$ & Ilb & B \\
\hline $\begin{array}{l}\text { - Cardiac pacing may be indicated in patients with } \\
\text { tilt-induced cardioinhibitory response with } \\
\text { recurrent frequent unpredictable syncope and } \\
\text { age }>40 \text { after alternative therapy has failed }\end{array}$ & llb & C \\
\hline $\begin{array}{l}\text { - Cardiac pacing is not indicated in the absence of a } \\
\text { documented cardioinhibitory reflex }\end{array}$ & III & C \\
\hline - $\beta$-Adrenergic blocking drugs are not indicated & III & A \\
\hline
\end{tabular}

\subsubsection{Orthostatic hypotension and orthostatic intolerance syndromes}

Education regarding the nature of the condition in conjunction with lifestyle advice outlined above can improve orthostatic symptoms markedly, even though the rise in BP is relatively small (10$15 \mathrm{mmHg}$ ); raising the standing $\mathrm{BP}$ just enough to be within the autoregulatory zone can make a substantial functional difference. Ambulatory BP recordings may be helpful in identifying abnormal diurnal patterns. These recordings may also help identify supine or nocturnal hypertension in treated patients.

The principal treatment strategy in drug-induced ANF is elimination of the offending agent. Expansion of extracellular volume is an important goal. In the absence of hypertension, patients should be instructed to take sufficient salt and water intake, targeting 2-3 $\mathrm{L}$ of fluids per day and $10 \mathrm{~g}$ of $\mathrm{NaCl}^{178}$ Rapid cool water ingestion is reported to be effective in combating orthostatic intolerance and post-prandial hypotension. ${ }^{179}$ Sleeping with the head of the bed elevated $\left(10^{\circ}\right)$ prevents nocturnal polyuria, maintains a more favourable distribution of body fluids, and ameliorates nocturnal hypertension. ${ }^{180,181}$

Gravitational venous pooling in older patients can be treated with abdominal binders or compression stockings. ${ }^{14,182}$ PCMs such as leg crossing and squatting should be encouraged in patients with warning symptoms able to perform them. ${ }^{180}$ 
In contrast to reflex syncope, the use of the $\alpha$-agonist, midodrine, is a useful addition to the first-line treatment in patients with chronic ANF. It cannot be regarded as a cure, nor is it helpful in all affected patients, but it is very useful in some. There is no doubt that midodrine increases BP in both supine and upright posture and that it amelioriates the symptoms of $\mathrm{OH}$. Midodrine $(5-20 \mathrm{mg}$, three times daily) has been shown to be effective in three randomized placebo-controlled trials. ${ }^{183-185}$

Fludrocortisone (0.1-0.3 mg once daily) is a mineralocorticoid that stimulates renal sodium retention and expands fluid volume. ${ }^{186}$ The evidence in favour of fludrocortisone is from two small observational studies (in combination with head-up sleeping) and one double-blind trial in 60 patients; the observational studies showed haemodymanic benefit and, in the trial, treated patients were less symptomatic with higher blood pressures. $^{186-188}$

Additional and less frequently used treatments, alone or in combination, include desmopressin in patients with nocturnal polyuria, octeotride in post-prandial hypotension, erythropoietin in anaemia, pyridostigmine, use of walking-sticks, frequent small meals, and judicious exercise of leg and abdominal muscles, especially swimming.

\begin{tabular}{|c|c|c|}
\hline \multicolumn{3}{|c|}{$\begin{array}{l}\text { Recommendations: treatment of orthostatic } \\
\text { hypotension }\end{array}$} \\
\hline Recommendations & Class $^{\mathrm{a}}$ & Levet ${ }^{b}$ \\
\hline $\begin{array}{l}\text { Adequate hydration and salt intake must be } \\
\text { maintained }\end{array}$ & 1 & C \\
\hline $\begin{array}{l}\text { Midodrine should be administered as adjunctive } \\
\text { therapy if needed }\end{array}$ & Ila & B \\
\hline $\begin{array}{l}\text { - Fludrocortisone should be administered as } \\
\text { adjunctive therapy if needed }\end{array}$ & \|la & C \\
\hline - PCMs may be indicated & llb & C \\
\hline $\begin{array}{l}\text { - Abdominal binders and/or support stockings to } \\
\text { reduce venous pooling may be indicated }\end{array}$ & Ilb & C \\
\hline $\begin{array}{l}\text { Head-up tilt sleeping }\left(>10^{\circ}\right) \text { to increase fluid } \\
\text { volume may be indicated }\end{array}$ & $\| \mathrm{lb}$ & C \\
\hline & $\begin{array}{l}{ }^{\mathrm{a}} \text { Class of recommendation. } \\
\text { 'Level of evidence. }\end{array}$ \\
\hline PCM = physical counterpressure manoeuvre. & & \\
\hline
\end{tabular}

\subsection{Cardiac arrhythmias as primary cause}

Treatment goals are prevention of symptom recurrence, improvement of quality of life, and prolongation of survival.

The basis of syncope in these situations is multifactorial, and is influenced by the ventricular rate, left ventricular function, and the adequacy of vascular compensation (including the potential impact of neurally mediated reflex).

\subsubsection{Sinus node dysfunction}

In general, cardiac pacemaker therapy is indicated and has proved highly effective in patients with sinus node dysfunction when bradyarrhythmia has been demonstrated to account for syncope by means of ECG documentation during spontaneous syncope, or as a consequence of abnormal SNRT. ${ }^{134,189}$ Permanent pacing frequently relieves symptoms but may not affect survival. Despite adequate pacing, syncope recurs in $\sim 20 \%$ of patients in long-term follow-up. ${ }^{190}$ This is due to the frequent association of a vasodepressor reflex mechanism with sinus node disease. Newly developed atrial-based minimal ventricular pacing modes are recommended as an alternative to conventional DDDR (dual chamber rateadaptive pacemaker) pacing in patients essentially needing atrial support. ${ }^{70,73}$

Elimination of drugs that may exacerbate or unmask underlying susceptibility to bradycardia is an important element in preventing syncope recurrence. However, when substitution is not feasible, cardiac pacing may be necessary. Percutaneous cardiac ablative techniques for atrial tachyarrhythmia control have become of increasing importance in selected patients with the bradycardia-tachycardia form of sick sinus syndrome, but are only infrequently used primarily for prevention of syncope.

\subsubsection{Atrioventricular conduction system disease}

Cardiac pacing is the treatment of syncope associated with symptomatic AV block. The indications and preferential modes of pacing in AV block have been updated recently. The possible deleterious role of permanent right ventricular apical pacing has recently been underscored, but alternative pacing sites are still a matter of debate. Biventricular pacing should be considered in those patients with an indication for pacing due to AV bock and depressed LVEF, heart failure (HF), and prolonged QRS duration. $^{70,73}$

\subsubsection{Paroxysmal supraventricular and ventricular tachycardias}

In patients with paroxysmal AV nodal reciprocating tachycardia, AV reciprocating tachycardia, or typical atrial flutter associated with syncope, catheter ablation is the first-choice treatment. In those patients, the role of drug therapy is limited to being a bridge to ablation or when ablation has failed. In patients with syncope associated with atrial fibrillation or atypical left atrial flutter, the decision should be individualized.

Syncope due to torsade de pointes is not uncommon and is, in its acquired form, the result of drugs which prolong the QT interval. Treatment is the immediate discontinuation of the suspected drug. Catheter ablation or drug therapy should be considered in patients with syncope due to VT in the setting of a normal heart or of heart disease with mild cardiac dysfunction. ICD is indicated in patients with syncope and depressed cardiac function, and VT or fibrillation without correctable cause. $^{71,72}$ Although in these patients ICD usually does not prevent syncopal recurrences, it is indicated to reduce the risk of SCD. 
Recommendations: treatment of syncope due to cardiac arrhythmias

\begin{tabular}{|c|c|c|}
\hline Recommendations & Class $^{a}$ & Level $^{\mathrm{b}}$ \\
\hline $\begin{array}{l}\text { - Syncope due to cardiac arrhythmias must receive } \\
\text { treatment appropriate to the cause }\end{array}$ & 1 & B \\
\hline \multicolumn{3}{|l|}{ Cardiac pacing } \\
\hline $\begin{array}{l}\text { Pacing is indicated in patients with sinus node disease } \\
\text { in whom syncope is demonstrated to be due to sinus } \\
\text { arrest (symptom-ECG correlation) without a } \\
\text { correctable cause }\end{array}$ & 1 & C \\
\hline $\begin{array}{l}\text { - Pacing is indicated in sinus node disease patients with } \\
\text { syncope and abnormal CSNRT }\end{array}$ & I & C \\
\hline $\begin{array}{l}\text { Pacing is indicated in sinus node disease patients } \\
\text { with syncope and asymptomatic pauses } \geq 3 \mathrm{~s} \\
\text { (with the possible exceptions of young trained } \\
\text { persons, during sleep, and in medicated patients) }\end{array}$ & 1 & $\mathrm{C}$ \\
\hline $\begin{array}{l}\text { - Pacing is indicated in patients with syncope and } \\
\text { second degree Mobitz II, advanced or complete AV } \\
\text { block }\end{array}$ & 1 & B \\
\hline $\begin{array}{l}\text { - Pacing is indicated in patients with syncope, BBB, and } \\
\text { positive EPS }\end{array}$ & 1 & B \\
\hline $\begin{array}{l}\text { Pacing should be considered in patients with } \\
\text { unexplained syncope and BBB }\end{array}$ & Ila & C \\
\hline $\begin{array}{l}\text { - Pacing may be indicated in patients with unexplained } \\
\text { syncope and sinus node disease with persistent sinus } \\
\text { bradycardia itself asymptomatic }\end{array}$ & llb & C \\
\hline $\begin{array}{l}\text { - Pacing is not indicated in patients with unexplained } \\
\text { syncope without evidence of any conduction } \\
\text { disturbance }\end{array}$ & III & $\mathrm{C}$ \\
\hline \multicolumn{3}{|l|}{ Catheter ablation } \\
\hline $\begin{array}{l}\text { Catheter ablation is indicated in patients with } \\
\text { symptom-arrhythmia ECG correlation in both SVT } \\
\text { and VT in the absence of structural heart disease (with } \\
\text { the exception of atrial fibrillation) }\end{array}$ & 1 & C \\
\hline $\begin{array}{l}\text { - Catheter ablation may be indicated in patients with } \\
\text { syncope due to the onset of rapid atrial fibrillation }\end{array}$ & llb & C \\
\hline \multicolumn{3}{|l|}{ Antiarrhythmic drug therapy } \\
\hline $\begin{array}{l}\text { Antiarrhythmic drug therapy, including rate control } \\
\text { drugs, is indicated in patients with syncope due to } \\
\text { onset of rapid atrial fibrillation }\end{array}$ & 1 & C \\
\hline $\begin{array}{l}\text { Drug therapy should be considered in patients with } \\
\text { symptom-arrhythmia ECG correlation in both SVT } \\
\text { and VT when catheter ablation cannot be undertaken } \\
\text { or has failed }\end{array}$ & Ila & $\mathrm{C}$ \\
\hline \multicolumn{3}{|l|}{ Implantable cardioverter defibrillator } \\
\hline $\begin{array}{l}\text { - ICD is indicated in patients with documented VT and } \\
\text { structural heart disease }\end{array}$ & 1 & B \\
\hline $\begin{array}{l}\text { - ICD is indicated when sustained monomorphic VT is } \\
\text { induced at EPS in patients with previous myocardial } \\
\text { infarction }\end{array}$ & I & B \\
\hline $\begin{array}{l}\text { ICD should be considered in patients with } \\
\text { documented VT and inherited cardiomyopathies or } \\
\text { channelopathies }\end{array}$ & Ila & B \\
\hline
\end{tabular}

${ }^{\mathrm{a} C l a s s}$ of recommendation.

'Level of evidence.

$\mathrm{AV}=$ atrioventricular; $\mathrm{BBB}=$ bundle branch block; $\mathrm{CSNRT}=$ corrected sinus node recovery time; $E C G$ = electrocardiogram; $E P S=$ electrophysiological study; ICD = implantable cardioverter defibrillator; SVT = supraventricular tachycardia; VT $=$ ventricular tachycardia.

\subsubsection{Implanted device malfunction}

Infrequently, implantable pacing systems have been associated with provoking near-syncope or syncope. More often, however, syncope in such patients may be unrelated to the device. ${ }^{191}$
When syncope is attributable to the implanted device, it may occur as a result of pulse generator battery depletion or failure, or lead failure. Device/lead replacement is indicated and eliminates the problem. Alternatively, some patients may experience syncope due to pacemaker syndrome, a condition, which incorporates many possible mechanisms of hypotension. In pacemaker syndrome with retrograde AV conduction, device re-programming to eliminate the problem is usually feasible, although replacement is occasionally needed (e.g. replace a single-chamber ventricular with a dual chamber-pacing system). ICDs may also be associated with syncope most commonly because even appropriate intervention is too late to prevent LOC. ${ }^{49}$ Re-programming of the device (more aggressive antitachycardia pacing and/or earlier shock) is only seldom able to solve the problem. In those patients, antiarrhythmic drugs or catheter ablation may be helpful.

\subsection{Syncope secondary to structural cardiac or cardiovascular disease}

In patients with syncope secondary to structural cardiac disease, including congenital heart malformations, or cardiopulmonary disease, the goal of treatment is not only to prevent syncopal recurrence, but also to treat the underlying disease and to decrease the risk of SCD.

Structural cardiac or cardiopulmonary disease can be present in some patients with syncope, and its incidence increases in older patients. The mere presence of heart disease does not imply that syncope is related to the underlying cardiac disorder. Some of these patients have typical reflex syncope, but in others, such as those with inferior myocardial infarction or aortic stenosis, the underlying cardiac disease may play a role in triggering or potentiating a reflex mechanism. In addition, in many of these patients the underlying cardiac disease may be the substrate for supraventricular or ventricular arrhythmia that cause syncope.

Treatment of syncope associated with structural heart disease varies with the diagnosis. In patients with syncope secondary to severe aortic stenosis or to atrial myxoma, surgical treatment of the underlying disease is indicated. In patients with syncope secondary to acute cardiovascular disease, such as pulmonary embolism, myocardial infarction, or pericardial tamponade, treatment should be directed to the underlying process. In hypertrophic cardiomyopathy (with or without left ventricle outflow tract obstruction), specific treatment of the arrhythmia is usually warranted; in most of these patients, an ICD should be implanted to prevent SCD. There are no data on the effect of reducing the outflow gradient on relief of syncope. In syncope associated with myocardial ischaemia, pharmacological therapy and/or revascularization is clearly the appropriate strategy in most cases. On the other hand, when syncope is caused by primary pulmonary hypertension or restrictive cardiomyopathy, it is often impossible adequately to ameliorate the underlying problem. Other less common causes of syncope include left ventricular inflow tract obstruction in patients with mitral stenosis, right ventricular outflow tract obstruction, and right to left shunting secondary to pulmonary stenosis or pulmonary hypertension. 


\subsection{Unexplained syncope in patients with high risk of sudden cardiac death}

In patients at high risk of SCD a disease-specific treatment is warranted in order to reduce the risk of death and of lifethreatening events, even if the exact mechanism of syncope is still unknown or uncertain at the end of a complete work-up. In these patients the goal of treatment is primarily the reduction of mortality risk.

It is important to bear in mind, however, that even if an effective specific treatment of the underlying disease is found, patients may remain at risk of recurrence of syncope. For example, ICD-treated patient may remain at risk for fainting because only the SCD risk is being addressed and not the cause of syncope. An analysis of the Sudden Cardiac Death in Heart Failure Trial (SCD-HeFT) ${ }^{50}$ has shown that ICD did not protect patients against syncope recurrence compared with those treated with amiodarone or placebo. This implies the need for precise identification of the mechanism of syncope and specific treatment as far as possible.

\subsubsection{Ischaemic and non-ischaemic cardiomyopathies}

The risk of death in patients with acute or chronic coronary artery disease and depressed LVEF is increased. This necessitates evaluation of ischaemia and, if indicated, revascularization. However, arrhythmia evaluation, including EPS with premature ventricular stimulation, can still be needed because, when present, the substrate for malignant ventricular arrhythmia may not be ameliorated by revascularization. Patients with HF and an established ICD indication by current guidelines should receive an ICD before and independently of the evaluation of the mechanism of syncope. This group includes, for example, patients with ischaemic or dilated cardiomyopathy and depressed LVEF (ranging from $<30 \%$ to $<40 \%$ and New York Heart Association (NYHA) class $\geq$ II according to current guidelines). ${ }^{70-73}$

Few data exist concerning the therapeutic implications of unexplained syncope in patients with ischaemic or dilated cardiomyopathy. A prospective substudy from the Antiarrhythmics Versus Implantable Defibrillators (AVID) trial $^{47}$ showed that syncope patients derived important survival benefit from ICDs. A survival benefit from the device is also suggested by small retrospective studies. $^{49,192}$ However, patients with syncope and HF carry a high risk of death regardless of the cause of syncope. ${ }^{45} \mathrm{~A}$ recent analysis of the SCD-HeFT ${ }^{49}$ has shown that appropriate ICD shocks are more likely in patients with syncope; yet ICD did not protect against either syncope recurrence or risk of death.

At the two ends of the spectrum, we find on one side the group of syncope patients with preserved LVEF and negative EPS that do not warrant aggressive treatment with an ICD, ${ }^{119}$ and on the other those with congestive HF and severely depressed LVEF who warrant an ICD despite the fact that it will not provide protection against syncope. In this group, it was found that mortality was higher in patients with syncope compared with those without. ${ }^{49}$

\subsubsection{Hypertrophic cardiomyopathy}

Unexplained syncope is a major risk factor for SCD in hypertrophic cardiomyopathy particularly if it has occurred in close temporal proximity ( $<6$ months) to the evaluation (relative risk $>5$ ). Conversely, older ( $>40$ years) patients with remote episodes of syncope ( $>5$ years before evaluation) and patients with a typical history of VVS have low risk of SCD. ${ }^{193}$ However, in addition to self-terminating ventricular arrhythmia, many other mechanisms can cause syncope in hypertrophic cardiomyopathy, including SVT, severe outflow tract obstruction, bradyarrhythmia, decreased $\mathrm{BP}$ in response to exercise, and reflex syncope. The presence or absence of other SCD risk factors such as family history of SCD, frequent non-sustained VT, hypotension during exercise, or marked hypertrophy may help in the determination of risk. Observational studies have demonstrated that ICD therapy is effective in high risk patients with hypertrophic cardiomyopathy. ${ }^{71,72}$

\subsubsection{Arrhythmogenic right ventricular cardiomyopathy/dysplasia}

Syncope occurs in about one-third of patients with arrhythmogenic right ventricular cardiomyopathy (ARVC) referred to tertiary centres. Young age, extensive right ventricular dysfunction, left ventricular involvement, polymorphic VT, late potentials, epsilon waves, and family history of SD, in the absence of other competing diagnoses, indicates therapy with an ICD..$^{71,72}$ In a multicentre study conducted on 132 patients in order to evaluate the impact of ICD for prevention of SCD, the patients with unexplained syncope had a rate of appropriate ICD intervention of $\sim 15 \%$ per year, a figure which was similar to that of patients with cardiac arrest or ventricular tachycardia with haemodynamic compromise. ${ }^{194}$

\subsubsection{Patients with primary electrical diseases}

Unexplained syncope is regarded as an ominous finding in patients with inherited cardiac ion channel abnormalities. An ICD should be carefully considered in the absence of another competing diagnosis or when ventricular tachyarrhythmia cannot be excluded as a cause of syncope. Nevertheless, the mechanism of syncope may be heterogeneous, being caused by life-threatening arrhythmias in some, but being of a more benign origin, i.e. reflex, in many others. Therefore, in these settings, it seems that syncope does not necessarily carry a high risk of major life-threatening cardiac events and yields a lower sensitivity than a history of documented cardiac arrest. $^{52,53}$ In long QT syndrome, especially those with LQTS2 and LQTS3, the number of cardiac events before the age of 18 years, very prolonged QT intervals, and female gender predict a worse outcome. ${ }^{195}$ Brugada syndrome patients with a spontaneous type 1 ECG pattern have a worse outcome than those with a type 2 or drug-induced pattern. ${ }^{52,140}$ The usefulness of ICD in patients with syncope is controversial, but it is undoubtely more questionable than in cardiac arrest survivors. In the largest multicentre study, ${ }^{196}$ in 220 patients with Brugada syndrome and ICD including 18 (8\%) with a history of cardiac arrest and 88 (40\%) with a history of syncope, the rates of appropriate ICD shocks were 22 and 10\%, respectively, during a mean follow-up period of $38 \pm 27$ months. 


\section{Recommendations: indications for ICD in patients with unexplained syncope and a high risk of SCD}

\begin{tabular}{|c|c|c|c|}
\hline Clinical situation & Class $^{\mathrm{a}}$ & Level ${ }^{\mathrm{b}}$ & Comments \\
\hline $\begin{array}{l}\text { - In patients with ischaemic cardiomyopathy with severely depressed LVEF or HF, ICD therapy is indicated } \\
\text { according to current guidelines for ICD-cardiac resynchronization therapy implantation }\end{array}$ & I & A & \\
\hline $\begin{array}{l}\text { - In patients with non-ischaemic cardiomyopathy with severely depressed LVEF or HF, ICD therapy is } \\
\text { indicated according to current guidelines for ICD-cardiac resynchronization therapy implantation }\end{array}$ & I & A & \\
\hline - In hypertrophic cardiomyopathy ICD therapy should be considered in patients at high risk (see text) & Ila & C & In non-high risk, consider ILR \\
\hline - In right ventricular cardiomyopathy ICD therapy should be considered in patients at high risk (see text) & Ila & C & In non-high risk, consider ILR \\
\hline - In Brugada syndrome ICD therapy should be considered in patients with spontaneous type I ECG & Ila & B & $\begin{array}{l}\text { In the absence of spontaneous } \\
\text { type I pattern, consider ILR }\end{array}$ \\
\hline - In long QT syndrome, ICD therapy, in conjunction with $\beta$-blockers, should be considered in patients at risk & Ila & B & In non-high risk, consider ILR \\
\hline $\begin{array}{l}\text { - In patients with ischaemic cardiomyopathy without severely depressed LVEF or HF and negative } \\
\text { programmed electrical stimulation ICD therapy may be considered }\end{array}$ & Illb & C & $\begin{array}{l}\text { Consider ILR to help define the } \\
\text { nature of unexplained syncope }\end{array}$ \\
\hline $\begin{array}{l}\text { - In patients with non-ischaemic cardiomyopathy without severely depressed LVEF or HF ICD therapy } \\
\text { may be considered }\end{array}$ & llb & C & $\begin{array}{l}\text { Consider ILR to help define the } \\
\text { nature of unexplained syncope }\end{array}$ \\
\hline
\end{tabular}

ICD discharge in syncope patients was similar to that of asymptomatic patients. In a recent study ${ }^{197}$ that evaluated the outcome of 59 Brugada patients treated with ICD, none of the 31 patients with syncope received an appropriate ICD shock during a mean of 39 months follow-up, and appropriate device therapy was limited to cardiac arrest survivors; conversely, the overall complication rate was high.

However, the differential diagnosis between benign and malignant forms is usually very difficult in the setting of an inherited disease based on conventional investigations. Consequently, in some patients there is a rationale for more precise diagnosis (i.e. ILR documentation) of the mechanism of syncope before embarking on ICD therapy, although existing data are insufficient to make recommendations. The few available data in the literature on patients with syncope and short QT syndrome do not permit any recommendation.

\section{Part 4. Special issues}

\subsection{Syncope in the elderly}

The most common causes of syncope in the elderly are $\mathrm{OH}$, reflex syncope, especially CSS, and cardiac arrhythmias. ${ }^{198,199}$ Different forms may often co-exist in a patient, making diagnosis difficult. Hospitalization related to $\mathrm{OH}$ increases progressively with age: $4.2 \%$ of 65 - to 74 -year-old patients and $30.5 \%$ of patients older than 75 years. ${ }^{57}$ In symptomatic patients, 25\% have 'age-related' $\mathrm{OH}$; in the remainder $\mathrm{OH}$ is predominantly due to medication and primary or secondary atrial fibrillation. Supine systolic hypertension is often present in older patients with $\mathrm{OH}$ and complicates treatment, given that most agents used for treatment of $\mathrm{OH}$ exacerbate supine hypertension and vice versa.

Cardioinhibitory CSS is the recognized cause of symptoms in up to $20 \%$ of elderly patients with syncope. CSH of predominantly vasodepressor form is equally prevalent, ${ }^{198}$ but its potential role in syncope is much less clear.

\section{Diagnostic evaluation}

Following a standardized algorithm a definite diagnosis may be obtained in $>90 \%$ of older patients with syncope. ${ }^{199}$

Some aspects of the history, which may be difficult to obtain, are pertinent in older patients. Syncope occurring in the morning favours $\mathrm{OH}$. One-third of individuals over 65 years are taking three or more prescribed medications, which may cause or contribute to syncope. Their withdrawal reduces recurrences of syncope and falls. ${ }^{200}$ Medication history should include the time relationship with onset of syncope. History should include co-morbidity, association with physical frailty, and locomotor disability.

Gait, balance instability, and slow protective reflexes are present in $20-50 \%$ of community-dwelling elderly. In these circumstances moderate haemodynamic changes, insufficient to cause syncope, may result in falls. Therefore, it is important to pursue a witness account of episodes, although this is not available in up to $60 \%$ of cases. ${ }^{200}$

Cognitive impairment is present in $5 \%$ of 65 year olds and $20 \%$ of 80 year olds. This may attenuate the patient's memory of syncope and falls. ${ }^{40}$ The cognitive status should be determined in addition to details of social circumstances, injurious events, impact of events on confidence, and ability to carry out activities of daily life.

Initial evaluation determines a definite diagnosis in a lower proportion than in the young because symptoms suggestive of VVS are less frequent in older patients. ${ }^{40,198}$ In all, assessment of the autonomic system (CSM, tilt test) may be necessary.

Evaluation of neurological and locomotor systems, including observation of gait and balance, is useful. If cognitive impairment is suspected, the Mini-Mental State Examination should be performed. Otherwise, the clinical examination and diagnostic work-up is the same as for younger adults with the exception of routine supine and upright CSM at the first assessment. 
Some important aspects of diagnostic testing and use of devices in older patients are illustrated:

- $\mathrm{OH}$ is not always reproducible in older adults (particularly medication- and age-related). Therefore, orthostatic BP appraisal should be repeated, preferably in the morning and/or promptly after syncope.

- CSM is particularly important to use even if non-specific CSH is frequent without history of syncope.

- In evaluation of reflex syncope in older patients, tilt testing is well tolerated and safe, with positivity rates similar to those observed in younger patients, particularly after nitroglycerine challenge.

- Twenty-four hour ambulatory BP recordings may be helpful if instability of BP is suspected (e.g. medication or post-prandial).

- Due to the high frequency of arrhythmias, an ILR may be especially useful in the elderly with unexplained syncope. ${ }^{108,119,120}$

\section{Evaluation of the frail elderly}

Being old is not a contraindication to assessment and treatment. However, in frail patients, the rigour of assessment will depend on compliance with tests and on prognosis. Evaluation of mobile, independent, cognitively normal older adults must be performed as for younger individuals.

Orthostatic BP measurements, CSM, and tilt testing are well tolerated, even in the frail elderly with cognitive impairment.

Multiple risk factors are more common in the frail elderly and distinguishing falls from syncope may be difficult. In one recent study, symptomatic elderly patients with cognitive impairment had a median of five risk factors for syncope or falls. ${ }^{57}$ There is some evidence that modification of cardiovascular risk factors for falls/syncope reduces the incidence of subsequent events in community-dwelling frail elderly, even in those with dementia, but not in institutionalized elderly. ${ }^{201}$ The influence of hypotension or arrhythmia on cognitive decline in patients with dementia remains unknown. ${ }^{58}$

\subsection{Syncope in paediatric patients}

Diagnostic evaluation

Diagnostic evaluation in paediatric patients is similar to that in adults. Reflex syncope represents the vast majority of the aetiology, but in rare cases syncope is the manifestation of lifethreatening cardiac arrhythmia or structural abnormalities. Syncope should also be differentiated from epilepsy and psychogenic pseudosyncope, which are rare but important causes of T-LOC in paediatric patients.

Two specific conditions ${ }^{202}$ occur in early childhood:

(1) Infantile reflex syncopal attacks (also called pallid breathholding spells or reflex anoxic seizures), elicited by a brief unpleasant stimulus, are caused by vagally mediated cardiac inhibition.

(2) Apnoeic hypoxic T-LOC (also called cyanotic breath-holding spells), are characterized by an expiratory cessation of respiration during crying, leading to cyanosis and usually T-LOC.

Careful personal and family history and standard ECG are most important in distinguishing benign reflex syncope (also including reflex anoxic seizure or breath-holding spells) from other causes. If the family history is positive, genetic causes of electrical disease of the heart should be considered first. Some children with reflex syncope also have a positive family history, ${ }^{203}$ the genetics of which are not understood. In patients with a typical history of reflex syncope, normal physical examination and ECG are usually sufficient to cease investigation. Tilt testing seems to have high false-negative and false-positive rates and should be used with caution for primary identification of patients with reflex syncope. A remarkably high incidence of near-fainting (40\%) was reported during tilt testing after placement of a simple intravenous line in healthy children and teenagers. Since tilt protocols commonly used in adults may lack specificity in teenage patients, in one study a shorter tilt test duration of $10 \mathrm{~min}$ at 60 or $70^{\circ}$ was used and showed a specificity $>85 \%{ }^{204}$

In young patients, syncope may rarely be the initial manifestation of unusual but life-threatening conditions, like the long QT syndrome, Kearns-Sayre syndrome (external ophthalmoplegia and progressive heart block), Brugada syndrome, catecholaminergic polymorphic VT, Wolff-Parkinson-White syndrome, right ventricular arrhythmogenic cardiomyopathy, hypertrophic cardiomyopathy, pulmonary arterial hypertension, myocarditis, arrhythmia after repaired congenital heart disease, or anomalous origin of a coronary artery.

Some aspects of the history can suggest a cardiac origin, and should prompt cardiac evaluation:

- Family history: premature SCD $<30$ years; familial heart disease.

- Known or suspected heart disease.

- Event triggers: loud noise, fright, extreme emotional stress.

- Syncope during exercise, including swimming.

- Syncope without prodrome, while supine or sleeping, or preceded by chest pain or palpitations.

Therapy

The therapeutic approach is the same as in adults. However, it should be stressed that effectiveness of pharmacological agents and tilt training for recurrent syncope is undetermined in the absence of welldesigned paediatric trials. Furthermore, even in the presence of VVS with prolonged asystole, pacemakers should be avoided due to the relatively transient and benign nature of the syndrome. ${ }^{205}$

In summary, the key points for the evaluation of syncope in paediatrics are as follows:

- Syncope in childhood is common, the vast majority being of reflex origin, with only a minority having a potentially lifethreatening cause.

- Discrimination between benign and serious causes is made primarily by history, physical examination, and ECG.

- The cornerstone of therapy for young patients with reflex syncope includes education and reassurance.

\subsection{Driving and syncope}

In a survey ${ }^{206}$ among 104 patients, 3\% of patients with syncope reported it to have occurred while they were driving; only $1 \%$ crashed their vehicles. Among those advised not to drive, only $9 \%$ followed this advice. Among patients with life-threatening ventricular arrhythmias enrolled in the AVID trial, ${ }^{207}$ symptoms suggestive of tachyarrhythmia recurred frequently while driving, but they were unlikely to lead to motor vehicle accidents $(0.4 \%$ per patient-year). The probability of an accident was lower than the 


\section{Recommendations concerning driving in patients with syncope}

\begin{tabular}{|c|c|c|}
\hline Diagnosis & Group 1 (private drivers) & Group 2 (professional drivers) \\
\hline \multicolumn{3}{|l|}{ Cardiac arrhythmias } \\
\hline Cardiac arrhythmia, medical treatment & After successful treatment is established & After successful treatment is established \\
\hline Pacemaker implant & After 1 week & After appropriate function is established \\
\hline Successful catheter ablation & After successful treatment is established & After long-term success is confirmed \\
\hline ICD implant & $\begin{array}{l}\text { In general low risk, restriction according } \\
\text { current recommendations }\end{array}$ & Permanent restriction \\
\hline \multicolumn{3}{|l|}{ Reflex syncope } \\
\hline Single/mild & No restrictions & $\begin{array}{l}\text { No restriction unless it occurred during } \\
\text { high risk activity* }\end{array}$ \\
\hline Recurrent and severe* & After symptoms are controlled & $\begin{array}{l}\text { Permanent restriction unless effective } \\
\text { treatment has been established }\end{array}$ \\
\hline \multicolumn{3}{|l|}{ Unexplained syncope } \\
\hline & $\begin{array}{l}\text { No restrictions unless absence of prodrome, } \\
\text { occurrence during driving, or presence } \\
\text { of severe structural heart disease }\end{array}$ & $\begin{array}{l}\text { After diagnosis and appropriate therapy is } \\
\text { established }\end{array}$ \\
\hline
\end{tabular}

Group 1: private drivers of motorcycles, cars and other small vehicles with and without a trailer; Group 2: professional drivers of vehicles over 3.5 tons or passenger-carrying vehicles exceeding eight seats excluding the driver. Drivers of taxicabs, small ambulances, and other vehicles form an intermediate category between the ordinary private driver and the vocational driver and should follow local legislation.

*Neurally mediated syncope is defined as severe if it is very frequent, or occurring during the prosecution of a 'high risk' activity, or recurrent or unpredictable in 'high risk' patients (see Part 3, treatment).

annual accident rate in the general population and was independent of the duration of abstinence from driving. A recent study ${ }^{208}$ provided long-term follow-up information on recurrence of syncope in a large population who had syncope while driving. Among 3877 consecutive patients evaluated for syncope, 380 (9.8\%) had syncope while driving, which was commonly caused by reflex syncope (37\%) or cardiac arrhythmia (12\%). Recurrence of syncope during driving occurred in only 10 patients. The cumulative probability of recurrence while driving was $7 \%$ in 8 years. Total recurrence rate and long-term survival in the driving group was comparable with that of patients who did not have syncope while driving. For public safety, the risk of syncope-mediated driving accidents $(0.8 \%$ per year) appeared to be substantially less than in young (16-24 years) and in elderly drivers (high risk accident groups).

The 2004 ESC Guidelines on syncope made recommendations on driving and syncope. ${ }^{1}$ This TF has the benefit of a further relevant publication. ${ }^{208}$ Data suggest that the risk of vehicle accident in patients with a history of syncope is not different from that of the general population of drivers without syncope. Specific recommendations for driving in patients with an implanted ICD have been recently published. ${ }^{209}$ The mere presence of syncope while driving should not change the clinical evaluation.

\section{Part 5. Organizational aspects}

\subsection{Management of syncope in general practice}

Syncope is a common phenomenon in general practice (Figure 6). ${ }^{26,28}$ Recurrent typical VVS is the most common diagnosis in this setting. The diagnosis is based upon a carefully taken medical history and the context of the event. Most of these typical common faints can be diagnosed by the patient's general practitioner and need only reassurance. An active searching for alarming symptoms is recommended. Alarming symptoms are: syncope during exertion, syncope in the lying position, absence of external factors, family history of SCD, or slow recovery from syncope (Tables 9 and 10).

If the diagnosis remains uncertain and there is potential risk of dangerous consequences then the patient should be referred to cardiologist, internist, neurologist, psychologist/psychiatrist as appropriate or to a specialized syncope facility if available.

\subsection{Management of syncope in the Emergency Department}

The evaluation of syncope in the setting of ED has changed from attempts to make a diagnosis of the cause of syncope to risk stratification (Table 8) in order to: (i) recognize patients with lifethreatening conditions and admit them to the hospital; (ii) recognize patients with low risk conditions to be discharged and referred later to local syncope facilities; (iii) recognize those who do not need any further evaluation and treatment; ${ }^{210}$ and (iv) choose a timing and setting where further diagnostic tests should be performed in patients with inconclusive initial evaluation.

\subsection{Syncope (T-LOC) Management Unit}

Despite publication of several guidelines, current strategies for the assessment of T-LOC suspected of being syncope vary widely 
among physicians and hospitals. This results in inappropriate use of diagnostic tests and in many misdiagnosed and/or unexplained episodes.

It is the opinion of this Syncope TF that a cohesive, structured care pathway delivered either within a single syncope facility or as a more multifaceted service, is optimal for quality service delivery. Furthermore, considerable improvement in diagnostic yield and costeffectiveness (i.e. cost per reliable diagnosis) can be achieved.

\subsubsection{Existing models of Syncope (T-LOC) Management Units}

Models of care delivery vary from a single 'one site-one stop' syncope facility to a wider multifaceted service with many specialists involved in syncope management.

The Rapid Access Falls and Syncope Service (FASS) adopted by the Newcastle group is a rapid access, multidisciplinary approach, based on standardized algorithms, ${ }^{211}$ to referrals with syncope and falls for adults of all ages, but with the addition of particular expertise in the evaluation of older patients with these overlapping problems. There is a rapid access pathway for inpatients and for those attending the ED, with as many investigations as possible completed at the initial assessment. FASS has a full range of tilt testing, beat-to-beat BP monitoring, and ambulatory monitoring equipment as well as physiotherapy, occupational therapy, and specialist nursing expertise. All patients have an initial detailed assessment by a general physician, geriatrician, or general practitioner with falls and syncope expertise, and then are either managed at the Service or referred to colleagues associated with the Service in neurology, neurophysiology, cardiology, or ear nose and throat surgery, depending on the symptoms and the findings at the initial assessment. This group showed a significant saving in emergency hospital costs. The savings were attributed to a combination of factors - reduced re-admission rates, rapid access to day case facilities for ED staff and community physicians, and reduced event rates because of effective targeted treatment strategies for syncope and falls. ${ }^{64}$

The Manchester experience is a model of a T-LOC Facility where cardiologists (with an interest in syncope) and neurologists (with an interest in epilepsy) developed a multidisciplinary facility for a comprehensive evaluation of T-LOC with special emphasis on differential diagnosis between syncope, epilepsy, and psychogenic episodes. $^{212}$

A randomized, single centre study ${ }^{213}$ showed that a Syncope Observation Unit in the ED, with appropriate resources and multidisciplinary collaboration, could improve the diagnostic yield, reduce hospital admission, and achieve favourable long-term outcome in survival and recurrence of syncope. After initial evaluation patients had telemetry for up to $6 \mathrm{~h}$, hourly vital signs and orthostatic BP checks, and echocardiogram for patients with abnormal ECG or cardiovascular examination. Tilt table testing, carotid sinus massage, and electrophysiology consultations were available to the ED physicians. After completion of syncope observational unit evaluation, follow-up appointment at the outpatient syncope management unit can be arranged, if the patient is not admitted to hospital.

The model adopted in some Italian hospitals is a functional Syncope Management Unit managed by cardiologists inside the Department of Cardiology, with dedicated personnel. Patients attending this Syncope Unit have preferential access to all other facilities within the department including admission to the intensive care unit. Patients are referred to the syncope unit from the ED and from inpatient or outpatient clinics, but the personnel of the unit are not usually involved in the initial evaluation of the patient. In the Evaluation of Guidelines in Syncope Study (EGSYS) $2^{32,131}$ implementation of this practice was facilitated by decision-making software based on the ESC Guidelines, a designated physician trained in syncope evaluation, and a central supervisor. Among 19 Italian hospitals, these investigators demonstrated that $78 \%$ of study subjects adhered to the guideline-based evaluation, resulting in a lower hospitalization rate (39\% vs. 47\%), shorter in-hospital stay $(7.2 \pm 5.7$ vs. $8.1 \pm 5.9$ days), and fewer tests performed per patient (median $2.6 \%$ vs. 3.4) than historical controls. More standardized-care patients had a diagnosis of reflex $(65 \%$ vs. $46 \%)$ and orthostatic syncope (10\% vs. $6 \%$ ). The mean cost per patient and the mean cost per diagnosis were 19 and $29 \%$ lower in the standardized-care group.

\subsubsection{Proposed model}

The model of care delivery should be that which is most appropriate to existing practice and resources. Referral sources, extent of screening prior to presentation at the facility, and presenting age are issues which influence the model of care delivery.

Referral can be directly from family practitioners, ED, acute hospital inpatients, or from institutional settings after the initial screening and risk stratification (Figure 7, Table 10). In general, half of the patients with T-LOC are referred to a Syncope Unit for diagnosis and/or therapy. ${ }^{32,131}$

\section{Objectives}

Any syncope (T-LOC) facility is aimed at reaching the following goals:

- Provide state-of-the-art guideline-based assessment of symptomatic patients in order to risk-stratify them, then obtain an accurate aetiological diagnosis and assess prognosis.

- Physician(s) in charge of the syncope facility lead the process of comprehensive management from those listed above to therapy, and, if necessary, follow-up. They perform the core laboratory tests and have preferential access to hospitalization, diagnostic tests, and therapeutic procedures.

- Reduce hospitalizations. The majority of patients can be investigated as out-patients or day cases.

- Set standards for clinical excellence in adherence to the recommendations on syncope.

Professional skill mix for the Syncope Unit. It is not appropriate to be dogmatic regarding the training of personnel responsible for a syncope facility. In a single dedicated facility the skill mix will depend on the specialty of the physician in charge of the unit. Cardiologists (with interest in pacing and electrophysiology), neurologists (with interest in autonomic disorders and epilepsy), general physicians, internists, and geriatricians (with interest in age-related cardiology and falls) have led syncope facilities without evidence of superiority of any model. If referrals hail directly from the community and/or from the ED, a broader skill mix is required. Experience and training in key components of cardiology, neurology, emergency and geriatric medicine are pertinent, in addition to access to psychiatry and clinical psychology. Core medical and support personnel should be involved full time or most of the time in the management of the Unit and should interact with other stakeholders within the hospital and community. 


\section{Equipment}

Core equipment for the Syncope Unit includes: ECG recorders, BP monitors, tilt table, external and implantable ECG monitoring systems, $24 \mathrm{~h}$ ambulatory BP monitoring, and autonomic function testing. The facility should have preferential access to echocardiography, EPS, coronary angiography, stress testing, and, when needed, CT, MRI, and electroencephalography. Patients should have preferential access to hospitalization for dedicated therapeutic procedures: pacemaker and defibrillator implantation, catheter ablation, etc.

Key points for standardized care delivery:
- A cohesive, structured care pathway-delivered either within a single syncope facility or as a more multifaceted service - is recommended for global assessment of patients with T-LOC (suspected syncope).

- Referral can be directly from: family practitioners, ED, acute hospital inpatients, institutional settings.

- Objectives are to: give the patient continuity of care, reduce inappropriate hospitalizations, and set standards of clinical excellence.

- Experience and training in key components of cardiology, neurology, emergency and geriatric medicine are pertinent.

The CME Text 'Guidelines for the diagnosis and management of syncope' is accredited by the European Board for Accreditation in Cardiology (EBAC). EBAC works according to the quality standards of the European Accreditation Council for Continuing Medical Education (EACCME), which is an institution of the European Union of Medical Specialists (UEMS). In compliance with EBAC/EACCME guidelines, all authors participating in this programme have disclosed potential conflicts of interest that might cause a bias in the article. The Organizing Committee is responsible for ensuring that all potential conflicts of interest relevant to the programme are declared to the participants prior to the CME activities.

CME questions for this article are available at: European Heart Journal http://cme.oxfordjournals.org/cgi/hierarchy/oupcme_node;ehj and European Society of Cardiology http://www.escardio.org/guidelines.

\section{References}

1. Brignole M, Alboni P, Benditt DG, Bergfeldt L, Blanc J), Bloch Thomsen PE, van Dijk JG, Fitzpatrick A, Hohnloser S, Janousek J, Kapoor W, Kenny RA, Kulakowski P, Masotti G, Moya A, Raviele A, Sutton R, Theodorakis G, Ungar A, Wieling W; Task Force on Syncope, European Society of Cardiology. Guidelines on management (diagnosis and treatment) of syncope-update 2004. Europace 2004:6:467-537.

2. Thijs RD, Benditt DG, Mathias CJ, Schondorf R, Sutton R, Wieling W, van Dijk JG. Unconscious confusion-a literature search for definitions of syncope and related disorders. Clin Auton Res 2005;15:35-39.

3. Soteriades ES, Evans JC, Larson MG, Chen MH, Chen L, Benjamin EJ, Levy D. Incidence and prognosis of syncope. N Engl J Med 2002;347:878-885.

4. Strickberger SA, Benson DW, Biaggioni I, Callans DJ, Cohen MI, Ellenbogen KA, Epstein AE, Friedman P, Goldberger J, Heidenreich PA, Klein G], Knight BP, Morillo CA, Myerburg RJ, Sila CA; American Heart Association Councils on Clinical Cardiology, Cardiovascular Nursing, Cardiovascular Disease in the Young, and Stroke; Quality of Care and Outcomes Research Interdisciplinary Working Group; American College of Cardiology Foundation; Heart Rhythm Society. AHA/ACCF scientific statement on the evaluation of syncope. J Am Coll Cardiol 2006;47:473-484

5. Hoefnagels WA, Padberg GW, Overweg J, van der Velde EA, Roos RA. Transient loss of consciousness: the value of the history for distinguishing seizure from syncope. J Neurol 1991;238:39-43.

6. Stephenson J. Fits and Faints. Oxford: Blackwell Scientific Publications; 1990. 41-57.

7. van Dijk JG, Sheldon R. Is there any point to vasovagal syncope? Clin Auton Res 2008;18:167-169.

8. Tea SH, Mansourati J, L'Heveder G, Mabin D, Blanc JJ. New insights into the pathophysiology of carotid sinus syndrome. Circulation 1996;93:1411-1416.

9. Alboni P, Alboni M, Bertorelle G. The origin of vasovagal syncope: to protect the heart or to escape predation? Clin Auton Res 2008;18:170-178.

10. Mathias C], Mallipeddi R, Bleasdale-Barr K. Symptoms associated with orthostatic hypotension in pure autonomic failure and multiple system atrophy. J Neurol 1999;246:893-898.

11. Naschitz J, Rosner I. Orthostatic hypotension: framework of the syndrome. Postgrad Med J 2007;83:568-574.

12. Consensus statement on the definition of orthostatic hypotension, pure autonomic failure, and multiple system atrophy. J Neurol Sci 1996;144:218-219.

13. Wieling W, Krediet P, van Dijk N, Linzer M, Tschakovsky M. Initial orthostatic hypotension: review of a forgotten condition. Clin Sci (Lond) 2007;112:157-165.

14. Podoleanu C, Maggi R, Brignole M, Croci F, Incze A, Solano A, Puggioni E, Carasca E. Lower limb and abdominal compression bandages prevent progressive orthostatic hypotension in the elderly. A randomized placebo-controlled study. J Am Coll Cardiol 2006;48:1425-1432.

15. Gibbons $\mathrm{CH}$, Freeman R. Delayed orthostatic hypotension: a frequent cause of orthostatic intolerance. Neurology 2006;67:28-32.
16. Verheyden B, Gisolf J, Beckers F, Karemaker JM, Wesseling KH, Aubert A, Wieling W. Impact of age on the vasovagal response provoked by sublingual nitroglycerine in routine tilt testing. Clin Sci (Lond) 2007;113:329-337.

17. Grubb BP, Kosinski DJ, Boehm K, Kip K. The postural orthostatic tachycardia syndrome: a neurocardiogenic variant identified during head-up tilt table testing. Pacing Clin Electrophysiol 1997;20:2205-2212.

18. Leitch JW, Klein GJ, Yee R, Leather RA, Kim YH. Syncope associated with supraventricular tachycardia: an expression of tachycardia or vasomotor response? Circulation 1992;85:1064-1071

19. Brignole M, Gianfranchi L, Menozzi C, Raviele A, Oddone D, Lolli G, Bottoni N. Role of autonomic reflexes in syncope associated with paroxysmal atrial fibrillation. J Am Coll Cardiol 1993;22:1123-1129.

20. Ebert SN, Liu XK, Woosley RL. Female gender as a risk factor for drug-induced cardiac arrhythmias: evaluation of clinical and experimental evidence. J Womens Health 1998;7:547-557.

21. Zareba W, Moss AJ, Le Cessie S, Locati EH, Robinson JL, Hall WJ, Andrews ML. Risk of cardiac events in family members of patients with Long QT syndrome. J Am Coll Cardiol 1995;26:1685-1691.

22. Lombroso CT, Lerman P. Breathholding spells (cyanotic and pallid infantile syncope). Pediatrics 1967;39:563-581.

23. Wieling W, Ganzeboom KS, Saul JP. Reflex syncope in children and adolescents. Heart 2004;90:1094-1100.

24. Ganzeboom KS, Colman N, Reitsma JB, Shen WK, Wieling W. Prevalence and triggers of syncope in medical students. Am J Cardiol 2003;91:1006-1008.

25. Serletis A, Rose S, Sheldon AG, Sheldon RS. Vasovagal syncope in medical students and their first-degree relatives. Eur Heart J 2006;27:1965-1970.

26. Colman N, Nahm K, Ganzeboom KS, Shen WK, Reitsma J, Linzer M, Wieling W, Kaufmann H. Epidemiology of reflex syncope. Clin Auton Res 2004;14(Suppl 1): i9-i17.

27. Ganzeboom KS, Mairuhu G, Reitsma J, Linzer M, Wieling W, van Dijk N. Lifetime cumulative incidence of syncope in the general population: a study of 549 Dutch subjects aged 35-60 years. J Cardiovasc Electrophysiol 2006;17:1172-1176.

28. Olde Nordkamp LAR, van Dijk N, Ganzeboom KS, Reitsma JB, Luitse JSK, Dekker LRC, Shen WK, Wieling W. Syncope prevalence in the ED compared to that in the general practice and population: a strong selection process. Am J Emerg Med 2009;27:271-279.

29. Ammirati F, Colivicchi F, Santini M. Diagnosing syncope in clinical practice. Implementation of a simplified diagnostic algorithm in a multicentre prospective trial-the OESIL 2 study (Osservatorio Epidemiologico della Sincope nel Lazio). Eur Heart J 2000;21:935-940.

30. Blanc J), L'Her C, Touiza A, Garo B, L'Her E, Mansourati J. Prospective evaluation and outcome of patients admitted for syncope over a 1 year period. Eur Heart J 2002; 23:815-820

31. Blanc JJ, L'Her C, Gosselin G, Cornily JC, Fatemi M. Prospective evaluation of an educational programme for physicians involved in the management of syncope. Europace 2005;7:400-406. 
32. Brignole M, Menozzi C, Bartoletti A, Giada F, Lagi A, Ungar A, Ponassi I, Mussi C, Maggi R, Re G, Furlan R, Rovelli G, Ponzi P, Scivales A. A new management of syncope: prospective systematic guideline-based evaluation of patients referred urgently to general hospitals. Eur Heart J 2006;27:76-82.

33. Crane SD. Risk stratification of patients with syncope in an accident and emergency department. Emerg Med J 2002;19:23-27.

34. Disertori M, Brignole M, Menozzi C, Raviele A, Rizzon P, Santini M, Proclemer A, Tomasi C, Rossillo A, Taddei F, Scivales A, Migliorini R, De Santo T. Management of patients with syncope referred urgently to general hospitals. Europace 2003;5: $283-291$.

35. Sarasin FP, Louis-Simonet M, Carballo D, Slama S, Rajeswaran A, Metzger JT, Lovis C, Unger PF, Junod AF. Prospective evaluation of patients with syncope: a population-based study. Am J Med 2001;111:177-184.

36. Chen LY, Gersh BJ, Hodge DO, Wieling W, Hammill SC, Shen WK. Prevalence and clinical outcomes of patients with multiple potential causes of syncope. Mayo Clin Proc 2003;78:414-420.

37. Kenny RA. Syncope in the elderly: diagnosis, evaluation, and treatment. J Cardiovasc Electrophysiol 2003;14:S74-S77.

38. Romme JJ, van Dijk N, Boer KR, Dekker LR, Stam J, Reitsma JB, Wieling W. Influence of age and gender on the occurrence and presentation of reflex syncope. Clin Auton Res 2008;18:127-133.

39. Del Rosso A, Alboni P, Brignole M, Menozzi C, Raviele A. Relation of clinical presentation of syncope to the age of patients. Am / Cardiol 2005;96:1431-1435.

40. Martin TP, Hanusa BH, Kapoor WN. Risk stratification of patients with syncope. Ann Emerg Med 1997;29:459-466.

41. Colivicchi F, Ammirati F, Melina D, Guido V, Imperoli G, Santini M; OESIL (Osservatorio Epidemiologico sulla Sincope nel Lazio) Study Investigators. Development and prospective validation of a risk stratification system for patients with syncope in the emergency department: the OESIL risk score. Eur Heart J 2003;24:811-819.

42. Del Rosso A, Ungar A, Maggi R, Giada F, Petix NR, De Santo T, Menozzi C, Brignole M. Clinical predictors of cardiac syncope at initial evaluation in patients referred urgently to a general hospital: the EGSYS score. Heart 2008;94: 1620-1626.

43. Sarasin FP, Hanusa BH, Perneger T, Louis-Simonet M, Rajeswaran A, Kapoor WN. A risk score to predict arrhythmias in patients with unexplained syncope. Acad Emerg Med 2003;10:1312-1317.

44. Quinn J, McDermott D, Stiell I, Kohn M, Wells G. Prospective validation of the San Francisco Syncope Rule to predict patients with serious outcomes. Ann Emerg Med 2006;47:448-454.

45. Middlekauff R, Stevenson WG, Stevenson LW, Saxon LA. Syncope in advanced heart failure; high risk of sudden death regardless of origin of syncope. J Am Coll Cardiol 1993:21:110-116.

46. Brembilla-Perrot B, Suty-Selton C, Beurrier D, Houriez P, Nippert M, de la Chaise AT, Louis P, Claudon O, Andronache M, Abdelaal A, Sadoul N, Juillière $Y$. Differences in mechanism and outcomes of syncope patients with coronary artery disease or idiopathic left ventricular dysfunction as assessed by electrophysiologic testing. J Am Coll Cardiol 2004;44:594-601.

47. Steinberg JS, Beckman K, Greene HL, Marinchak R, Klein RC, Greer SG, Ehlert F, Foster P, Menchavez E, Raitt M, Wathen MS, Morris M, Hallstrom A. Follow-up of patients with unexplained syncope and inducible ventricular tachyarrhythmias: analysis of the AVID registry and AVID substudy.Antiarrhythmics versus Implantable Defibrillators. J Cardiovasc Electrophysiol 2001;12:996-1001.

48. Pezawas T, Stix G, Kastner J, Wolzt M, Mayer C, Moertl D, Schmidinger H. Unexplained syncope in patients with structural heart disease and no documented ventricular arrhythmias: value of electrophysiologically guided implantable cardioverter defibrillator therapy. Europace 2003;5:305-312.

49. Olshansky B, Poole JE, Johnson G, Anderson J, Hellkamp AS, Packer D, Mark DB, Lee KL, Bardy GH; SCD-HeFT Investigators. Syncope predicts the outcome of cardiomyopathy patients: analysis of the SCD-HeFT study. J Am Coll Cardiol 2008; 51:1277-1282.

50. Wehrens XH, Vos MA, Doevendans PA, Wellens HJ. Novel insights in the congenital long QT syndrome. Ann Intern Med 2002;137:981-992.

51. Antzelevitch C, Brugada P, Borggrefe M, Brugada J, Brugada R, Corrado D, Gussak I, LeMarec H, Nademanee K, Perez Riera AR, Shimizu W, Schulze-Bahr E, Tan H, Wilde A. Brugada syndrome: report of the Second Consensus Conference: endorsed by the Heart Rhythm Society and the European Heart Rhythm Association. Circulation 2005;111:659-670.

52. Giustetto C, Di Monte F, Wolpert C, Borggrefe M, Schimpf R, Sbragia P, Leone G, Maury P, Anttonen O, Haissaguerre M, Gaita F. Short QT syndrome: clinical findings and diagnostic-therapeutic implications. Eur Heart J 2006;27: 2440-2447.

53. Brignole M, Vardas P, Hoffman E, Huikuri H, Moya A, Ricci R, Sulke N, Wieling W. Indications for the use of diagnostic implantable and external ECG loop recorders. Europace 2009;11;671-687.
54. Bartoletti A, Fabiani P, Bagnoli L, Cappelletti C, Cappellini M, Nappini G, Gianni R, Lavacchi A, Santoro G. Physical injuries caused by a transient loss of consciousness: main clinical characteristics of patients and diagnostic contribution of carotid sinus massage. Eur Heart J 2008;29:618-624.

55. Costantino G, Perego F, Dipaola F, Borella M, Galli A, Cantoni G, Dell'Orto S, Dassi S, Filardo N, Duca PG, Montano N, Furlan R; STePS Investigators. Shortand long-term prognosis of syncope, risk factors, and role of hospital admission: results from the STePS (Short-Term Prognosis of Syncope) study. J Am Coll Cardiol 2008;51:276-283.

56. Ungar A, Mussi C, Del Rosso A, Noro G, Abete P, Ghirelli L, Cellai T, Landi A, Salvioli G, Rengo F, Marchionni N, Masotti G. Diagnosis and characteristics of syncope in older patients referred to geriatric departments. J Am Geriatr Soc 2006; 54:1531-1536.

57. Linzer M, Pontinen M, Gold DT, Divine GW, Felder A, Brooks WB. Impairment of physical and psychosocial function in recurrent syncope. J Clin Epidemiol 1991; 44:1037-1043.

58. Rose MS, Koshman ML, Spreng S, Sheldon R, The relationship between health-related quality of life and the frequency of spells in patients with syncope. J. Clin. Epidemiol 2000;53:1209-1216.

59. van Dijk N, Sprangers M, Colman N, Boer K, Wieling W, Linzer M. Clinical factors associated with quality of life in patients with transient loss of consciousness. J Cardiovasc Electrophysiol 2006;17:998-1003.

60. van Dijk N, Sprangers MA, Boer KR, Colman N, Wieling W, Linzer M. Quality of life within one year following presentation after transient loss of consciousness. Am J Cardiol 2007;100:672-676.

61. Brignole M, Disertori M, Menozzi C, Raviele A, Alboni P, Pitzalis MV, Delise P, Puggioni E, Del Greco M, Malavasi V, Lunati M, Pepe M, Fabrizi D. On behalf of the Evaluation of Guidelines in Syncope Study (EGSYS) group. Management of syncope referred urgently to general hospitals with and without syncope units. Europace 2003;5:293-298.

62. Ammirati F, Colaceci R, Cesario A, Strano S, Della Scala A, Colangelo I, De Santo T, Toscano E, Ricci R, Santini M. Management of syncope: clinical and economic impact of a Syncope Unit. Europace 2008;10:471-476.

63. Kenny RA, O'Shea D, Walker HF. Impact of a dedicated syncope and falls facility for older adults on emergency beds. Age Ageing 2002;31:272-275.

64. Brignole M, Ungar A, Bartoletti A, Lagi A, Mussi C, Ribani MA, Tava G, Disertori M, Quartieri F, Alboni P, Raviele A, Ammirati F, Scivales A, De Santo T. Standardized-care pathway vs. usual management of syncope patients presenting as emergencies at general hospitals. Europace 2006;8:644-650.

65. Sun B Jr., Emond J, Comargo C Jr. Direct medical costs of syncope-related hospitalizations in the United States. Am J Cardiol 2005;95:668-671.

66. Wieling W, Ganzeboom KS, Krediet CT, Grundmeijer HG, Wilde AA, van Dijk JG. Initial diagnostic strategy in the case of transient losses of consciousness: the importance of the medical history. Ned Tijdschr Geneeskd 2003;147:849-854.

67. Sheldon R, Rose S, Ritchie D, Connolly SJ, Koshman ML, Lee MA, Frenneaux M, Fisher M, Murphy W. Historical criteria that distinguish syncope from seizures. J Am Coll Cardiol 2002;40:142-148.

68. Alboni P, Brignole M, Menozzi C, Raviele A, Del Rosso A, Dinelli M, Solano A, Bottoni N. Diagnostic value of history in patients with syncope with or without heart disease. J Am Coll Cardiol 2001;37:1921-1928.

69. Croci F, Brignole M, Alboni P, Menozzi C, Raviele A, Del Rosso A, Dinelli M, Solano A, Bottoni N, Donateo P. The application of a standardized strategy of evaluation in patients with syncope referred to three Syncope Units. Europace 2002;4:351-356.

70. Vardas PE, Auricchio A, Blanc JJ, Daubert JC, Drexler H, Ector H, Gasparini M, Linde C, Morgado FB, Oto A, Sutton R, Trusz-Gluza M; European Society of Cardiology; European Heart Rhythm Association. Guidelines for cardiac pacing and cardiac resynchronization therapy. Eur Heart J 2007;28:2256-2295.

71. Goldberger JJ, Cain ME, Hohnloser SH, Kadish AH, Knight BP, Lauer MS, Maron BJ, Page RL, Passman RS, Siscovick D, Stevenson WG, Zipes DP; American Heart Association; American College of Cardiology Foundation; Heart Rhythm Society. American Heart Association/American College of Cardiology Foundation/Heart Rhythm Society scientific statement on noninvasive risk stratification techniques for identifying patients at risk for sudden cardiac death: a scientific statement from the American Heart Association Council on Clinical Cardiology Committee on Electrocardiography and Arrhythmias and Council on Epidemiology and Prevention. Circulation 2008;118:1497-1518.

72. Zipes DP, Camm AJ, Borggrefe M, Buxton AE, Chaitman B, Fromer M, Gregoratos G, Klein G, Moss AJ, Myerburg RJ, Priori SG, Quinones MA, Roden DM, Silka MJ, Tracy C, Priori SG, Blanc JJ, Budaj A, Camm AJ, Dean V, Deckers JW, Despres C, Dickstein K, Lekakis J, McGregor K, Metra M, Morais J, Osterspey A, Tamargo JL, Zamorano JL, Smith SC Jr, Jacobs AK, Adams CD, Antman EM, Anderson JL, Hunt SA, Halperin JL, Nishimura R, Ornato JP, Page RL, Riegel B; American College of Cardiology; American Heart Association Task Force; European Society of Cardiology Committee for 
Practice Guidelines; European Heart Rhythm Association; Heart Rhythm Society. ACC/AHA/ESC 2006 guidelines for management of patients with ventricular arrhythmias and the prevention of sudden cardiac death: a report of the American College of Cardiology/American Heart Association Task Force and the European Society of Cardiology Committee for Practice Guidelines. Europace 2006;8:746-837.

73. Epstein AE, DiMarco JP, Ellenbogen KA, Estes NA 3rd, Freedman RA, Gettes LS, Gillinov AM, Gregoratos G, Hammill SC, Hayes DL, Hlatky MA, Newby LK, Page RL, Schoenfeld MH, Silka MJ, Stevenson LW, Sweeney MO, Smith SC Jr, Jacobs AK, Adams CD, Anderson JL, Buller CE, Creager MA, Ettinger SM, Faxon DP, Halperin JL, Hiratzka LF, Hunt SA, Krumholz HM, Kushner FG, Lytle BW, Nishimura RA, Ornato JP, Page RL, Riegel B, Tarkington LG, Yancy CW ACC/AHA/HRS 2008 Guidelines for Device-Based Therapy of Cardiac Rhythm Abnormalities: a report of the American College of Cardiology/American Heart Association Task Force on Practice Guidelines (Writing Committee to Revise the ACC/AHA/NASPE 2002 Guideline Update for Implantation of Cardiac Pacemakers and Antiarrhythmia Devices) developed in collaboration with the American Association for Thoracic Surgery and Society of Thoracic Surgeons. J Am Coll Cardiol 2008;51:e1-e62.

74. Puggioni E, Guiducci V, Brignole M, Menozzi C, Oddone D, Donateo P, Croci F, Solano A, Lolli G, Tomasi C, Bottoni N. Results and complications of the carotid sinus massage performed according to the 'methods of symptoms'. Am J Cardiol 2002;89:599-560.

75. Kerr SR, Pearce MS, Brayne C, Davis RJ, Kenny RA. Carotid sinus hypersensitivity in asymptomatic older persons: implications for diagnosis of syncope and falls. Arch Intern Med 2006;166:515-520.

76. Brignole M, Menozzi C, Lolli G, Bottoni N, Gaggioli G. Long-term outcome of paced and non paced patients with severe carotid sinus syndrome. Am J Cardiol 1992;69:1039-1043.

77. Claesson JE, Kristensson BE, Edvardsson N, Wahrborg P. Less syncope and milder symptoms in patients treated with pacing for induced cardioinhibitory carotid sinus syndrome: a randomized study. Europace 2007;9:932-936.

78. Menozzi C, Brignole M, Lolli G, Bottoni N, Oddone D, Gianfranchi L, Gaggioli G. Follow-up of asystolic episodes in patients with cardioinhibitory, neurally mediated syncope and VVI pacemaker. Am J Cardiol 1993;72:1152-1155.

79. Maggi R, Menozzi C, Brignole M, Podoleanu C, lori M, Sutton R, Moya A, Giada F, Orazi S, Grovale N. Cardioinhibitory carotid sinus hypersensitivity predicts an asystolic mechanism of spontaneous neurally-mediated syncope. Europace 2007;9:563-567.

80. Munro NC, Mclntosh S, Lawson J, Morley CA, Sutton R, Kenny RA. The incidence of complications after carotid sinus massage in older patients with syncope. J Am Geriatr Soc 1994;42:1248-1251.

81. Davies AG, Kenny RA. Frequency of neurologic complications following carotid sinus massage. Am J Cardiol 1998;81:1256-1257.

82. Smit AAJ, Halliwill JR, Low PA, Wieling W. Topical review. Pathophysiological basis of orthostatic hypotension in autonomic failure. J Physiol 1999;519:1-10.

83. Accurso V, Winnicki M, Shamsuzzaman AS, Wenzel A, Johnson AK, Somers VK. Predisposition to vasovagal syncope in subjects with blood/injury phobia. Circulation 2001;104:903-907

84. Brignole M, Menozzi C, Gianfranchi L, Oddone D, Lolli G, Bertulla A. Neurally mediated syncope detected by carotid sinus massage and head-up tilt test in sick sinus syndrome. Am J Cardiol 1991;68:1032-1036.

85. Kenny RA, Ingram A, Bayliss J, Sutton R. Head-up tilt: a useful test for investigating unexplained syncope. Lancet 1986;1:1352-1355.

86. Benditt DG, Ferguson DW, Grubb BP, Kapoor WN, Kugler J, Lerman BB, Maloney JD, Raviele A, Ross B, Sutton R, Wolk MJ, Wood DL. Tilt table testing for assessing syncope. American College of Cardiology. I Am Coll Cardiol 1996;28:263-275

87. Morillo CA, Klein GJ, Zandri S, Yee R. Diagnostic accuracy of a low-dose isoproterenol head-up tilt protocol. Am Heart J 1995;129:901-906.

88. Bartoletti A, Alboni P, Ammirati F, Brignole M, Del Rosso A, Foglia Manzillo G, Menozzi C, Raviele A, Sutton R. 'The Italian Protocol': a simplified head-up tilt testing potentiated with oral nitroglycerin to assess patients with unexplained syncope. Europace 2000;2:339-342.

89. Parry SW, Gray JC, Baptist M, O'Shea D, Newton JL, Kenny RA. 'Front-loaded' glyceryl trinitrate-head-up tilt table testing: validation of a rapid first line tilt protocol for the diagnosis of vasovagal syncope. Age Ageing 2008;37:411-415.

90. Zaidi A, Clough P, Cooper P, Scheepers B, Fitzpatrick AP. Misdiagnosis of epilepsy: many seizure-like attacks have a cardiovascular cause. J Am Coll Cardiol 2000;36:181-184

91. Petersen ME, Williams TR, Sutton R. Psychogenic syncope diagnosed by prolonged head-up tilt testing. QJM 1995;88:209-213.

92. Heitterachi E, Lord SR, Meyerkort P, McCloskey I, Fitzpatrick R. BP changes on upright tilting predict falls in older people. Age Ageing 2002;31:181-186.
93. Moya A, Permanyer-Miralda G, Sagrista-Sauleda J, Carne X, Rius T, Mont L, Soler-Soler J. Limitations of head-up tilt test for evaluating the efficacy of therapeutic interventions in patients with vasovagal syncope: results of a controlled study of etilefrine versus placebo. J Am Coll Cardiol 1995;25:65-69.

94. Brignole M, Croci F, Menozzi C, Solano A, Donateo P, Oddone D, Puggioni E, Lolli $G$. Isometric arm counter-pressure maneuvers to abort impending vasovagal syncope. J Am Coll Cardiol 2002;40:2053-2059.

95. Krediet CT, van Dijk N, Linzer M, van Lieshout J, Wieling W. Management of vasovagal syncope: controlling or aborting faints by leg crossing and muscle tensing. Circulation 2002;106:1684-1689.

96. van Dijk N, Quartieri F, Blanc JJ, Garcia-Civera R, Brignole M, Moya A, Wieling W; PC-Trial Investigators. Effectiveness of physical counterpressure maneuvers in preventing vasovagal syncope: the Physical Counterpressure Manoeuvres Trial (PC-Trial). J Am Coll Cardiol 2006;48:1652-1657.

97. Brignole M, Menozzi C, Del Rosso A, Costa S, Gaggioli G, Bottoni N, Bartoli P, Sutton R. New classification of haemodynamics of vasovagal syncope: beyond the VASIS classification. Analysis of the pre-syncopal phase of the tilt test without and with nitroglycerin challenge. Vasovagal Syncope International Study. Europace 2000;2:66-76.

98. Deharo JC, Jego C, Lanteaume A, Djiane P. An implantable loop recorder study of highly symptomatic vasovagal patients: the heart rhythm observed during a spontaneous syncope is identical to the recurrent syncope but not correlated with the head-up tilt test or adenosine triphosphate test. J Am Coll Cardiol 2006; 47:587-593.

99. Brignole M, Sutton R, Menozzi C, Garcia-Civera R, Moya A, Wieling W, Andresen D, Benditt DG, Grovale N, De Santo T, Vardas P; International Study on Syncope of Uncertain Etiology 2 (ISSUE 2) Group. Lack of correlation between the responses to tilt testing and adenosine triphosphate test and the mechanism of spontaneous neurally mediated syncope. Eur Heart J 2006;27: 2232-2239.

100. Leman RB, Clarke E, Gillette P. Significant complications can occur with ischemic heart disease and tilt table testing. Pacing Clin Electrophysiol 1999;22:675-677.

101. Kenny RA, O'Shea D, Parry SW. The Newcastle protocols for head-up tilt table testing in the diagnosis of vasovagal syncope, carotid sinus hypersensitivity, and related disorders. Heart 2000;83:564-569.

102. de Castro RR, Mesquita ET, da Nobrega AC. Parasympathetic-mediated atrial fibrillation during tilt test associated with increased baroreflex sensitivity. Europace 2006;8:349-351

103. Krahn A, Klein G, Norris C, Yee R. The etiology of syncope in patients with negative tilt table and electrophysiologic testing. Circulation 1995;92:1819-1824.

104. Krahn AD, Klein G], Yee R, Takle-Newhouse T, Norris C. Use of an extended monitoring strategy in patients with problematic syncope. Reveal Investigators. Circulation 1999; 26:99:406-410.

105. Krahn AD, Klein GL, Tee R, Skanes AC. Detection of asymptomatic arrhythmias in unexplained syncope. Am Heart J 2004;148:326-332.

106. Ermis C, Zhu AX, Pham S, Li JM, Guerrero M, Vrudney A, Hiltner L, Lu F, Sakaguchi S, Lurie KG, Benditt DG. Comparison of automatic and patientactivated arrhythmia recordings by implantable loop recorders in the evaluation of syncope. Am J Cardiol 2003;92:815-819.

107. Moya A, Brignole M, Sutton R, Menozzi C, Garcia-Civera R, Wieling W, Andresen D, Benditt D, Garcia-Sacristan JF, Beiras X, Grovale N, De Santo T, Vardas P. Reproducibility of electrocardiographic findings in patients with neurally-mediated syncope. Am J Cardiol 2008;102:1518-1523.

108. Moya A, Brignole M, Menozzi C, Garcia-Civera R, Tognarini S, Mont L, Botto G, Giada F, Cornacchia D. Mechanism of syncope in patients with isolated syncope and in patients with tilt-positive syncope. Circulation 2001;104:1261-1267.

109. Solano A, Menozzi C, Maggi R, Donateo P, Bottoni N, Lolli G, Tomasi C, Croci F, Oddone D, Puggioni E, Brignole M. Incidence, diagnostic yield and safety of the implantable loop-recorder to detect the mechanism of syncope in patients with and without structural heart disease. Eur Heart J 2004;25:1116-1119.

110. Brignole M, Sutton R, Menozzi C, Garcia-Civera R, Moya A, Wieling W Andresen D, Benditt DG, Vardas P; International Study on Syncope of Uncertain Etiology 2 (ISSUE 2) Group. Early application of an implantable loop recorder allows effective specific therapy in patients with recurrent suspected neurally mediated syncope. Eur Heart J 2006;27:1085-1092.

111. Pezawas T, Stix G, Kastner J, Schneider B, Wolzt M, Schmidinger H. Implantable loop recorder in unexplained syncope: classification, mechanism, transient loss of consciousness and role of major depressive disorder in patients with and without structural heart disease. Heart 2008;94:e17.

112. Bass EB, Curtiss El, Arena VC, Hanusa BH, Cecchetti A, Karpf M, Kapoor WN. The duration of Holter monitoring in patients with syncope: is $24 \mathrm{~h}$ enough? Arch Intern Med 1990;150:1073-1078.

113. Kinlay S, Leitch JW, Neil A, Chapman BL, Hardy DB, Fletcher PJ. Cardiac event recorders yield more diagnoses and are more cost-effective than 48-hour Holter 
monitoring in patients with palpitations. A controlled clinical trial. Ann Intern Med 1996;124:16-20.

114. Linzer M, Pritchett EL, Pontinen M, McCarthy E, Divine GW. Incremental diagnostic yield of loop electrocardiographic recorders in unexplained syncope. Am J Cardiol 1990;66:214-219.

115. Schuchert A, Maas R, Kretzschmar C, Behrens G, Kratzmann I, Meinertz T. Diagnostic yield of external loop recorders in patients with recurrent syncope and negative tilt table test. Pacing Clin Electrophysiol 2003;26:1837-1840.

116. Rockx MA, Hoch JS, Klein GJ, Yee R, Skanes AC, Gula LJ, Krahn AD. Is ambulatory monitoring for 'community-acquired' syncope economically attractive? A cost-effectiveness analysis of a randomized trial of external loop recorders versus Holter monitoring. Am Heart J 2005;150:1065.

117. Krahn A, Klein GJ, Yee R, Skanes AC. Randomized assessment of syncope trial. Conventional diagnostic testing versus a prolonged monitoring strategy. Circulation 2001; 104:46-51.

118. Farwell D, Freemantle N, Sulke N. The clinical impact of implantable loop recorders in patients with syncope. Eur Heart J 2006;27:351-356.

119. Menozzi C, Brignole M, Garcia-Civera R, Moya A, Botto G, Tercedor L, Migliorini R, Navarro X; International Study on Syncope of Uncertain Etiology (ISSUE) Investigators. Mechanism of syncope in patients with heart disease and negative electrophysiologic test. Circulation 2002;105:2741-2745.

120. Brignole M, Menozzi C, Moya A, Garcia-Civera R, Mont L, Alvarez M, Errazquin F, Beiras J, Bottoni N, Donateo P; International Study on Syncope of Uncertain Etiology (ISSUE) Investigators. Mechanism of syncope in patients with bundle branch block and negative electrophysiological test. Circulation 2001;104:2045-2050

121. Nierop P, van Mechelen R, Elsacker A, Luijten RH, Elhendy A. Heart rhythm during syncope and presyncope: results of implantable loop recorders. Pacing Clin Electrophysiol 2000;23:1532-1538.

122. Boersma L, Mont L, Sionis A, Garcia E, Brugada J. Value of implantable loop recorder for the management of patients with unexplained syncope. Europace 2004;6:70-76.

123. Lombardi F, Calosso E, Mascioli G, Marangoni E, Donato A, Rossi S, Pala M, Foti F, Lunati M. Utility of implantable loop recorder (Reveal Plus) in the diagnosis of unexplained syncope Europace 2005;7:19-24.

124. Pierre B, Fauchier L, Breard L, Marie O, Poret F, Babuty D. Implantable loop recorder for recurrent syncope: influence of cardiac conduction abnormalities showing up on resting electrocardiogram and of underlying cardiac disease on follow-up developments. Europace 2008;10:477-481.

125. Kenny RA, Richardson DA, Steen N, Bexton RS, Shaw FE, Bond J. Carotid sinus syndrome: a modifiable risk factor for nonaccidental falls in older adults (SAFE PACE). J Am Coll Cardiol 2001;38:1491-1496.

126. Rothman SA, Laughlin JC, Seltzer J, Walia JS, Baman RI, Siouffi SY, Sangrigoli RM, Kowey PR. The diagnosis of cardiac arrhythmias: a prospective multi-center randomized study comparing mobile cardiac outpatient telemetry versus standard loop event monitoring. J Cardiovasc Electrophysiol 2007;18:241-247.

127. Brignole M, Moya A, Menozzi C, Garcia-Civera R, Sutton R. Proposed electrocardiographic classification of spontaneous syncope documented by an implantable loop recorder. Europace 2005;7:14-18.

128. Krahn AD, Klein GJ, Yee R, Hoch JS, Skanes AC. Cost implications of testing strategy in patients with syncope: randomized assessment of syncope trial. J Am Coll Cardiol 2003;42:495-501.

129. Donateo P, Brignole M, Menozzi C, Bottoni N, Alboni P, Dinelli M, Del Rosso A, Croci F, Oddone D, Solano A, Puggioni E. Mechanism of syncope in patients with positive adenosine triphosphate tests J Am Coll Cardiol 2003;41:93-98.

130. Linzer M, Yang EH, Estes NA 3rd, Wang P, Vorperian VR, Kapoor WN. Part 2: Unexplained syncope. Clinical Efficacy Assessment Project of the American College of Physicians. Ann Intern Med 1997;127:76-86.

131. Brignole M, Ungar A, Bartoletti A, Ponassi I, Lagi A, Mussi C, Ribani MA, Tavav G, Disertori M, Quartieri F, Alboni P, Raviele A, Ammirati F, Scivales A, De Santo T; Evaluation of Guidelines in Syncope Study 2 (EGSYS-2) GROUP. Standardizedcare pathway vs. usual management of syncope patients presenting as emergencies at general hospitals. Europace 2006;8:644-650.

132. Narula OS, Samet P, Javier RP. Significance of the sinus-node recovery time. Circulation 1972;45:140-158.

133. Gann D, Tolentino A, Samet P. Electrophysiologic evaluation of elderly patients with sinus bradycardia. A long-term follow-up study. Ann Intern Med 1979;90: 24-29.

134. Menozzi C, Brignole M, Alboni P, Boni L, Paparella N, Gaggioli G, Lolli G. The natural course of untreated sick sinus syndrome and identification of the variables predictive of unfavourable outcome. Am / Cardiol 1998;82:1205-1209.

135. McAnulty JH, Rahimtoola SH, Murphy E, DeMots H, Ritzmann L, Kanarek PE, Kauffman S. Natural history of 'high risk' bundle branch block. Final report of a prospective study. N Engl J Med 1982;307:137-143.
136. Scheinman MM, Peters RW, Suavé MJ, Desai J, Abbott JA, Cogan J, Wohl B, Williams $\mathrm{K}$. Value of the $\mathrm{H}-\mathrm{Q}$ interval in patients with bundle branch block and the role of prophylactic permanent pacing. Am J Cardiol 1982;50:1316-1322.

137. Olshansky B, Hahn EA, Hartz VL, Prater SP, Mason JW. Clinical significance of syncope in the electrophysiologic study versus electrocardiographic monitoring (ESVEM) trial. The ESVEM Investigators. Am Heart J 1999;137:878-886.

138. Mittal S, Hao SC, Iwai S, Stein KM, Markowitz SM, Slotwiner DJ, Lerman BB. Significance of inducible ventricular fibrillation in patients with coronary artery disease and unexplained syncope. J Am Coll Cardiol 2001;38:371-376.

139. Link MS, Kim KM, Homoud MK, Estes NA, Wang PJ. Long-term outcome of patients with syncope associated with coronary artery disease and a non diagnostic electrophysiological evaluation. Am J Cardiol 1999;83:1334-1337.

140. Paul M, Gerss J, Schulze-Bahr E, Wichter T, Vahlhaus C, Wilde AA, Breithardt G, Eckardt L. Role of programmed ventricular stimulation in patients with Brugada syndrome: a meta-analysis of worldwide published data. Eur Heart J 2007;28: 2126-2133.

141. Woelfel AK, Simpson RJ Jr, Gettes LS, Foster JR. Exercise induced distal atrioventricular block. J Am Coll Cardiol 1983;2:578-581.

142. Benbadis SR, Chichkova R. Psychogenic pseudosyncope: an underestimated and provable diagnosis. Epilepsy Behav 2006;9:106-110.

143. Freeman R. Clinical practice. Neurogenic orthostatic hypotension. N Engl J Med 2008;358:615-624.

144. Hennerici M, Klemm C, Rautenberg W. The subclavian steal phenomenon: a common vascular disorder with rare neurologic deficits. Neurology 1988;38: 669-673.

145. Thijs RD, Kruit MC, van Buchem MA, Ferrari MD, Launer LJ, van Dijk JG. Syncope in migraine: the population-based CAMERA study. Neurology 2006;66: 1034-1037.

146. Lempert T, Bauer M, Schmidt D. Syncope: a videometric analysis of 56 episodes of transient cerebral hypoxia. Ann Neurol 1994;36:233-237.

147. Sheldon R, Rose S, Connolly S, Ritchie D, Koshman ML, Frenneaux M. Diagnostic criteria for vasovagal syncope based on a quantitative history. Eur Heart J 2006;27:344-350.

148. Parry SW, Kenny RA. Drop attacks in older adults: systematic assessment has a high diagnostic yield. J Am Geriatr Soc 2005;53:74-78.

149. Abubakr A, Wambacq I. The diagnostic value of EEGs in patients with syncope. Epilepsy Behav 2005;6:433-434.

150. Di Girolamo E, Di lorio C, Leonzio L, Sabatini P, Barsotti A. Usefulness of a tilt training program for the prevention of refractory neurocardiogenic syncope in adolescents: a controlled study. Circulation 1999;100:1798-1801.

151. Reybrouck T, Heidbuchel H, Van De Werf F, Ector H. Long-term follow-up results of tilt training therapy in patients with recurrent neurocardiogenic syncope. Pacing Clin Electrophysiol 2002;25:1441-1446.

152. Foglia-Manzillo G, Giada F, Gaggioli G, Bartoletti A, Lolli G, Dinelli M, Del Rosso A, Santarone M, Raviele A, Brignole M. Efficacy of tilt training in the treatment of neurally mediated syncope. A randomized study. Europace 2004;6: 199-204.

153. Kinay O, Yazici M, Nazli C, Acar G, Gedikli O, Altinbas A, Kahraman H, Dogan A, Ozaydin M, Tuzun N, Ergene O. Tilt training for recurrent neurocardiogenic syncope: effectiveness, patient compliance, and scheduling the frequency of training sessions. Jpn Heart J 2004;45:833-843.

154. On YK, Park J, Huh J, Kim JS. Is home orthostatic self-training effective in preventing neurocardiogenic syncope? A prospective and randomized study. Pacing Clin Electrophysiol 2007;30:638-643.

155. Duygu H, Zoghi M, Turk U, Akyuz S, Ozerkan F, Akilli A, Erturk U, Onder R, Akin $M$. The role of tilt training in preventing recurrent syncope in patients with vasovagal syncope: a prospective and randomized study. Pacing Clin Electrophysiol 2008;31:592-596.

156. Kaufman H, Saadia D, Voustianiouk A. Midodrine in neurally mediated syncope: a double-blind randomized cross-over study. Ann Neurol 2002;52:342-345.

157. Raviele A, Brignole M, Sutton R, Alboni P, Giani P, Menozzi C, Moya A. Effect of etilefrine in preventing syncopal recurrence in patients with vasovagal syncope: a double-blind, randomized, placebo-controlled trial. The Vasovagal Syncope International Study. Circulation 1999;99:1452-1457.

158. Samniah N, Sakaguchi S, Lurie KG, Iskos D, Benditt DG. Efficacy and safety of midodrine hydrochloride in patients with refractory vasovagal syncope. Am J Cardiol 2001;88:80-83.

159. Perez-Lugones A, Schweikert R, Pavia S, Sra J, Akhtar M, Jaeger F, Tomassoni GF, Saliba W, Leonelli FM, Bash D, Beheiry S, Shewchik J, Tchou PJ, Natale A. Usefulness of midodrine in patients with severely symptomatic neurocardiogenic syncope: a randomized control study. J Cardiovasc Electrophysiol 2001;12: 935-938.

160. Ward CR, Gray JC, Gilroy JJ, Kenny RA. Midodrine: a role in the management of neurocardiogenic syncope. Heart 1998;79:45-49. 
161. Qingyou Z, Junbao D, Chaoshu T. The efficacy of midodrine hydrochloride in the treatment of children with vasovagal syncope. J Pediatr 2006;149:777-780.

162. Salim MA, Di Sessa TG. Effectiveness of fludrocortisone and salt in preventing syncope recurrence in children: a double blind, placebo-controlled, randomized trial. J Am Coll Cardiol 2005:45;484-488.

163. Sheldon R, Rose S, Flanagan P, Koshman ML, Killam S. Effect of beta blockers on the time to first syncope recurrence in patients after a positive isoproterenol tilt table test. Am / Cardiol 1996;78:536-539.

164. Madrid AH, Ortega J, Rebollo JG, Manzano JG, Segovia JG, Sánchez A, Peña G, Moro C. Lack of efficacy of atenolol for the prevention of neurally mediated syncope in a highly symptomatic population: a prospective, double-blind, randomized and placebo-controlled study. J Am Coll Cardiol 2001;37:554-559.

165. Flevari P, Livanis EG, Theodorakis GN, Zarvalis E, Mesiskli T, Kremastinos DT. Vasovagal syncope: a prospective, randomized, crossover evaluation of the effect of propranolol, nadolol and placebo on syncope recurrence and patients' well-being. J Am Coll Cardiol 2002;40:499-504.

166. Brignole M, Menozzi C, Gianfranchi L, Lolli G, Bottoni N, Oddone D. A controlled trial of acute and long-term medical therapy in tilt-induced neurally mediated syncope. Am J Cardiol 1992;70:339-342.

167. Sheldon R, Connolly S, Rose S, Klingenheben T, Krahn A, Morillo C, Talajic M, Ku T, Fouad-Tarazi F, Ritchie D, Koshman ML; POST Investigators. Prevention of Syncope Trial (POST): a randomized, placebo-controlled study of metoprolol in the prevention of vasovagal syncope. Circulation 2006;113:1164-1170.

168. Di Girolamo E, Di lorio C, Sabatini P, Leonzio L, Barbone C, Barsotti A. Effects of paroxetine hydrochloride, a selective serotonin reuptake inhibitor, on refractory vasovagal syncope: a randomized, double-blind, placebo-controlled study. J Am Coll Cardiol 1999:33:1227-1230.

169. Sutton R, Brignole M, Menozzi C, Raviele A, Alboni P, Giani P, Moya A. Dualchamber pacing in the treatment of neurally mediated tilt-positive cardioinhibitory syncope: pacemaker versus no therapy: a multicenter randomized study. The Vasovagal Syncope International Study (VASIS) Investigators. Circulation 2000; 102:294-299.

170. Ammirati F, Colivicchi F, Santini M. Permanent cardiac pacing versus medical treatment for the prevention of recurrent vasovagal syncope: a multicenter, randomized, controlled trial. Circulation 2001;104:52-57.

171. Connolly SJ, Sheldon R, Roberts RS, Gent M. The North American Vasovagal Pacemaker Study (VPS). A randomized trial of permanent cardiac pacing for the prevention of vasovagal syncope. J Am Coll Cardiol 1999;33:16-20.

172. Connolly SJ, Sheldon R, Thorpe KE, Roberts RS, Ellenbogen KA, Wilkoff BL, Morillo C, Gent M; VPS II Investigators. Pacemaker therapy for prevention of syncope in patients with recurrent severe vasovagal syncope: Second Vasovagal Pacemaker Study (VPS II): a randomized trial. JAMA 2003;289:2224-2229.

173. Raviele A, Giada F, Menozzi C, Speca G, Orazi S, Gasparini G, Sutton R, Brignole M; Vasovagal Syncope and Pacing Trial Investigators. A randomized, double-blind, placebo-controlled study of permanent cardiac pacing for the treatment of recurrent tilt-induced vasovagal syncope. The vasovagal syncope and pacing trial (SYNPACE). Eur Heart J 2004;25:1741-1748.

174. Sud S, Massel D, Klein GJ, Leong-Sit P, Yee R, Skanes AC, Gula LJ, Krahn AD. The expectation effect and cardiac pacing for refractory vasovagal syncope. Am J Med 2007;120:54-62.

175. Sud S, Klein GJ, Skanes AC, Gula LJ, Yee R, Krahn AD. Implications of mechanism of bradycardia on response to pacing in patients with unexplained syncope. Europace 2007;9:312-318.

176. Morley CA, Perrins EJ, Grant PL, Chan SL, Mc Brien DJ, Sutton R. Carotid sinus syncope treated by pacing. Analysis of persistent symptoms and role of atrioventricular sequential pacing. Br Heart J 1982;47:411-418.

177. Brignole M, Sartore B, Barra M, Menozzi C, Lolli G. Ventricular and dual chamber pacing for treatment of carotid sinus syndrome. Pacing Clin Electrophysiol 1989;12:582-590.

178. Claydon VE, Hainsworth R. Salt supplementation improves orthostatic cerebral and peripheral vascular control in patients with syncope. Hypertension 2004;43: 809-813.

179. Schroeder C, Bush VE, Norcliffe LJ, Luft FC, Tank J, Jordan J, Hainsworth R. Water drinking acutely improves orthostatic tolerance in healthy subjects. Circulation 2002; 106:2806-2811.

180. van Lieshout JJ, ten Harkel AD, Wieling W. Physical manoeuvres for combating orthostatic dizziness in autonomic failure. Lancet 1992;339:897-898.

181. Omboni S, Smit AA, van Lieshout J], Settels J], Langewouters GJ, Wieling W. Mechanisms underlying the impairment in orthostatic tolerance after nocturnal recumbency in patients with autonomic failure. Clin Sci (Lond) 2001;101: 609-618.

182. Smit AA, Wieling W, Fujimura J, Denq JC, Opfer-Gehrking TL, Akarriou M, Karemaker JM, Low PA. Use of lower abdominal compression to combat orthostatic hypotension in patients with autonomic dysfunction. Clin Auton Res 2004; 14:167-175.
183. Jankovic J, Gilden JL, Hiner BC, Kaufmann H, Brown DC, Coghlan CH, Rubin M, Fouad-Tarazi FM. Neurogenic orthostatic hypotension: a double-blind, placebocontrolled study with midodrine. Am J Med 1993;95:38-48.

184. Low PA, Gilden JL, Freeman R, Sheng KN, McElligott MA. Efficacy of midodrine vs placebo in neurogenic orthostatic hypotension. A randomized, double-blind multicenter study. Midodrine Study Group. JAMA 1997;277:1046-1051.

185. Wright RA, Kaufman HC, Perera R, Opfer-Gehrking TL, McEllogott MA, Sheng KN, Low PA. A double-blind, dose-response study of midodrine in neurogenic orthostatic hypotension. Neurology 1998;51:120-124.

186. van Lieshout J], ten Harkel AD, Wieling W. Fludrocortisone and sleeping in the head-up position limit the postural decrease in $\mathrm{CO}$ in autonomic failure. Clin Auton Res 2000;10:35-42.

187. Finke J, Sagemüller I. Fludrocortisone in the treatment of orthostatic hypotension: ophthalmodynamography during standing Dtsch Med Wochenschr 1975; 100:1790-1792.

188. ten Harkel AD, van Lieshout JJ, Wieling W. Treatment of orthostatic hypotension with sleeping in the head-up tilt position, alone and in combination with fludrocortisones. J Intern Med 1992;232:139-145.

189. Alboni P, Menozzi C, Brignole M, Paparella N, Gaggioli G, Lolli G, Cappato R. Effects of permanent pacemaker and oral theophylline in sick sinus syndrome the THEOPACE study: a randomized controlled trial. Circulation 1997;96: $260-266$.

190. Sgarbossa EB, Pinski SL, Jaeger FJ, Trohman RG, Maloney JD. Incidence and predictors of syncope in paced patients with sick sinus syndrome. Pacing Clin Electrophysiol 1992;15:2055-2060.

191. Pavlovic SU, Kocovic D, Djordjevic M, Belkic K, Kostic D, Velimirovic D. The etiology of syncope in pacemaker patients. Pacing Clin Electrophysiol 1991;14: 2086-2091.

192. Andrews NP, Fogel RI, Pelargonio G, Evans J], Prystowsky EN. Implantable defibrillator event rates in patients with unexplained syncope and inducible sustained ventricular tachyarrhythmias: a comparison with patients known to have sustained ventricular tachycardia. I Am Coll Cardiol 1999;34:2023-2030.

193. Spirito P, Autore C, Rapezzi C, Bernabò P, Badagliacca R, Maron MS, Bongioanni $S$, Coccolo $F$, Estes NA, Barillà CS, Biagini E, Quarta G, Conte MR, Bruzzi P, Maron BJ. Syncope and risk of sudden death in hypertrophic cardiomyopathy. Circulation 2009;119:1703-1710.

194. Corrado D, Leoni L, Link MS, Della Bella P, Gaita F, Curnis A, Salerno JU, Igidbashian D, Raviele A, Disertori M, Zanotto G, Verlato R, Vergara G, Delise P, Turrini P, Basso C, Naccarella F, Maddalena F, Estes NA 3rd, Buja G, Thiene G. Implantable cardioverter-defibrillator therapy for prevention of sudden death in patients with arrhythmogenic right ventricular cardiomyopathy/dysplasia. Circulation 2003;108:3084-3091.

195. Goldenberg J, Moss AJ. Long QT syndrome. I Am Coll Cardiol 2008;51: 2291-2300.

196. Sacher F, Probst V, lesaka $Y$, Jacon $P$, Laborderie J, Mizon-Gérard F, Mabo $P$, Reuter S, Lamaison D, Takahashi Y, O'Neill MD, Garrigue S, Pierre B, Jaïs $P$, Pasquié JL, Hocini M, Salvador-Mazenq M, Nogami A, Amiel A, Defaye P, Bordachar P, Boveda S, Maury P, Klug D, Babuty D, Haïssaguerre M, Mansourati J. Clémenty J, Le Marec $\mathrm{H}$. Outcome after implantation of a cardioverter-defibrillator in patients with Brugada syndrome: a multicenter study. Circulation 2006;114:2317-2324.

197. Rosso R, Glick A, Glikson M, Wagshal A, Swissa M, Rosenhek S, Shetboun I, Khalamizer V, Fuchs T, Boulos M, Geist M, Strasberg B, Ilan M, Belhassen B; Israeli Working Group on Cardiac Pacing and Electrophysiology. Outcome after implantation of cardioverter defibrillator [corrected] in patients with Brugada syndrome: a multicenter Israeli study (ISRABRU). Isr Med Assoc J 2008;10:435-439.

198. McIntosh SJ, Lawson J, Kenny RA. Clinical characteristics of vasodepressor, cardioinhibitory, and mixed carotid sinus syndrome in the elderly. Am J Med 1993; 95:203-208

199. Galizia A, Abete P, Mussi C, Noro A, Morrione A, Langellotto A, Landi A, Cacciatore F, Masotti G, Rengo F, Marchionni N, Ungar A. Role of the early symptoms in assessment of syncope in the elderly people. Results from the Italian Group for the Study of Syncope in the elderly (GIS STUDY). J Am Geriatr Soc 2009:57:18-23.

200. Van der Velde $\mathrm{N}$, van den Meiracker AH, Pols HA, Stricker BH, van der Cammen TJ. Withdrawal of fall-risk-increasing drugs in older persons: effect on tilt-table test outcomes. J Am Geriatr Soc 2007;55:734-739.

201. Shaw FE, Bond J, Richardson DA, Dawson P, Steen IN, McKeith IG, Kenny RA. Multifactorial intervention after a fall in older people with cognitive impairment and dementia presenting to the accident and emergency department: randomised controlled trial. Br Med J 2003;326:73-80.

202. DiMario FJ. Prospective study of children with cyanotic and pallid breath-holding spells. Pediatrics 2001;107:265-269. 
203. Vlahos AP, Kolettis TM. Family history of children and adolescents with neurocardiogenic syncope. Pediatr Cardiol 2008;29:227.

204. Vlahos AP, Tzoufi M, Katsouras CS, Barka T, Sionti I, Michalis LK, Siamopoulou A, Kolettis TM. Provocation of neurocardiogenic syncope during head-up tilt testing in children: comparison between isoproterenol and nitroglycerin. Pediatrics 2007;119:e419-e425.

205. McLeod KA, Wilson N, Hewitt J, Norrie J, Stephenson JB. Cardiac pacing for severe childhood neurally mediated syncope with reflex anoxic seizures. Heart 1999;82:721-725.

206. Maas R, Ventura R, Kretzschmar C, Aydin A, Schuchert A. Syncope, driving recommendations, and clinical reality: survey of patients. Br Med J 2003;326:21.

207. Akiyama T, Powell JL, Mitchell LB, Ehlert FA, Baessler C; Antiarrhythmics versus Implantable Defibrillators Investigators. Resumption of driving after lifethreatening ventricular tachyarrhythmia. N Engl J Med 2001;345:391-397.

208. Sorajja D, Nesbitt G, Hodge D, Low P, Hammill S, Gersh B, Shen WK. Syncope while driving: clinical characteristics, causes, and prognosis. Circulation 2009, doi:10.1161/CIRCULATIONAHA.108.827626.

209. Vijgen J, Botto G, Camm J, Hoijer C, Jung W, Le Heuzey J, Lubinski A, Norekvål TM, Santomauro M, Schalij M, Schmid J, Vardas P. Consensus statement of the European Heart Rhythm Association: updated recommendations for driving of patients with implantable cardioverter defibrillators. Europace 2009;11:1097-1107.

210. Huff JS, Decker WW, Quinn JV, Perron AD, Napoli AM, Peeters S, Jagoda AS: American College of Emergency Physicians. Clinical policy: critical issues in the evaluation and management of adult patients presenting to the emergency department with syncope. Ann Emerg Med 2007;49:431-444.

211. Parry SW, Frearson R, Steen N, Newton JL, Tryambake P, Kenny RA. Evidencebased algorithms and the management of falls and syncope in the acute medical setting. Clinical Medicine 2008;8:157-162.

212. Petkar S, Cooper P, Fitzpatrick AP. How to avoid a misdiagnosis in patients presenting with transient loss of consciousness. Postgrad Med J 2006;82: 630-641.

213. Shen WK, Decker WW, Smars PA, Goyal DG, Walker AE, Hodge DO, Trusty JM, Brekke KM, Jahangir A, Brady PA, Munger TM, Gersh BJ, Hammill SC, Frye RL. Syncope Evaluation in the Emergency Department Study (SEEDS): a multidisciplinary approach to syncope management. Circulation 2004;110:3636-3645. 